LBL-33867

UC-350

\title{
Energy Use and Conservation in China's Residential and
} Commercial Sectors: Patterns, Problems, and Prospects

\author{
F. Liu
}

Energy Analysis Program

Energy \& Environment Division

Lawrence Berkeley Laboratory

University of California

Berkeley, California 94720

July 1993

This work was supported by the Assistant Secretary for Conservation and Renewable Energy, Office of Building Technologies, of the U.S. Department of Energy under Contract No. DE-AC03-76SF00098. 


\section{CONTENTS}

ACKNOWLEDGMENT ...........................................................................................................

EXECUTIVE SUMMARY ....................................................................................vii

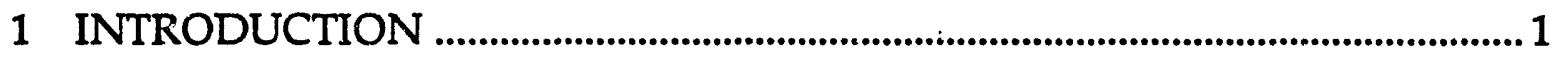

1.1 Background and Objective............................................................................................ 1

1.2 Methodology ............................................................................................................. 2

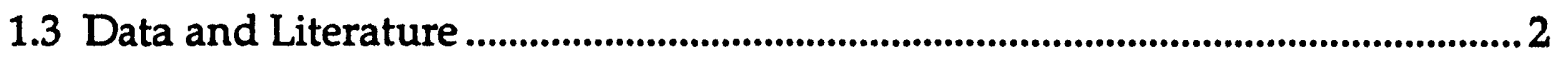

1.4 Organization of the Report ........................................................................................ 3

1.5 Units and Conversion Factors ......................................................................... 3

2 RESIDENTIAL AND COMMERCIAL SECTOR ENERGY USE .........................5

2.1 Sectoral Energy Use .......................................................................................................

2.2 Residential and Commercial Energy Use Patterns ................................................ 8

2.3 Determinants of Energy Demand in Buildings ...................................................... 16

2.3.1 Population and Household Structure .......................................................... 16

2.3.2 Household Income and Standard of Living............................................ 18

2.3.3 Consumer Behavior .................................................................................. 19

2.3.4 Appliances Stocks .................................................................................. 20

2.3.5 Climate Conditions ...........................................................................22

2.3.6 Residential and Commercial Building Stock ..............................................24

2.3.7 Building Energy Standards and the Construction Industry.....................26

3 RESIDENTIAL AND COMMERCIAL SECTOR ENERGY EFFICIENCY .......29

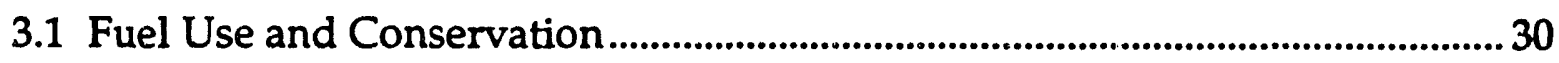

3.1.1 Cooking and Domestic Water Heating...................................................... 30

3.1.1.1 Urban Residential Cooking Fuel Use .................................................. 32

3.1.1.2 Rural Residential Cooking Fuel Use ..............................................36

3.1.1.3 Commercial Cooking and Water-Heating Fuel Use ...................... 38

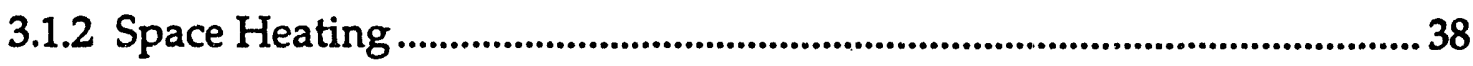

3.1.2.1 Space Heating through Stoves ...................................................... 39

3.1.2.2 Space Heating through Dispersed Small Boilers............................. 41

3.1.2.3 District Heating ................................................................................ 43

3.1.2.4 Heat Distribution Networks........................................................... 45 
3.1.2.5 Thermal Integrity of Heated Buildings.............................................4 47

3.1.2.6 Space Heating in the Transition Zone.............................................50

3.1.2.7 Other Issues of Space-Heating Energy Conservation....................51

3.1.3 Assessment of Fuel Conservation Measures ...............................................53

3.1.3.1 Criteria of Conservation Assessment..........................................54

3.1.3.2 Coal Prices and the Cost of New Coal-Supply Capacity ..............55

3.1.3.3 Conservation Measures and Their Cost-Effectiveness ...................55

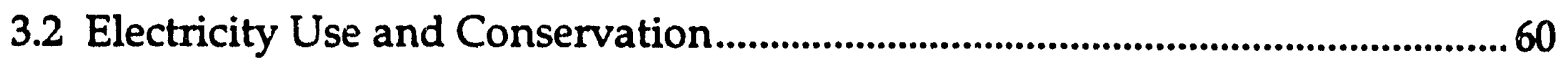

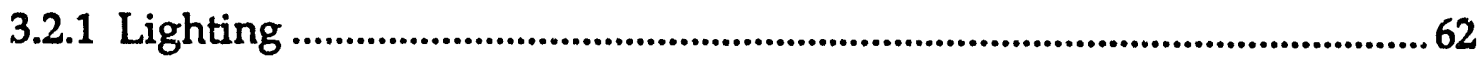

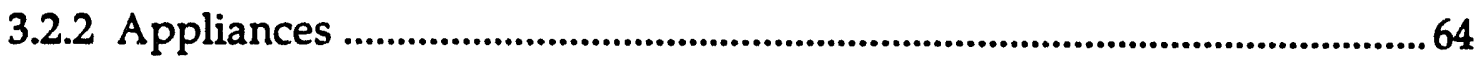

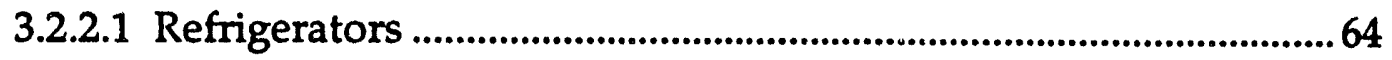

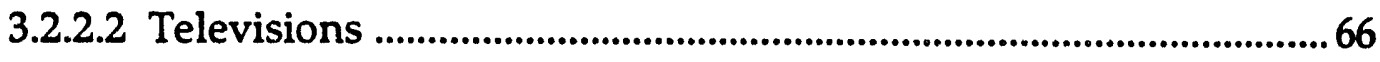

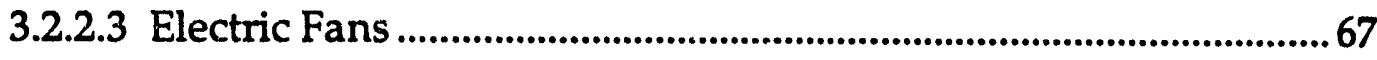

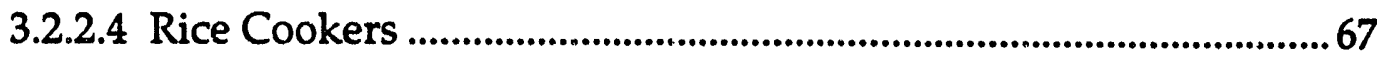

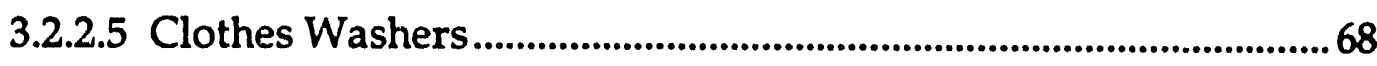

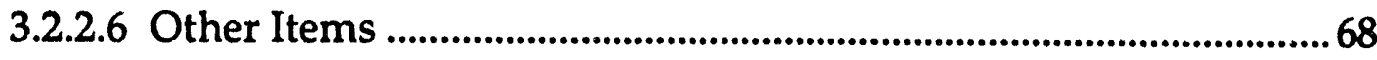

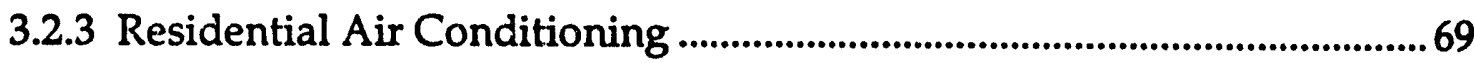

3.2.4 HVAC Systems of Commercial Buildings ...................................................71

3.2.5 Assessment of Electricity Conservation Measures ....................................72

3.2.5.1 Criteria of Conservation Assessment..............................................73

3.2.5.2 Electricity Prices and the Costs of New Generating Capacity ...73

3.2.5.3 Conservation Measures and Their Cost-Effectiveness ..................74

4. POLICY ISSUES OF BUILDING ENERGY CONSERVATION............................79

4.1 Conservation Policies for Residential Buildings.................................................79

4.2 Conservation Policies for Commercial Buildings................................................8 87

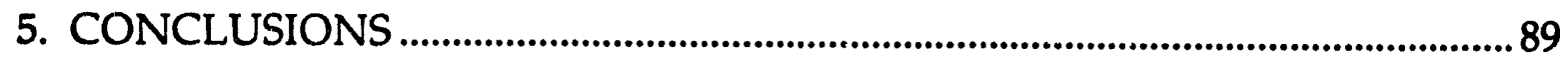

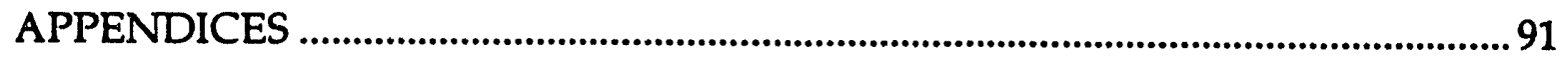

A. Costs of Energy Efficient Measures for Building Envelope Improvement...... 91

B. A Demonstration Project of Energy Efficient Residential Building Standard 94

C. Data for Figures in the Report .......................................................................97

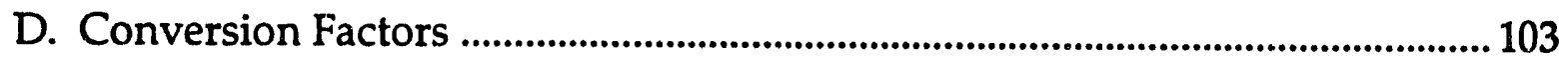

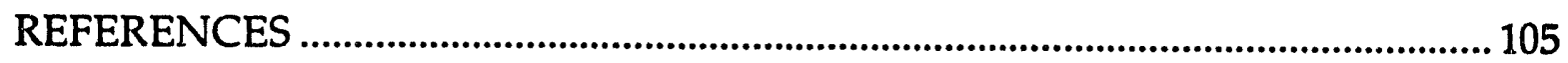




\section{FIGURES}

Figure 2-1 The Pattern of Sectoral Final Fuel Use, 1980-1990 ................................... 6

Figure 2-2 The Pattern of Sectoral Electricity Use, 1980-1990 ................................... 7

Figure 2-3 Residential Energy Use by Energy Source, 1980-1990 .......................... 9

Figure 2-4 Commercial Energy Use by Energy Source, 1980-1990 ......................... 9

Figure 2-5 Fuel Use by Building Category, 1980-1990 .............................................. 10

Figure 2-6 Electricity Us€ by Building Category, 1980-1990 ................................... 11

Figure 2-7 Urban Residential Energy Mix, 1980-1990 ................................................. 12

Figure 2-8 Per Capita Residential Energy Use, Rural vs. Urban, 1990 ................. 13

Figure 2-9 Energy Use in Residential Buildings, China vs. USA, 1988 ................ 14

Figure 2-10 Residential Electricity End Uses, 1981 vs. 1989................................... 15

Figure 2-11 Chinese Population Distribution by Residency, 1950-1990................ 17

Figure 2-12 Household Structure in China, 1982 and 1990 ..................................... 17

Figure 2-13 The Trend of Urban Ownership of Appliances, 1981-1991 ...............21

Figure 2-14 The Trend of Rural Ownership of Appliances, 1985-1991 ............... 21

Figure 2-15 The Pattern of Space-Heating Zoning (Map) ....................................... 23

Figure 3-1 Efficient Briquette-Burning Stove ........................................................... 33

Figure 3-2 Rural Firewood-Fired Stove...............................................................37

Figure 3-3 Refrigerator Saturation in Selected Major Cities, 1982, 1985, 1989 ... 64 


\section{TABLES}

Table 2-1 Rural Residential Energy Mix, 1979 and 1987......................................... 12

Table 2-2 Popular Appliances and Their Typical Unit Electricity Use................. 22

Table 2-3 Floor Space of Residential and Commercial Buildings, 1989 ............... 25

Table 3-1 Estimates of Building Fuel Use by End-Use, 1988...................................30

Table 3-2 Some Basic Data of Urban Buildings in the Heating Zone, 1989 ......... 39

Table 3-3 Heat Transfer Coefficients of Typical Apartment Buildings ................ 48

Table 3-4 Heat Losses of Typical Apartment Buildings in Beijing......................... 49

Table 3-5 Per Capita Residential and Commercial Electricity Use in Selected Countries, 1989 ....................................................................60

Table 3-6 Estimates of Residential Electricity End Uses ...........................................61

Table 3-7 Estimates of Residential Electricity End Uses, 1981 vs. 1989 .................69

Table 3-8 Cost Effectiveness of Introducing 16 W CFL ............................................75 


\section{ACKNOWLEDGMENTS}

I would like to thank Dr. Mark D. Levine of the Energy Analysis Program, Lawrence Berkeley Laboratory, for making this project possible. Dr. Levine not only provided financial support for my stay at Berkeley but also extensively advised me on my research.

Professor Mark Christensen, Energy and Resources Group, University of California, Berkeley, helped greatly in finishing the project with his valuable comments and timely instruction. I owe thanks to Professor John P. Holdren who helped $m e$ in the initial stage of defining the project.

Professors Siwei Lang and Xunchang Wang of the Air-Conditioning Research Institute, China Academy of Building Sciences, and Professors Xueyi Liu and Zhengping Jiang of the Energy Research Institute, China State Planning Commission, provided a great deal of essential data and information for the project. Y. Joe Huang and Steve P. Meyers of the Energy Analysis Program at LBL made thoughtful suggestions and comments for the improvement of the report. Ted D. Gartner, Karen H. Olson, and Tracy J. Stollar edited the manuscript.

I would also like to thank Jonathan E. Sinton, my classmate at the Energy and Resources Group, for many discussions and his assistance in collecting data. I am grateful to all students, professors, and staff members of the Energy and Resources Group for making my study at Berkeley an memorable experience. 


\section{EXECUTIVE SUMMARY}

This report discusses the determinants of residential and commercial energy demand, profiles the patterns and problems of energy consumption, and evaluates popular energy conservation measures of the People's Republic of China. It also discusses technological and institutional opportunities for realizing greater energy conservation. General characteristics related to energy use include the following:

- The residential sector in China consists of about 280 million households. About $70 \%$ of them are located in rural areas. Household structures have experienced major changes in the 1980s. The number of households grew twice as fast as the population, putting greater pressure on the residential energy supply as well as on other family accommodations.

- In the wake of brisk economic growth, energy-using activities in the commercial sector have been increasing rapidly. The growing stock of luxury hotels and modern office buildings is more energy-intensive to operate than traditional Chinese commercial buildings with no space conditioning.

- Residential and commercial energy use is an important part of the total energy use in China, commanding more than $20 \%$ of the modern energy share and more than $40 \%$ of the total energy share that includes biomass.

- Residential and commercial energy use in China is characterized by two distinct features: (1) Massive use of low-grade energy sources-solid biomass accounts for about $80 \%$ of rural residential energy supply and coal accounts for about $80 \%$ of urban residential energy supply. (2) Space heating and cooking dominate energy use, contributing more than $95 \%$ to rural residential energy use and about $90 \%$ to urban residential energy use. These percentages reflect China's special climate conditions and relatively low standards of living.

- Rapid improvements in the standard of living have resulted in a phenomenal growth in residential and commercial electricity demand, averaging $15 \%$ per year from 1980 to 1990. The increase of per capita energy use has become the major factor in rising residential energy demand. The speed of urbanization has been fast and steady compared to that of the previous two decades.

- Problems and difficulties facing energy planning and management in the residential and commercial sectors abound. Serious energy shortages exist in many rural regions. More than 40 million rural households still have no access to electricity. Most urban residents still use coal-fired stoves for cooking and space heating and suffer from serious indoor air pollution. Coal 
briquette supplies are inadequate. Central space-heating systems are inefficient and polluting because of the proliferation of inefficient coal-fired boilers. Little progress has been made in insulating buildings in spite of the introduction of energy-efficient residential building standards in 1986. Major appliances, although manufactured with relatively modern technologies, still lag behind similar products in the West in energy efficiency. Compact fluorescent lamps have had almost no market penetration. Regulations designed to deal with efficiency problems are insufficient and often not very effective. Capital for making transitions to greater energy efficiency is often short, while residential fuels are heavily subsidized by the government.

This study also examines specific energy end-uses and efficiency issues. Major findings are:

(1) Space Heating

- Primitive heating modes prevail and pose serious health hazards. Coal-fired stoves heat $75 \%$ of the urban residential floor area as well as the commercia! floor area in the heating zone.

- Central heating is inefficient and polluting. Commanding more than $75 \%$ of heating boiler capacity, dispersed small boilers (1-4 ton-steam/hr) with 50 $60 \%$ heat efficiency are the major heating facilities.

- Heat distribution networks are poorly insulated and construction quality is often inferior so as to further decrease central heating energy efficiency.

- Buildings are poorly insulated or not insulated at all. Old buildings with large exterior wall-area/volume ratios dominate the building stock. Steelframed single-glazed windows are popular in urban residential buildings in cold-climate regions. Poor construction quality results in thermal bridges and large amounts of infiltration. All these greatly impair a building's thermal integrity.

- Energy-efficient residential building standards have not produced expected results because of the resistance of builders and the lack of actual enforcement procedures and corresponding technical support. Because of constant housing shortages there is a severe conflict between building more apartments and building better apartments. There is not a developed market place in which to buy and sell energy-efficient products. Viable products are not readily available and of reasonable cost.

(2) Cooking and Water Heating

The trend of switching from coal to gaseous fuels is strong in urban areas, but coal still dominates the overall fuel supply. Some rural areas still face 
serious shortages of cooking fuel. Water-heating fuel use is minimal, but is considered to be potentially important in the long run.

\section{(3) Lighting and Appliances}

- Both residential lighting and appliance use are increasing in China, with appliances assuming an increasing percentage of the total electricity consumed in the residential sector. Incandescent lamps are the dominant device although small $(<10 \mathrm{~W}$ ) fluorescent lamps are very popular. The conservation potential and cost-effectiveness of introducing compact fluorescent lamps very much depend on the size (wattage) of the incandescent lamps replaced. Chinese housenolds are generally very frugal in their use of electric lighting.

- Because HVAC systems are rare, lighting is still the dominant electricity use (about $70 \%$ ) in commercial buildings . Fluorescent fixtures are the major devices for commercial lighting. Significant electricity savings can be achieved by introducing more efficient tube's and electronic ballasts. The stock of modern commercial buildings is on the rise. More attention should be directed to electricity conservation in commercial buildings.

- Refrigerators have become the major electricity users of average urban families. The potential for electricity saving from refrigerators is likely to be substantial according to the experiences of other countries.

- Air conditioning in residential buildings is still insignificant, but a few prosperous southern cities have seen a significant penetration of room air conditioners. Air conditioners have a large potential market in China since the most populous southern region has long, hot, and humid summers.

- The increasing popularity of electric cookware needs to be examined since the use of these appliances may aggravate evening peak loads.

In terms of the future direction of energy conservation in the residential and commercial sectors, the author considers the following to be important:

- Energy efficiency and environmental protection goals should receive priority in long-term urban and rural development plans. Policies should encourage sustainable biomass use in the rural areas and more gaseous fuel penetration in the urban areas.

- Efficient stoves and honeycomb briquettes are still important means to conserve coal and biomass because of their dominant use in both urban and rural areas.

- Mandatory energy-efficient building codes are necessary for fundamental improvement of the building thermal integrity and for space-conditioning 
energy conservation. Policies should promote the production and utilization of energy-efficient building materials and products.

- Innovative policy should be used in order to promote efficient lighting devices in residential buildings. The quality of products and the economies of manufacturing scale are important issues in promoting lighting efficiency.

- Energy-efficiency standards should be implemented for major appliances.

- Price reform is the key issue to speed up fuel switching and coal conservation in urban areas. 


\section{INTRODUCTION}

\subsection{BACKGROUND AND OBJECTIVE}

For the past 40 years, China has had one of the fastest growing economies in the world, with real gross national product (GNP) increasing at 6\% per year (atout $9 \%$ per year in the 1980s). Population has doubled in the same period, reaching more than 1.1 billion by 1990 . Accompanying this impressive economic progress and population growth is a thirty-fold increase in modern primary energy consumption, which makes China the third largest energy user in the world after the U.S. and the former Soviet Union. In 1990, China produced 1769 billion yuan of GNP ${ }^{1}$ and consumed 980 million tons of coal equivalent (Mtce) of modern primary energy ${ }^{2}$ [SSB, 1991].

The residential and commercial sectors account for about one-fifth of China's modern energy consumption. (Rural households consume an additional 250-300 Mtce of biomass.) With one-fifth of the world's population and a growing economy, residential and commercial energy use and conservation in China deserve special attention. Considering the low-level per capita residential and commercial energy use at present, the potential growth of energy demand is likely to be great. The future development of residential and commercial energy structures and end-use technologies will have a great impact on energy demand, indoor and ambient air pollution, as well as greenhouse gases emissions. By recognizing the strategic importance of residential and commercial energy use and conservation, this study intends to provide readers with an up-to-date ficture of energy activities and related equipment and technologies.

Energy issues for the residential and commercial sectors have had minimal importance in China's energy planning. The central issue of the national energy policy has always been to meet industrial demand. For decades fuel rationing was probably the most important residential energy policy. This attitude of "industrial development first and people's livelihood last" underwent significant change in the 1980s. Much of the progress in energy services for the residential and commercial sectors was achieved in this period. On the other hand, energy use and conservation in the residential and commercial sectors still receive less attention than they deserve. Government policies often have only symbolic meaning and are rarely followed through. This is revealed by the

1 This GNP value corresponds to about $\$ 322$ billion dollars at the present official exchange rate of $\$ 100=¥ 550$. One should not compare the converted number to that of any other economies because of the distortions in exchange rates and in calculating GNP among different countries.

2 Includes fossil fuels, hydro and nuclear electricity. 1 tce $=29.3 \mathrm{GJ}$. 
inadequate allocation of natural gas and quality anthracite for residential use, the continuing proliferation of poorly insulated buildings, and the widespread use of inefficient space-heating facilities.

The objectives of the study are to identify important factors constraining the improvement of end-use efficiency and to suggest how constraints might be eased and how demand-side policy initiatives could complement expansions in supply capacity.

\subsection{METHODOLOGY}

The primary goals of this study are to understand how energy is used and to identify conservation opportunities in the residential and commercial sectors. To achieve these goals, an end-use analysis approach is adopted. Two subjectsfuel-use efficiency and electricity-use efficiency-are separately discussed. The methodology followed for each subject consists of the following broad elements:

- Estimate and analyze current energy use in total and in disaggregated end uses and end-use equipment.

- Identify and evaluate major conservation measures.

In addition, past and current programs and policies to promote energy conservation are reviewed. On the basis of such work, new policy initiatives are recommended.

Since commercial sector energy use in China is much less understood than residential energy use, relevant discussion about the commercial sector in this report is brief and patchy. The main focus of this study is the residential sector. Further work is needed to extend the understanding of the commercial sector.

\subsection{DATA AND LITERATURE}

This study is primarily descriptive. A major part of this report intioduces the issues of energy use and efficiency in the residential and commercial sectors by presenting data of varying kinds.

Chinese energy end-use data has always had problems: inaccuracy, inconsistency, and incompleteness, for example. Energy and related data of the residential and commercial sectors are especially weak. Survey, field study, and estimated data of various origins are scattered in different literature. This study tries to put them together with adequate explanations. Readers should be aware of possible variances of data from the realities, although the author has compiled them carefully by cross-checking different sources. In several instances, the author also developed his own estimates in order to reach a certain level of disaggregation. 
A few books and articles have been quoted frequently in this study for data and information. They probably also represent the more important research sources of residential and commercial energy use. For those who may want to know more about these references, the following is a brief introduction:

Energy Statistical Yearbook of China 1989 and 1991 (in Chinese), edited by the State Statistical Bureau of China (SSB), is a primary source for energy data. Interesting data include energy balance tables (sectoral energy use data), energy production, and energy investment.

Studies of Techno-Economic Policies of Building Energy Conservation (in Chinese), 1991, [Tu, Li, and Shen, 1991] a report to the State Planning Commission and the Ministry of Construction, is a collection of papers discussing various issues of energy conservation such as boiler efficiency (district heating), building insulation, and case studies in residential buildings.

National Rural Energy Planning (in Chinese), 1990, Xu, Zhang, et al., China Standard Press, is one of the most important studies on rural energy in China. The : eport contains valuable assessments of biomass energy use in various regions of China as well as modern energy use in the rural areas.

\subsection{ORGANIZATION OF THE REPORT}

The report procee $1 s$ in the following urder. Chapter 2 describes the general background of energy consumption in China and explains the status quo in the residential and commercial sectors. This chapter also elaborates patterns of energy use by fuel type and by sub-sector. Some of the major factors of energy demand in the residential and commercial sectors are also discussed. Chapter 3 focuses on end-use analysis of energy use in the two sectors. The goal is to identify inefficient practices and to recommend feasible conservation measures. The cost-effectiveness of conservation measures is discussed wherever appropriate. Chapter 4 reviews experiences of energy conservation. Barriers and constraints are identified. Some policies that could ease such constraints and facilitate future conservation work are recommended. Chapter 5 concludes the report.

\subsection{UNITS AND CONVERSION FACTORS}

All data in this report are recorded in the metric system. Coal equivalent is used as the common unit for energy. Electricity is converted into coal equivalent according to the amount of coal currently required for generating a unit of electricity in China. For your reference conversion factors used in this report are listed in Appendix D. 


\section{RESIDENTIAL AND COMMERCIAL SECTOR ENERGYUSE}

The economy of the People's Repuhlic of China started from a tiny base in the early 1950s. ${ }^{1}$ Because of government interest in rapid modernization, industrial development led the rapidly growing gross domestic product throughout the decades (GDP). ${ }^{2}$ By 1990, 44.3\% of China's GDP was derived from the industrial sector, $28.4 \%$ from agriculture, and $27.3 \%$ from services, compared with the respective shares of $23 \%, 58 \%$, and $19 \%$ in 1952 [SSB, 1991]. ${ }^{3}$ In a developed economy, agriculture usually contributes a very small portion to GDP. Even in the U.S., a major world provider of agricultural products, agricultural valueadded accounts for only about $3 \%$ of the nation's GDP. The present Chinese GDP structure indicates that sectoral adjustments will be made in future decades, and consequently, these adjustments will have an important affect on future energy demand. For instance, a rapidly expanding service sector would underscore the increasing importance of energy demand in the commercial sector.

\subsection{SECTORAL ENERGY USE}

Like many other of the world's developing economies, China's energy consumption has outgrown GDP for most of the past 40 years. What is unusual is that since the late 1970s, when the nation's economy began to boom, the increase in energy demand has fallen behind GDP growth by half, resulting in a $37 \%$ reduction of energy intensity from 1978 to 1990.4 This impressive improvement of the energy/GDP ratio is related to many contributing factors. The more important ones are the rapid growth of light industry, which has been characterized by a momentous increase in the production of consumer goods (from 1978 to 1990, light industry outgrew the heavy industry by about 4

1 The People's Republic of China was founded in October 1, 1949. However, the first official five-year economic plan was put into action in 1952, the year that is commonly considered a proper starting time for economic statistics.

2 In China, the difference between gross national product (GNP) and gross domestic product (GDP) is negligible. For measuring the energy efficiency of the economy, GDP is considered to be the appropriate economic indicator.

3 Estimated from net output values from SSB, 1991.

4 Energy intensity is defined as modern primary energy use per unit of real GDP. Biomass use is not included because of insufficient data. 
percentage points per $y(4 \mathrm{dr})$, and the unprecedented energy-conservation regulations and investments begun in the early 1980s. Both economic structural changes and technological advances played essential roles in this development.

Because of abundant domestic resources and policies designed to achieve self-reliance in energy supplies, China has heavily favored coal for energy use. With a percentage share that has been slowly rising since the mid-1970s, coal supplied about $76 \%$ of modern primary energy use in 1990 and the dominance of coal is the most outstanding feature of energy consumption across every sector. Another important feature of Chinese energy use is the large-scale biomass consumption in rural areas.

In 1990, total modern fuel consumption was about $660 \mathrm{Mtce}$, of which the residential and commercial sectors contributed $20 \%$ and $4 \%$ respectively. Industry dominates modern fuel use with a share of $63 \%$. Biomass is almost exclusively used in rural households, which shelter over $70 \%$ of China's population. Including biomass, residential fuel use is about $44 \%$ of total fuel consumption. Figure 2-1 depicts the pattern of sectoral final fuel consumption from 1980 to 1990 .

The amount of residential biomass consumption implies a large future demand for modern energy if fossil fuels are to substitute for biomass, as is usually the case when nations modernize. The preservation or replacement of

Figure 2-1. The Pattern of Sectoral Final Fuel Use, 1980-1990

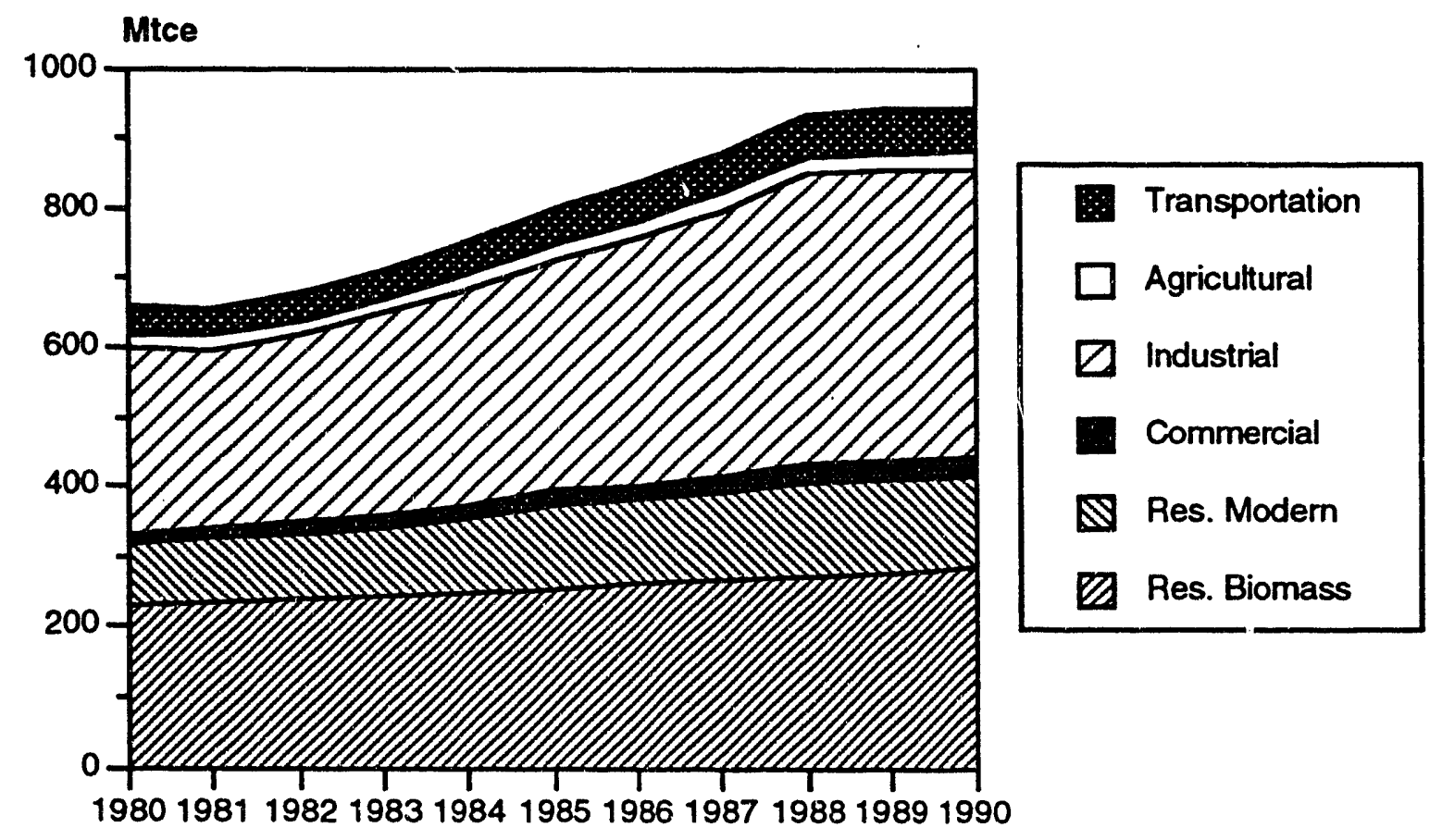

Note: Biomass use is linearly extrapolated from data of 1979 and 1987.

Source: SSB, 1990b, 1992b; Xu and Zhang, 1990. 
biomass use is one of the challenging issues of residential energy planning in China. The faults and merits of biomass use are examined more closely in Chapter 3.

Final electricity consumption in China reached 490 billion kWhs in 1990 (see Figure 2-2). Residential and commercial sectors account for only about $10 \%$ and $6 \%$ of the total, respectively. Industry again has the lion's share at $74 \%$. On the other hand, residential and commercial electricity use has been leading the growth of electricity use among all sectors since the late 1970s. From 1980 to 1990, annual growth rates of residential and commercial electricity use were a respective $16 \%$ and $12 \%$, compared with $7 \%$ for the industrial sector. In developed countries, residential and commercial electricity use comprises a much larger share (usually more than $40 \%$ ) of final electricity use. The U.S. is an extreme example at more than $60 \%$ [Schipper, 1993]. The low percentages here suggest a great increase in electricity demand in the Chinese residential and commercial sectors in the future.

Figure 2-2. The Pattern of Sectoral Electricity Use, 1980-1990

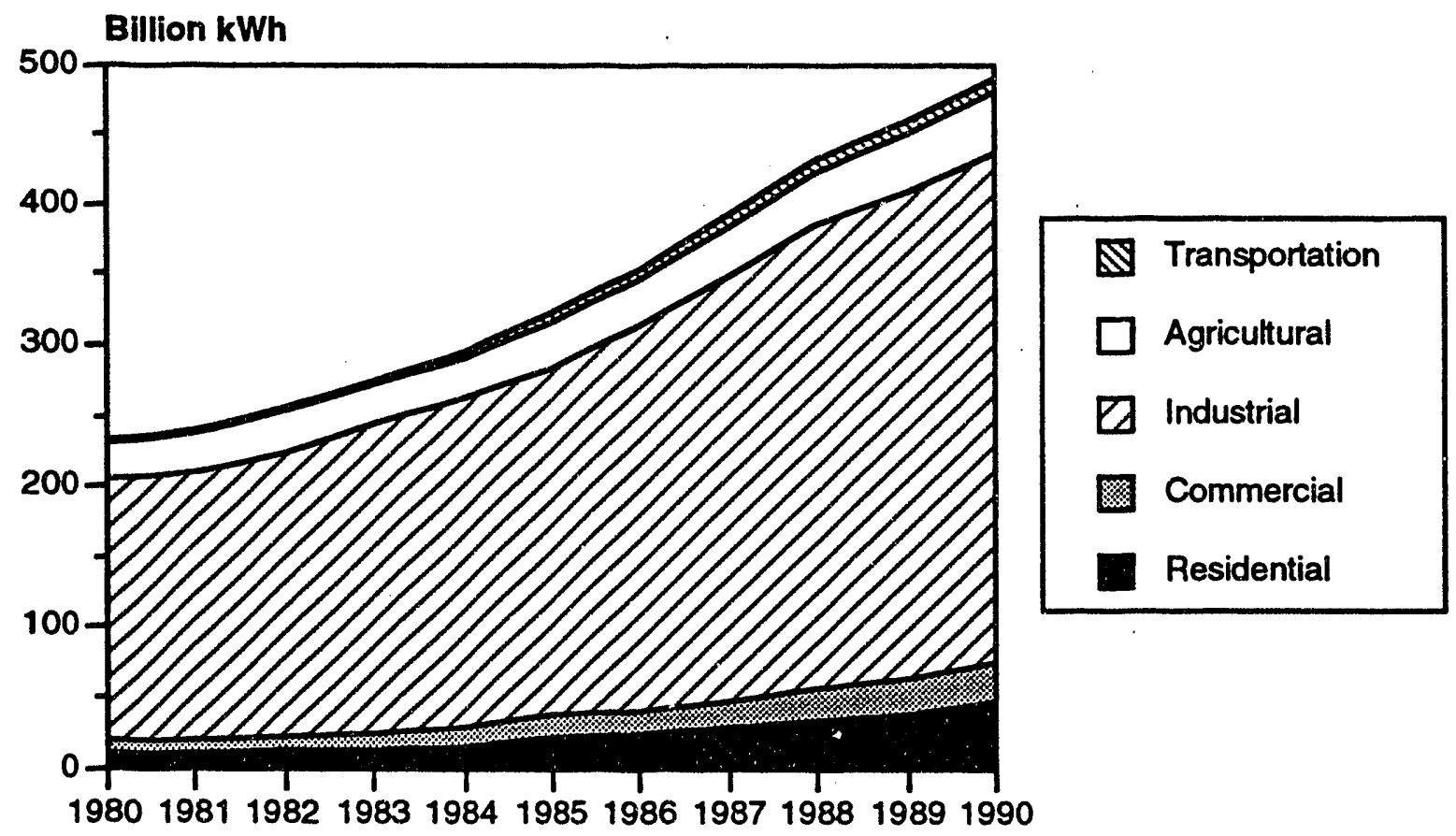

Source: SSB, 1990b, 1992b

The growth rate of residential and commercial electricity use is expected to be large considering the size of the unsaturated home appliances market in urban areas and a substantially larger market in rural areas, not even mentioning the coming age of air conditioning in residential and commercial buildings. Compared to electricity, demand for fuel may grow more slowly because of large efficiency gains obtained by substituting gaseous fuels for coal. Furthermore, 
most fuel is used to meet basic energy requirements in the residential and commercial sectors. ${ }^{5}$ It seems doubtful that coal use would be extended beyond cooking and space heating. But this is not to say that future residential and commercial fuel demands are less important issues. Instant hot water has so far been a luxury for most Chinese households, and space heating is still not accessible to about half of the population even though it is often needed. It is most likely that residential and commercial fuel demand, especially gaseous fuel demand, will grow significantly in the long run if there is no sizable switching from fuel to electricity.

\subsection{RESIDENTIAL AND COMMERCIAL ENERGY USE PATTERNS}

The structure of China's residential and commercial energy use is similar to that of other major developing countries where biomass is a major fuel source. It is, however, different because coal is also extremely important and space heating is a major end use.

Cooking and space heating in the residential sector are responsible for an unusually high percentage share of fuel consumption. As shown in Figure 2-3, in 1990 fuel use (including biomass) accounted for about $95 \%$ of total residential energy use while the share for electricity was less than $5 \% .6$ The share of electricity was less than $2 \%$ a decade ago. In comparison, over $60 \%$ of the U.S. residential energy use is from electricity.

Large-scale biomass consumption is the most striking feature of residential energy use in China. The growth rate of biomass is gradually diminishing as coal becomes accessible to more rural populations, but biomass still commanded about $65 \%$ of residential energy use in 1990, compared with its share of $70 \%$ in 1980 . Coal demand seems to have stagnated in recent years although the trend is probably short-lived because of the increasing demand from rural areas and the unlikely substitution of gaseous fuel for coal in space heating.

Commercial buildings, presumably all in urban areas, consume modern energy, but coal dominates in commercial buildings in northern China because of the demand for heating energy there. In 1990, total commercial sector energy demand was about $40 \mathrm{Mtce}$ in which coal contributed $55 \%$, while the share for electricity was about $28 \%$. Figure $2-4$ depicts the energy mix in the commercial sector.

5 The meaning of basic needs could change as, income increases. At present, most households need fuel for cooking; households that alsc iive in cold areas (which is about half of all households) also require fuel for space heating.

6 In this paper, electricity is converted into primary energy equivalent $(0.404 \mathrm{kgce} / \mathrm{kWh})$ which includes generation, transmission, and distribution losses. The heat equivalent of electricity is $0.123 \mathrm{kgce} / \mathrm{kWh}$. 
Figure 2-3. Residential Energy Use by Energy Source, 1980-1990

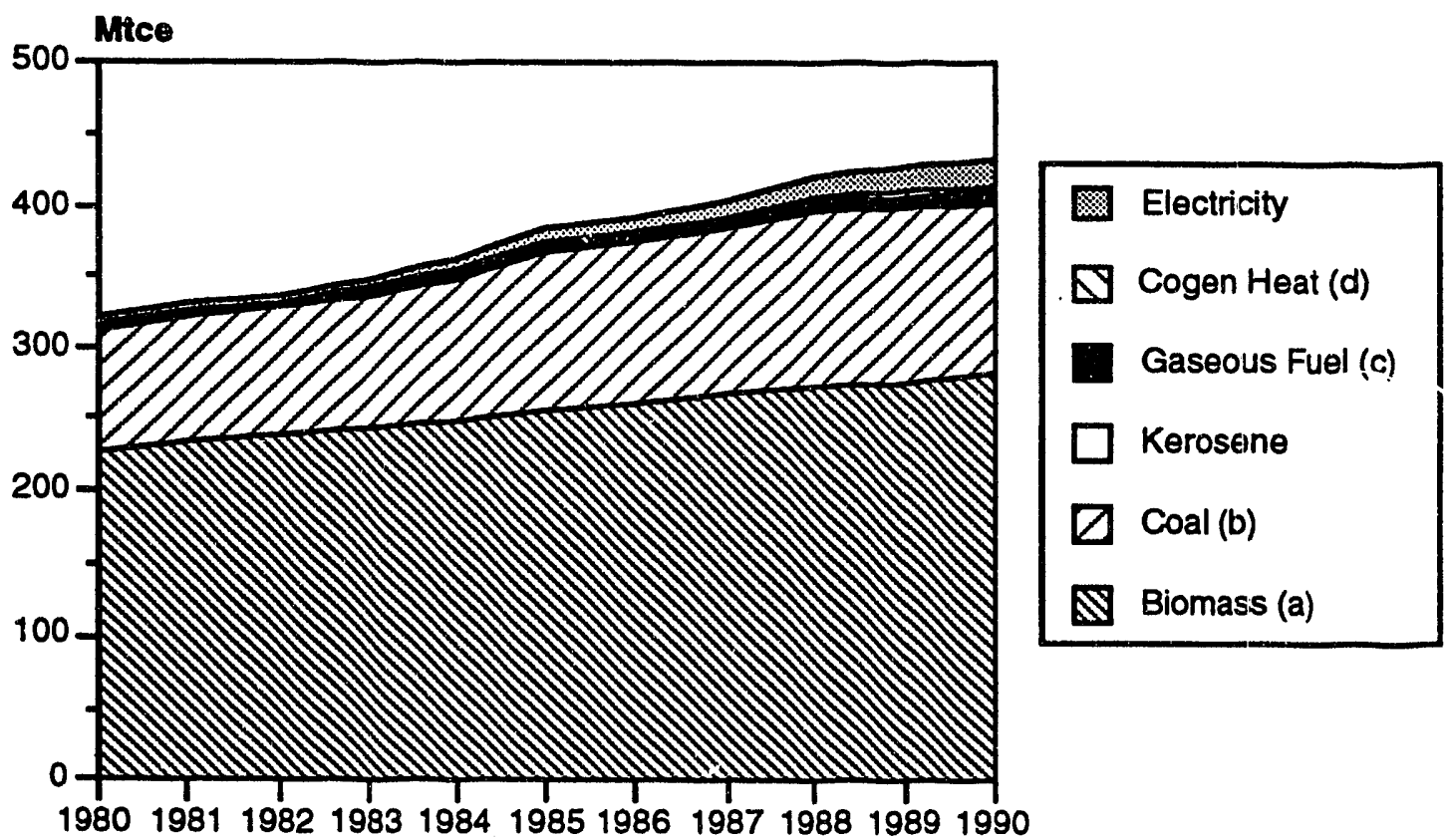

(a) Figures are linearly extrapolated from 1979 and 1987 data. Biomass includes mostly firewood and crop stalks. (b) Includes raw coal and briquettes. (c) Includes LPG, natural gas, and gases derived from coal. (d) Co-generated heat for district heating.

Source: SSB, 1992b; Xu and Zhang, 1990.

Figure 2-4. Commercial Energy Use by Energy Source, 1980-1990

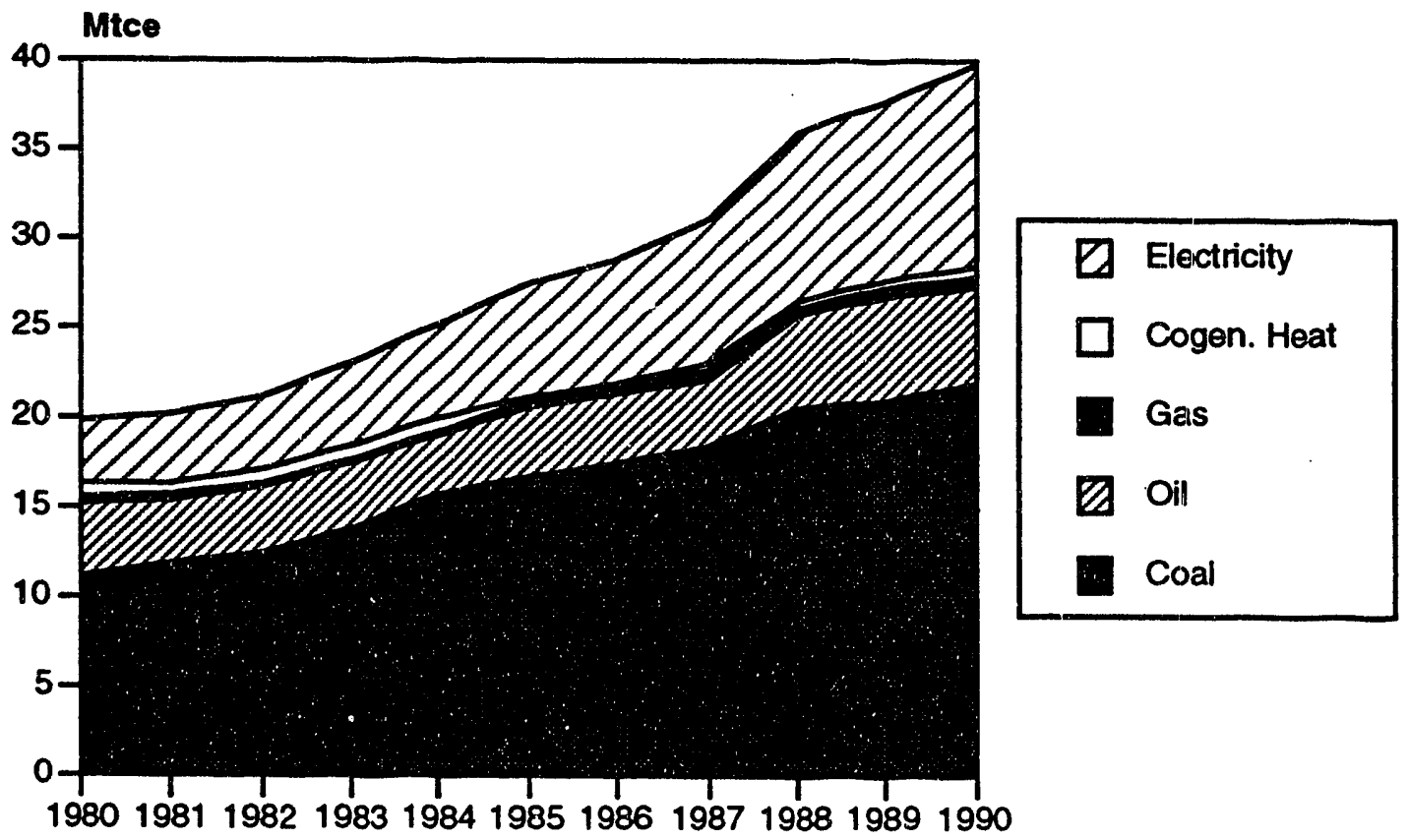

Source: SSB, 1990b, $1992 b$. 
Another way of looking at residential and commercial energy use is by building category. For the convenience of analysis, the residential and commercial building stock is divided into three categories: commercial buildings, urban residential buildings, and rural residential buildings. Fuel and electricity uses by building category are depicted in Figures 2-5 and Figure 2-6.

Urban residents, accounting for less than $30 \%$ of the total population, consumed about $55 \%$ of the total modern fuel and used $57 \%$ of the electricity in the residential sector in 1990. The transition from biomass to modern fuel in the rural areas has been slow. The government has been making efforts to promote efficient firewood stoves and plant firewood trees. The long-term rural energy strategy also stresses the importance of sustaining biomass use in order to ease the pressure of modern fuel demand [Xu and Zhang, 1990].

Figure 2-5. Residential and Commercial Fuel Use by Building Category

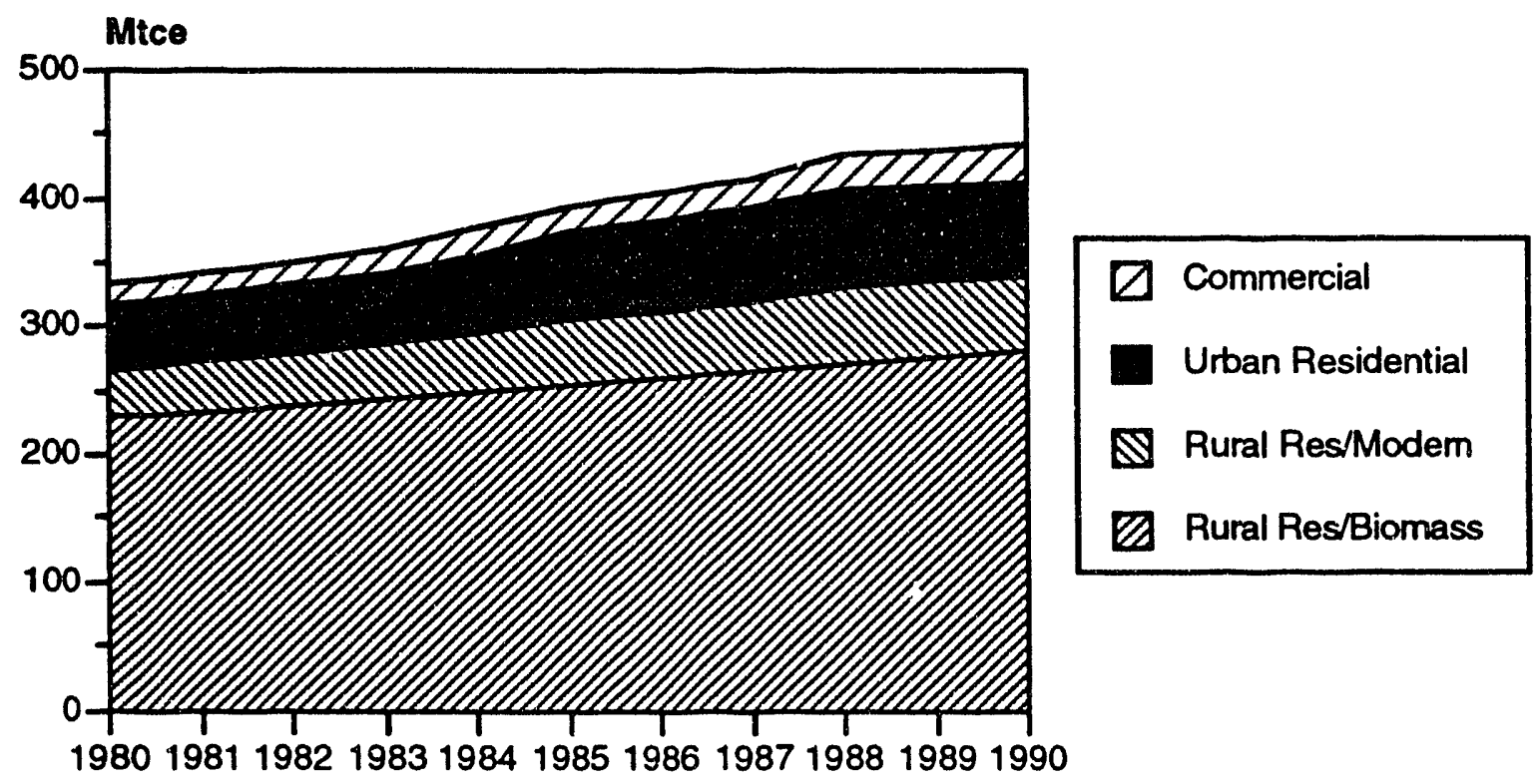

Source: SSB, 1992b; Xu and Zhang, 1990.

Fuel use in commercial buildings is relatively insignificant, contributing only about $6 \%$ of the total fuel use (inciuding biomass) and $16 \%$ of the modern fuel use in all buildings. Electricity use in the residential and commercial sectors shows a quite different pattern. Commercial buildings command about $37 \%$ of total electricity used in all buildings. Urban residents consume $36 \%$ of total building electricity, while rural residents, of whom about $25 \%$ still have no access to electricity, consume only $27 \%$ of total building electricity. Unlike electricity growth in urban residential buildings, which is caused by the sharp increase in appliance ownership, electrification (mostly for lighting) is likely to be an important factor for the growth of electricity use in rural residential buildings. Electrification will continue to be the priority of rural electricity development in years to come. 
Figure 2-6. Residential and Commercial Electricity Use by Building Category

Billion kWh

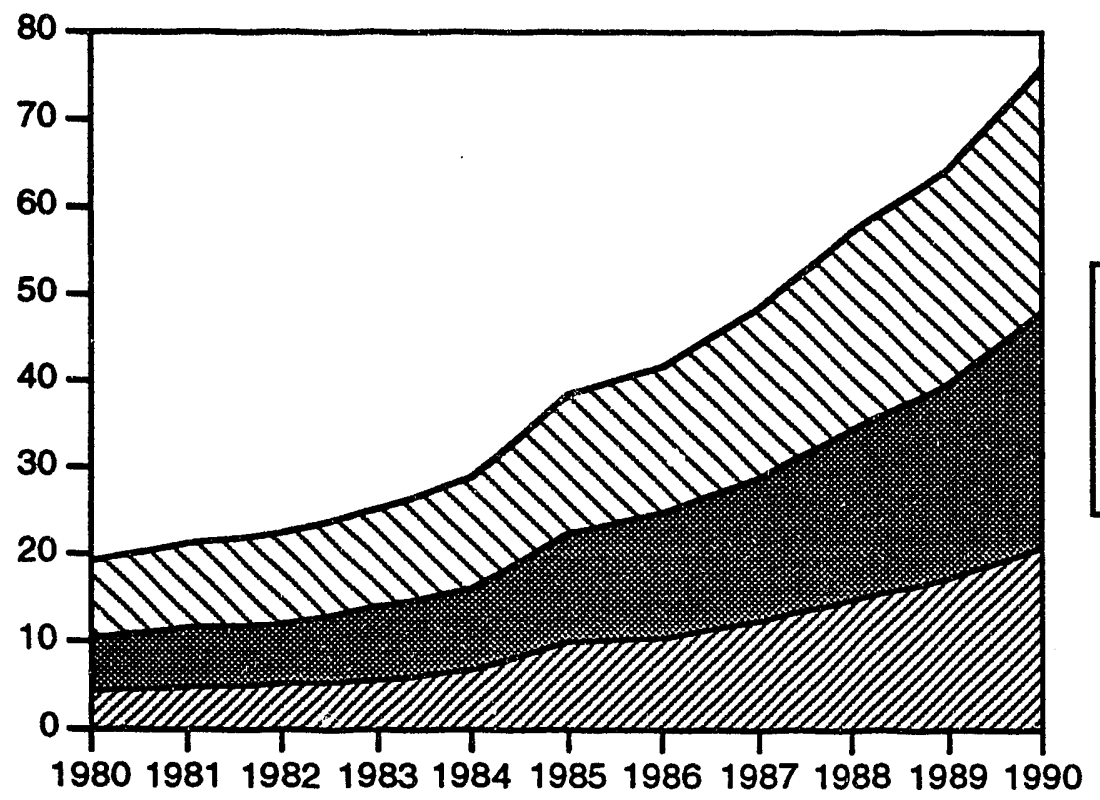

D Commercial

Urban Residential

Rural Residential

Source: SSB, 1990b, 1992b

Since great differences exist in residential energy use between the urban and the rural areas, it is helpful to look at each area's energy demands separately.

As shown in Figure 2-7, energy consumption by urban households is dominated by coal, which made up of about $75 \%$ of urban residential energy use in 1990. The growth rates of electricity and gaseous fuel from 1985 to 1990 averaged about $17 \%$ and $18 \%$ per year, while that of coal use was negligible. The respective annual growth rates from 1980 to 1985 were about $15 \%, 11 \%$, and $6 \%$. As of 1990 , electricity only accounted for about $13 \%$ of urban residential energy use and the share for gaseous fuel was about $8 \%$. The demand for electricity and gaseous fuels will continue to increase strongly and the dominance of coal will gradually decline. But a large decrease in coal use in the residential sector is unlikely because of the nature of domestic energy resources and the large spaceheating demand. Kerosene use is negligible and there is no obvious reason for its use to increase in the future.

Rural households show quite different patterns of energy use. Although coal dominates modern energy use, it is overshadowed by the enormous amount of biomass consumption in the rural areas. In 1987, biomass commanded about $80 \%$ of rural household energy use while coal only contributed $18 \%$. Kerosene is presumably used for lighting alone in areas where electricity is not available. 
Figure 2-7. Urban Residential Energy Mix, 1980-1990

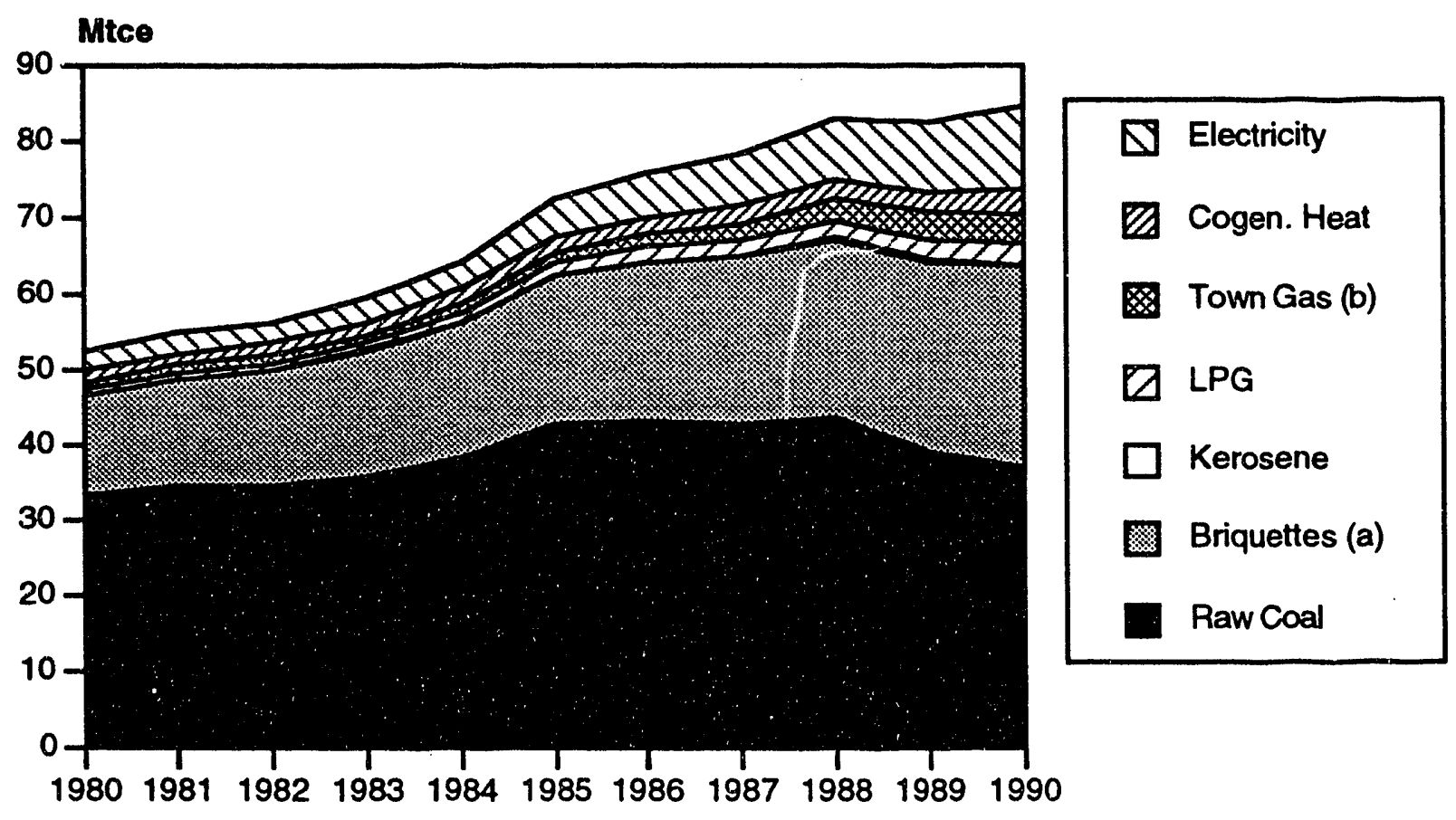

(a) Figures are linear extrapolation of 1981, 1985, and 1988 data. Raw coal use is calculated by subtracting briquette consumption from total coal use. (b) Town gas includes natural gas and gases derived from coal.

Source: SSB, 1992b; Jiang, 1991.

Table 2-1. Rural Residential Energy Mix (in Mtce), 1979 and 1987

\begin{tabular}{l|rrrr}
\multicolumn{1}{c|}{ Materials } & 1979 & $\%$ & 1987 & \multicolumn{1}{c}{$\%$} \\
\hline Crop stalks & 113.7 & $43.6 \%$ & 130.3 & $39.2 \%$ \\
Dung cake & 6.3 & $2.4 \%$ & 3.2 & $1.0 \%$ \\
Firewood & 103.8 & $39.8 \%$ & 132.6 & $39.9 \%$ \\
Coal & 32.6 & $12.5 \%$ & 59.6 & $17.9 \%$ \\
Kerosene & 1.5 & $0.6 \%$ & 1.9 & $0.6 \%$ \\
Electricity & 3.1 & $1.2 \%$ & 5 & $1.5 \%$ \\
Total & 261.0 & $100.0 \%$ & 332.6 & $100.0 \%$
\end{tabular}

Source: Xu and Zhang, 1990.

Table 2-1 compares rural residential energy fuel structures in 1979 and in 1987. Because the percentages of materials used increase in nearly all categories, it can be inferred that the modern energy supply has been inadequate to meet the rising demand. Consequently, biomass consumption continues to increase to fill the gap. The future transition of rural residential energy use in China is of great 
importance, for it may, on the one hand, further tax the nation's already strained energy supply system, and, on the other hand, provide a great opportunity to transform this important energy-consuming sector into a sustainable and environmentally sound one.

To summarize the differences between rural and urban residential energy use, Figure 2-8 plots the respective per capita energy use by energy source. The chart reveals great differences in the quality of energy services between rural and urban areas. Despite the higher per capita rural energy cor.sumption in terms of physical amounts, the useful amount consumed by the rural residents may be lower than that of the urban residents because of the inefficient use of large quantities of biomass. ${ }^{7}$ Briquette supplies to rural households are negligible. Most significantly, rural households have no access to gaseous fuels and central heating. Furthermore, urban residents consume four times as much electricity per person as rural residents.

Figure 2-8. Per Capita Residential Energy Use, Rural vs. Urban, 1990

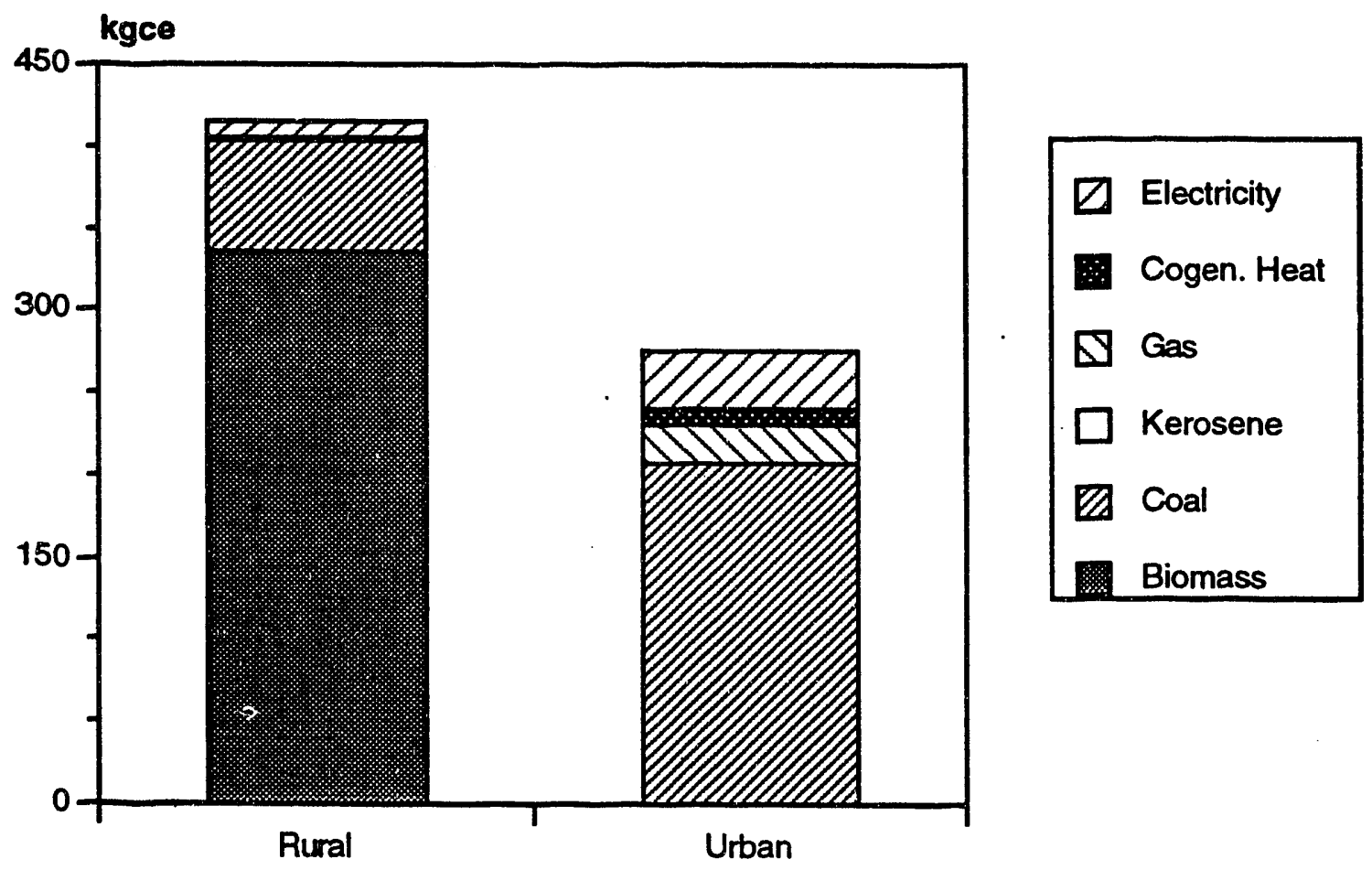

Source: Derived from data in SSB, 1992b; Xu and Zhang, 1990.

7 There is another dimension to rural household fuel use. That is the fuel used for pig feed preparation, a practice of most rural households, especially those in the southern region. It may not be easy to separate fuel for cooking animal feed from fuel for cooking human food in surveys since they are not differently treated by householders themselves. 
If the present biomass consumption were to be replaced by coal, about 160 Mtce, or 230 million ton of raw coal-approximately one-fifth of present raw coal production-would be needed. ${ }^{8}$ Raising the rural per capita electricity use to the average urban level (from $25 \mathrm{kWh}$ to $90 \mathrm{kWh} /$ person in 1990) would more than double present residential electricity use. By guiding the energy transition toward levels of modern and sustainable uses of biomass and other renewable energy sources, the government plays an essential role in minimizing the energy stresses of urbanization. Enforcing strict efficiency standards for appliances would also help reduce the stresses of residential electricity demand.

Finally, we discuss briefly the end-use patterns of energy consumption in the residential and commercial sectors.

As indicated by the structure of the residential energy mix, the predominant end-uses in urban households are cooking and space heating. Lighting and appliance energy use is insignificant compared to these predominant uses. We estimate that, in 1988, space heating, cooking, lighting, and appliances energy uses contributed about $36 \%, 55 \%, 3 \%$, and $6 \%$, respectively, to the energy used by urban households. For the rural households, the shares in turn are about $44 \%, 54 \%, 1 \%$, and $1 \%$ (see details in Table $3-1$ ). Figure 2-9 depicts the end-use patterns for both urban and rural households and compares them with the U.S. pattern. The comparison shows differences in

Figure 2-9. Energy Use in Residential Buildings, China vs. USA, 1988

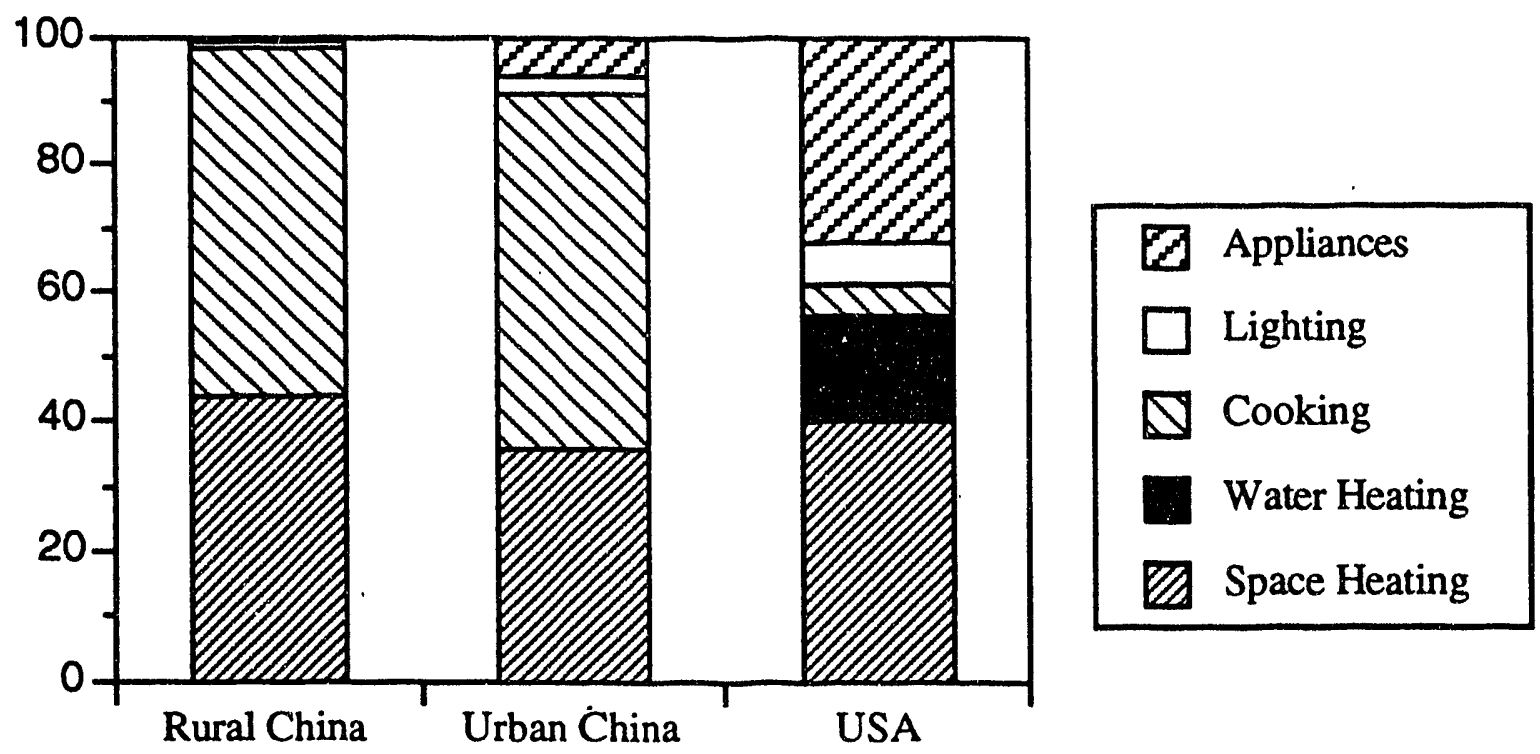

Source: China: detailed information in Tables 3-1 and 3-6; USA: Schipper, 1993,

8 Present biomass consumption of 270 Mtce translates into 40.5 Mtce useful energy at $15 \%$ heat efficiency and further translates into $162 \mathrm{Mtce}$ coal if $25 \%$ heat efficiency is assumed. This estimate may be conservative because many rural areas still experience fuel shortages. 
patterns of energy use that are caused not only by differences in the economies between the two countries but also by differences in lifestyles, climatic conditions, and energy structure and efficiency. It also hints that, in the long term, appliances and water heating are likely to be the major changing forces of residential energy demand in China. The rapid increase in the urban appliance stock in the last ten years provides initial evidence of such change.

Fuels are used almost exclusively for cooking and space heating in the Chinese residential sector. Some kerosene is also used for lighting in rural areas. Tap sed hot water supply is non-existent in residential buildings. Although small gas-heated shower devices have been gaining popularity in recent years, nationwide they still consume a negligible amount of fuel. Chinese households boil water for drinking and other daily uses. We include this practice as part of the cooking activity and do not separate out water-heating energy use in this study.

Figure 2-10. Residential Electricity End Uses (Billion kWh), 1981 and 1989

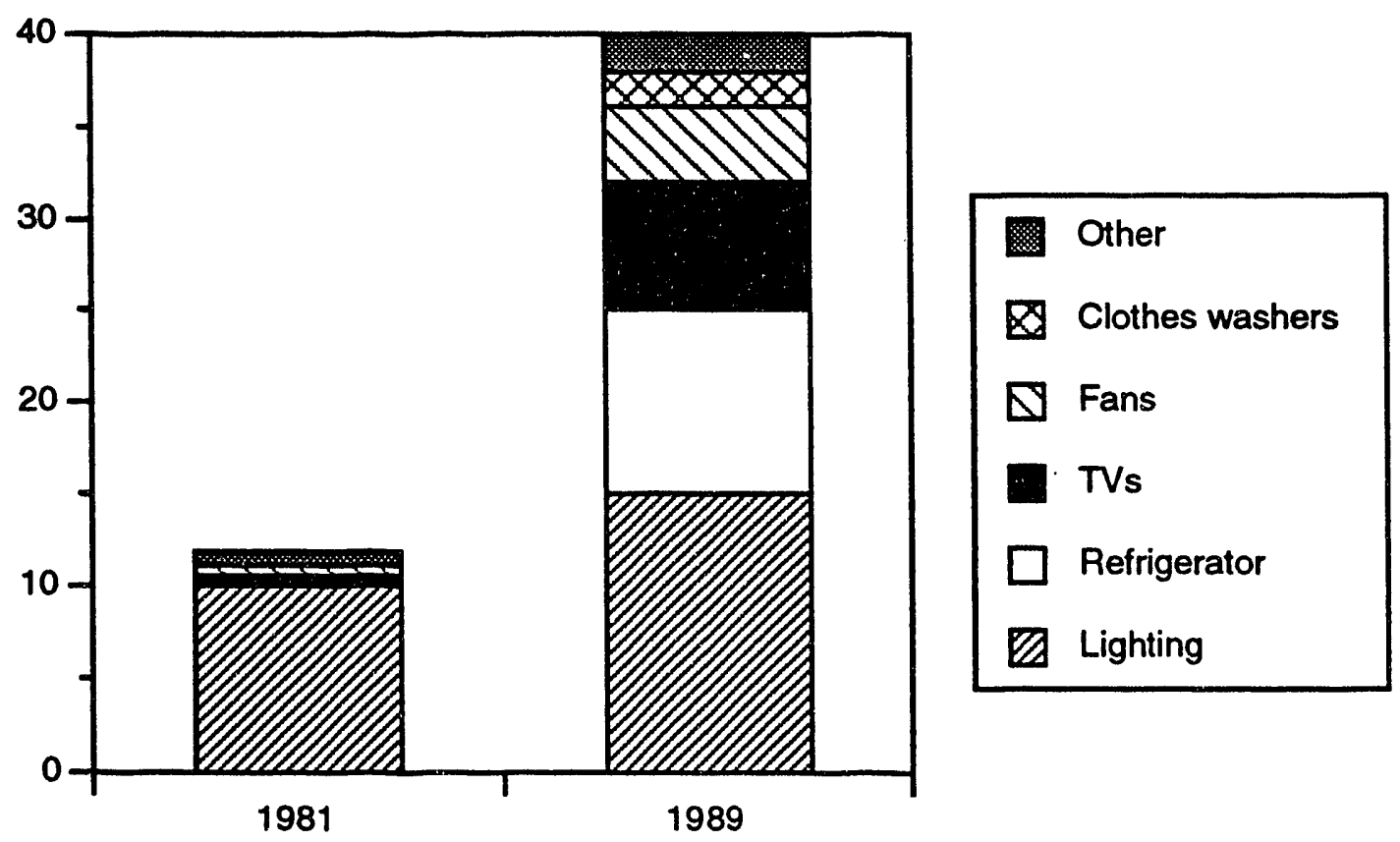

Note: Total residential electricity use data are from the SSB, 1992b and the end uses are estimated. See details in Section 3.2.

The rush to acquire appliances has fueled the rapid growth of residential electricity consumption in urban areas since the early 1980s. This momentum is likely to be maintained for a long period of time if the economy continues to excel. Figure 2-10 reveals the drastic changes in the structure of electricity end uses in the 1980s. Nationwide, the share of lighting electricity use decreased from about $85 \%$ in 1981 to less than $40 \%$ in 1989 . In the meantime, appliances became the dominant end use. This change is even greater if only the urban households are considered. Saturation rates of refrigerators and color televisions 
in the urban areas have reached about $50 \%$ and $70 \%$, respectively, from near zero in 1980.

Energy is mainly used for space heating and lighting in commercial buildings. Commercial cooking fuel use is also significant because of the popularity of restaurants and work-unit cafeterias in China. Other uses include public bathhouses and teahouse boilers. Ventilation and air conditioning energy use is still insignificant nationwide but has become increasingly important in large cities and coastal urban areas where the stock of tourist hotels and modern office buildings are on the rise. The end-use distribution of energy use in commercial buildings is difficult to estimate because of the lack of basic information such as data on equipment stock.

\subsection{DETERMINANTS OF ENERGY DEMAND IN BUILDINGS 9}

Many factors affect residential and commercial energy demand. The more important ones include the population size and the standard of living, appliance stock and energy efficiency, building stock and thermal integrity, climatic conditions, and household behaviors.

\subsubsection{Population and Household Structure}

Since the late 1970s, residential energy demand has been closely related to two distinctive demographic changes. The Chinese population is moving faster than ever to the urban areas and households are becoming smaller. From 1982 to 1990 (the latest two censuses), the share of urban population increased five percentage points and the growth rate in the number of households outpaced that of the population by a factor of two. In contrast, there was virtually no net migration of population from the rural areas to the urban areas in the 1960s and 1970s and the growth rate of the number of households lagged behind that of the population from 1953 to 1982 [SSB, 1989a].

The pace of urbanization was slow until the early 1980s because of the government's strict policy on population migration. Figure 2-11 depicts the Chinese population structure by residency. ${ }^{10}$ The restrictive policy on urban development has been a major factor that kept modern energy demand by the residential sector low for many years. The speed of urbanization has picked up since the late 1970s when economic reform first started. The accelerated urbanization in the 1980s was a major contributor to the increase in urban

9 In this report, the term "buildings" is used interchangeably with the term "residential and commercial sectors" unless otherwise specified.

10 The definitions of rural and urban areas have become less distinct in recent years because of the soaring rural industrial development that has brought many urban amenities to the rural areas. The State Statistical Bureau keeps track on the number of people with urban or rural residency certificates, which provide the basic information for such division of population. 
Figure 2-11. Chinese Population by Residency, 1950-1990

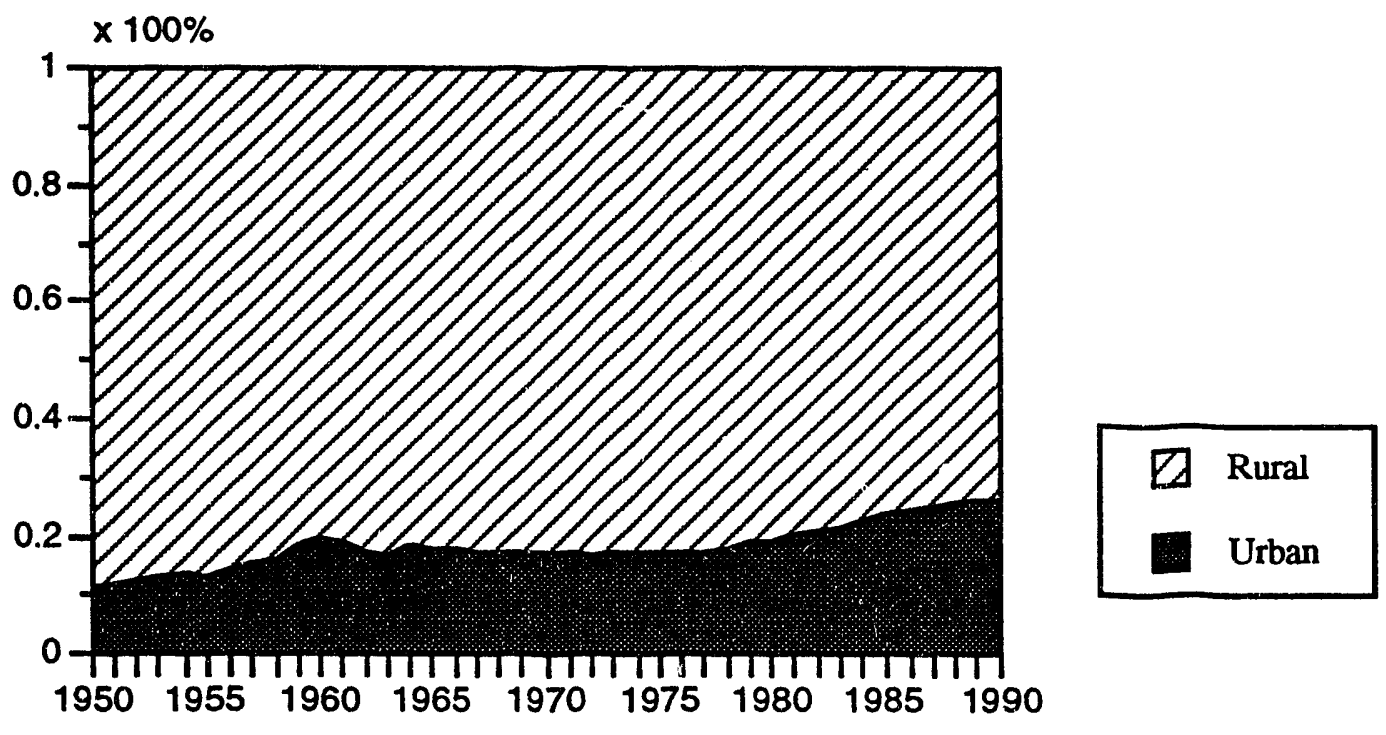

Source: SSB, 1992a.

Figure 2-12. Household Structure in China, 1982 and 1990

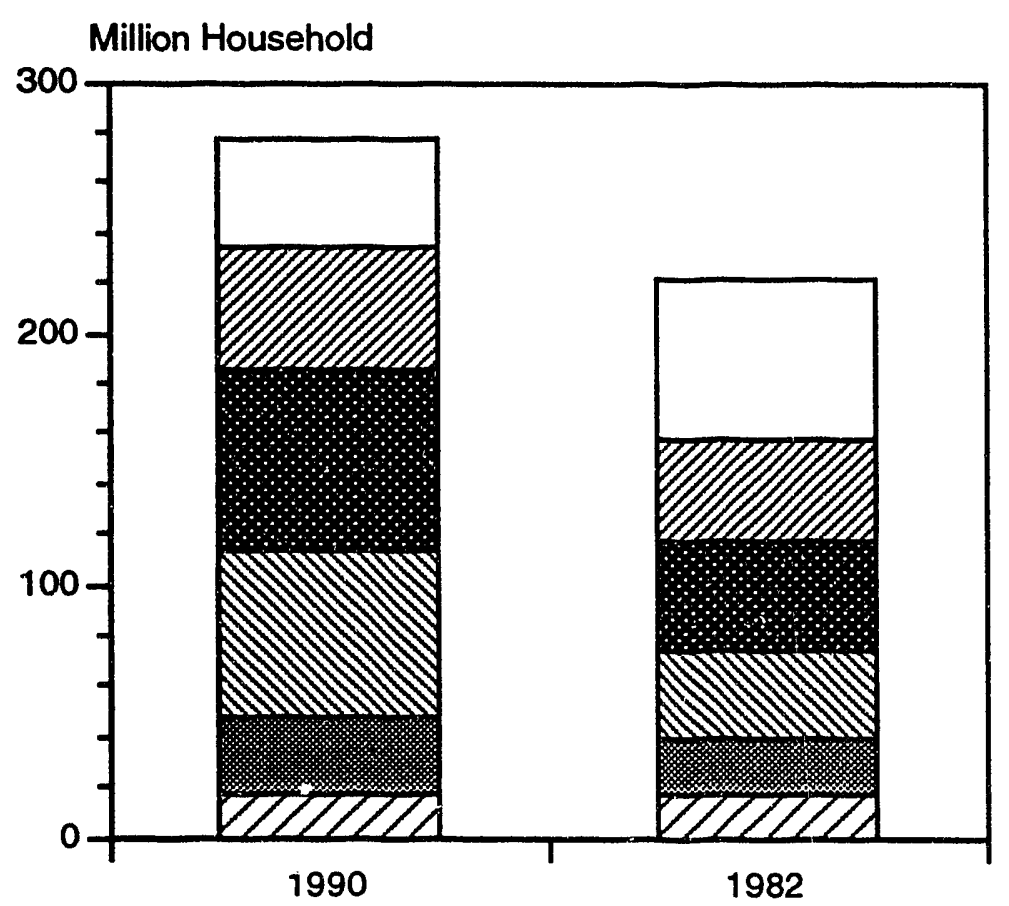

Six and Above

$\square$ Five Persons

Four Persons

Three Persons

Two Persons

曰 One Person

Source: SSB, 1989a; SSB, 1992a. 
residential energy use. Urban population increased 50\% from 1980 to 1988. About $75 \%$ of this increase is presumably caused by the migration of rural population and the expansion of the urban areas (assuming that the original 1980 urban population was growing at the natural growth rate of $1.3 \%$ of the national population). In the same period, urban residential energy consumption, mostly modern fuel demand brought about by the population increase, increased $58 \%$. The speed of urbanization in the future is likely to be the dominant factor in modern energy demand of the residential sector, considering the fact that twothirds of present residential fuel use is met by biomass.

In the 1980s, the rapid increase in the number of households caused by marriages of baby boomers (people born in the 1950s and 1960s) created another swell of residential energy demand. For the first time in four decades, the growth rate in the number of households surpassed the growth rate of the population . This trend is likely to continue because population growth is slowing and people born in the early to mid-1970s (the last period of baby boomers) are arriving at the age of marriage. Such a trend has important implications for residential energy demand, since housing and appliance stocks are directly linked to th? number of households. Figure 2-12 depicts the changes in household structure in the 1980s. The increase of three-to-four-person households is evident while the number of six-and-above-person households has decreased significantly.

\subsubsection{Huusehold Income and Standard of Living}

Historically, residential energy use in China has to a large extent served to meet the basic energy needs of daily life; population growth has probably contributed more to the increase in residential energy demand than intprovements in the standard of living has in the last 40 years. This assumption is justified for the years before the late 1970s when residential energy use was used almost exclusively for three applications: space-heating, cooking, and lighting.

Energy-using activities of the residential sector have changed considerably since the early 1980 s. In order to roughly separate contributions from population growth and increased energy activities, the energy growth rate from 1980 to 1988 is decomposed into three parts. ${ }^{11}$ Calculations indicate that increases of per capita residential energy use, presumably directly related to improvements in the standard of living, have become the major factor for the increase of resiciential energy demand in the 1980s. Fifty-seven percent of the shares of contributions to the residential energy (including biomass) growth rate for the years 1980-1988 came from the increases of per capita residential energy use, and

11 We can write energy demand as $\mathrm{E}=\mathrm{P} \cdot \mathrm{e}$ where $\mathrm{P}$ denotes population and e denotes per capita consumption. Energy growth rate can be written as $\Delta E / E=\Delta P / P+\Delta e / e+$ $\Delta \mathrm{P} \bullet \Delta \mathrm{e} / \mathrm{P} \bullet \mathrm{e}$, where $\Delta \mathrm{P} \cdot \Delta \mathrm{e} / \mathrm{P} \bullet \mathrm{e}$ is a residue to balance the equation and is usually small. In this way, residential energy growth rate is decomposed into the growth rate of population, the growth rate of per capita energy use, and a residual factor. 
$43 \%$ came from population growth. 12 The impact of rising per capita energy use on the growth of residential energy demand is expected to become larger in the future. Energy conservation could partly head off the momentum of the increase in per capita energy use and could ease the tension on the supply side.

The surge of urban residential electricity use in the 1980 s was closely related to the rapid increase of household income, which enabled households to acquire large and expensive appliances. The average real wage per employed person increased about 1.5 times from 1978 to 1990.13 In contrast, the same indicator did not change for almost two decades before 1978. From 1978 to 1990, per capita living expenditure (in real terms) of the rural and urban residents increased 2.1 and 1.8 times respectively, compared to 1.3 and 1.6 times in the previous 20 years [SSB, 1992a].

Expenditures on energy also increased significantly (there have been small increases in residential energy prices). From 1981 to 1990, fuel expenditure per urban resident increased from $¥ 10$ to $¥ 23$. Electricity expenditure per urban resident increased from $¥ 4$ to $¥ 19$ in the same period. In 1990, energy accounted for more than $3 \%$ of total urban household living expenditures [SSB, 1988 and 1992a].

Rising household incomes are expected to foster two developments in residential energy use. Domestic water heating (for showering) has become an increasingly popular activity as gaseous fuels become more accessible. Market research shows that the demand for air conditioners has also grown significantly since 1990 [Li, 1992]. Such trends will lead to greater demand for gaseous fuels and electricity in the future.

\subsubsection{Consumer Behavior}

Consumer behavior, in many cases, exerts significant influence on residential energy demand and is a major area of research in conservation programs. Chinese households are traditionally frugal compared to their Western counterparts, partly because of their relatively low income. In general, households are very sensitive to changes in energy prices. Not taking into account device efficiency, urban Chinese households probably use electricity so sparingly because electricity is metered and the prices are relatively high. Lights are always turned off when not in use. Minimum lighting is applied wherever it is acceptable. Many families even turn off refrigerators in the winter. However, such behavior of counted electricity use may be gradually disappearing with more affluent and smaller families becoming the dominant households.

12 From 1980 to 1988 , the residential energy growth rate was $3.5 \%$, the growth rate of per capita residential energy use was $2.0 \%$; energy use population growth rate was $1.5 \%$.

13 Actual real income may have increased more because the share of wages in personal income has been decreasing in the 1980 s. 
Consumer behavior in energy use is largely influenced by income, energy prices, and tixe quality of services. The rush to buy refrigerators in the mid- to late 1980s was the biggest multiplier of the residential electricity demand in the last ten years. Now, many cash-rich urban dwellers have begun to install air conditioners. While people are stocking energy-intensive appliances, few pay attention to energy-saving compact fluorescent lamps simply because people do not believe the savings will justify the cost. As lighting costs become less important in household electricity use, people may also become less concerned about lighting efficiency. Cost-benefit information and quality of services are considered crucial for breaking behavior barriers to energy conservation.

In centralized space heating where the common-pool problem is difficult to resolve, consumer behavior is an important dimension of energy management. Since heat meters are expensive, installing them in each household is hardly affordable. The usual case would be one meter per apartment building; but in China, central heating is not even metered. Heating service charges are based on floor area and are heavily subsidized. Customers always complain loudly if buildings are underheated but will not say a word if they are overheated for fear of service reduction. Efficiency and service improvements can come from reforms in the service charge scheme as well as from technical fine-tuning of the heating systems.

\subsubsection{Appliance Stock}

Household appliances have, in the last ten or so years, become the major electricity users in the residential sector. In the early 1980s, an average urban family would at most have the luxury of owning a black-and-white television set and an electric fan, using no more than $50 \%$ of the household's electricity. As of 1990 , an average urban family would have a clothes washer, a color television set, and very likely, a refrigerator. In this case, electricity use of appliances could take about $90 \%$ of the household's electricity use. The trend in urban appliances saturation is depicted in Figure 2-13. The trend in rural appliances saturation is depicted in Figure 2-14. As it is clear, the rural households still have a long way to go to catch up with their urban counterparts.

Major appliances in China are products of relative recent technologies and are usually smaller in size and power input compared to popular models in the West, especially the U.S.. Almost all color television production lines were imported from Japan in the 1980s and popular models include 18- and 20-inch sets. Refrigerator production lines were mostly imported from Japan and Italy in the 1980s and popular models are two-door 170-200 liter refrigerators. Table 2-2 lists some of the common appliances found in urban households and their respective energy consumption. A fully equipped household can use as much as $1460 \mathrm{kWh}$ of electricity per year for these appliances, four times as much as the present electricity use per urban household. 
Figure 2-13. The Trend in Urban Ownership of Appliances, 1981-1991

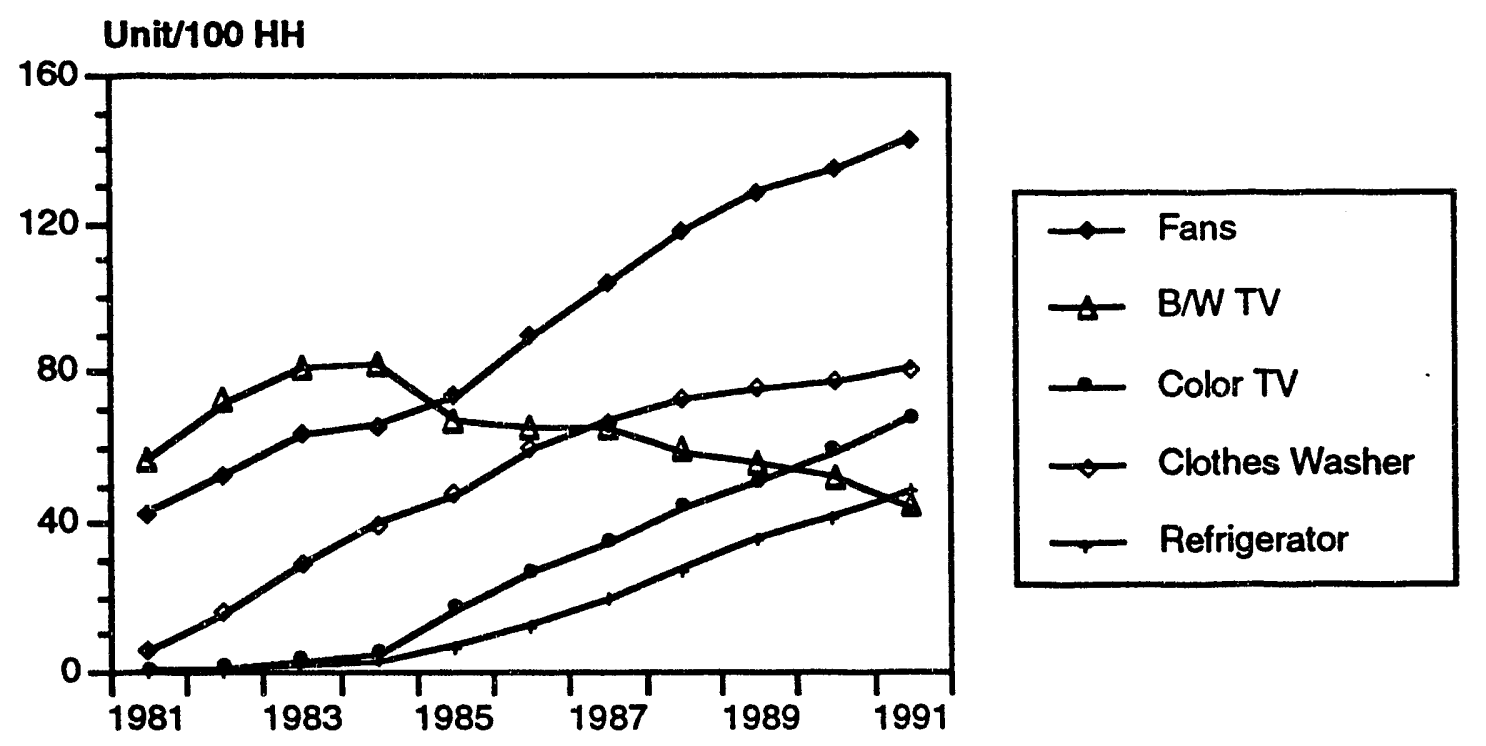

Source: SSB, 1992a.

Figure 2-14. The Trend in Rural Ownership of Appliances, 1985-1991

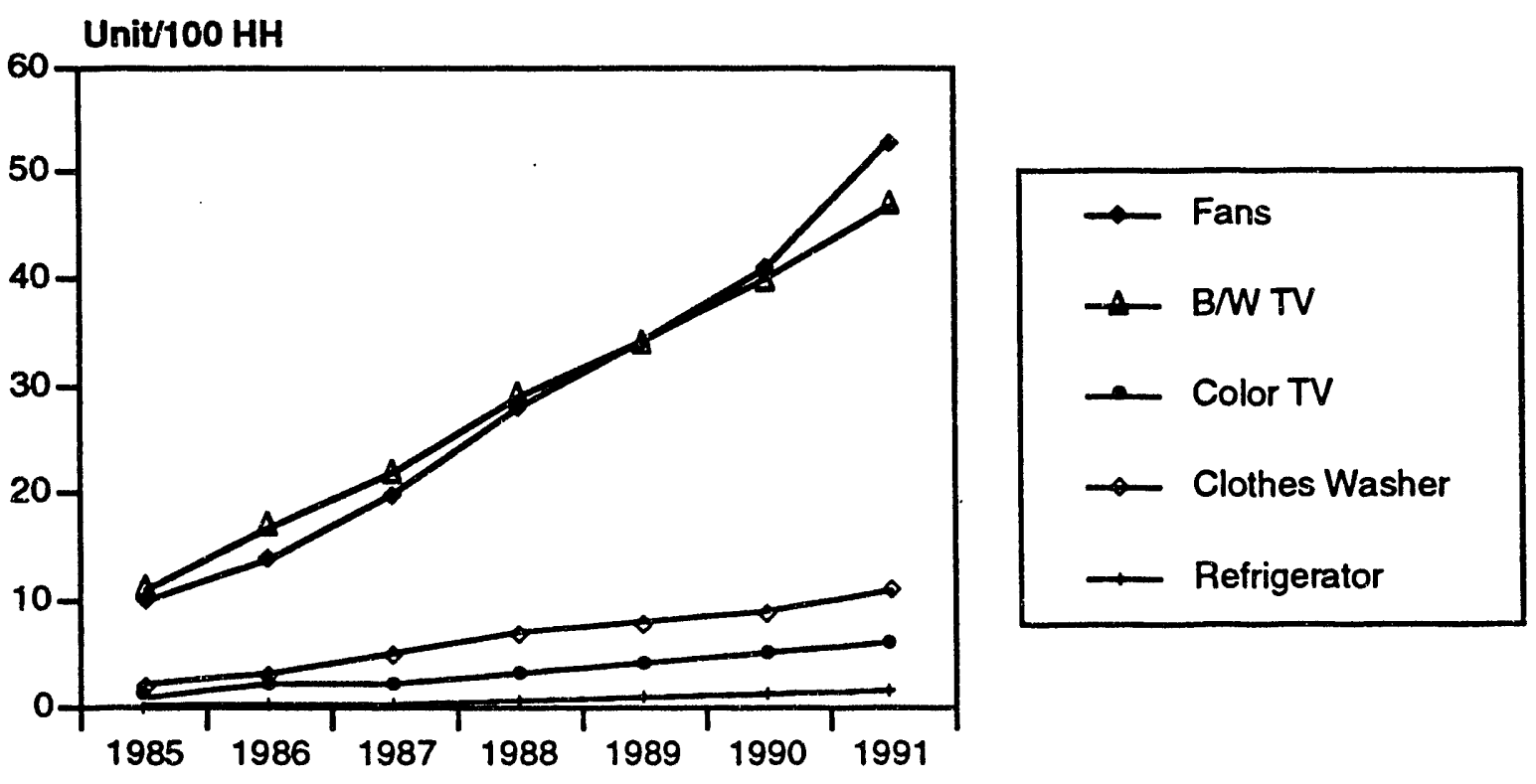

Source: SSB, 1992a 
From the experience in the 1980s, the development in appliance saturation will very much determine the future electricity demand in the residential sector. The appliances market represents a major opportunity for residential electricity conservation in the years to come, given that most rural households still do not possess major appliances.

\section{Table 2-2. Popular Appliance Models and Their Electricity Use}

\begin{tabular}{lccc} 
& $\begin{array}{c}\text { Rated Power Input } \\
\text { (Watts) }\end{array}$ & $\begin{array}{c}\text { Operating Time } \\
\text { (hrs/day) }\end{array}$ & $\begin{array}{c}\text { Annual Electricity Use } \\
\text { (kWh/yr) }\end{array}$ \\
\hline Refrigerator t & 122 & 24 & 400 \\
20" Color TV & 75 & 3 & 82 \\
$12 "$ B \&W TV & 30 & 3 & 32 \\
$400 \mathrm{~mm}$ Fan & 66 & $500 \mathrm{hrs} / \mathrm{yr}$ & 33 \\
Clothes Washer & 230 & $80 \mathrm{hrs} / \mathrm{yr}$ & 18 \\
Rice Cooker & 600 & 0.8 & 175 \\
Air Conditioner & 1500 & $500 \mathrm{hrs} / \mathrm{yr}$ & 750 \\
\hline
\end{tabular}

+ A two-door 170 liter model manufactured by Xuehua Electronics, Inc. Source: Zhou, et al, 1989; SSB, 1991.

\subsubsection{Climate Conditions}

A great part of China is under the impact of the East Asian monsoon. Each year from September/October to March/April, cold winter monsoons from Siberia and the Mongolian Plateau sweep southward, waning in strength along the way. This climate condition makes a large portion of China very dry and cold in the winter. Extreme differences in winter temperatures can reach more than $40^{\circ} \mathrm{C}$ between the north and the south. Compared with other regions of the world at the same latitudes, China's winter temperature is $5-20^{\circ} \mathrm{C}$ lower on the average from south to north [Tu and $\mathrm{Li}, 1991$ ]. For this reason, space heating demand in China is high and enduring.

On the positive side, northern China usually enjoys frequent sunny weather in the winter (from the beginning of October to the end of March, out of a total of 1800 daytime hours, we estimate that the northeast region averages 1050 hours of sunshine [SSB, 1992a]). There is much potential for the utilization of solar energy in buildings.

Because of shortages in both capital and energy, the central government had to restrict the space-heating energy supply in the past. Traditionally, the government has divided the nation into three climate zones for selecting different heating options. Areas that have more than 90 days of below $5^{\circ} \mathrm{C}$ outdoor daily average temperature per year are classified as heating zones. Areas that have 60 to 89 such days per year, or areas that have more than 75 days per year during 
Figure 2-15. The Pattern of Space-Heating Zoning

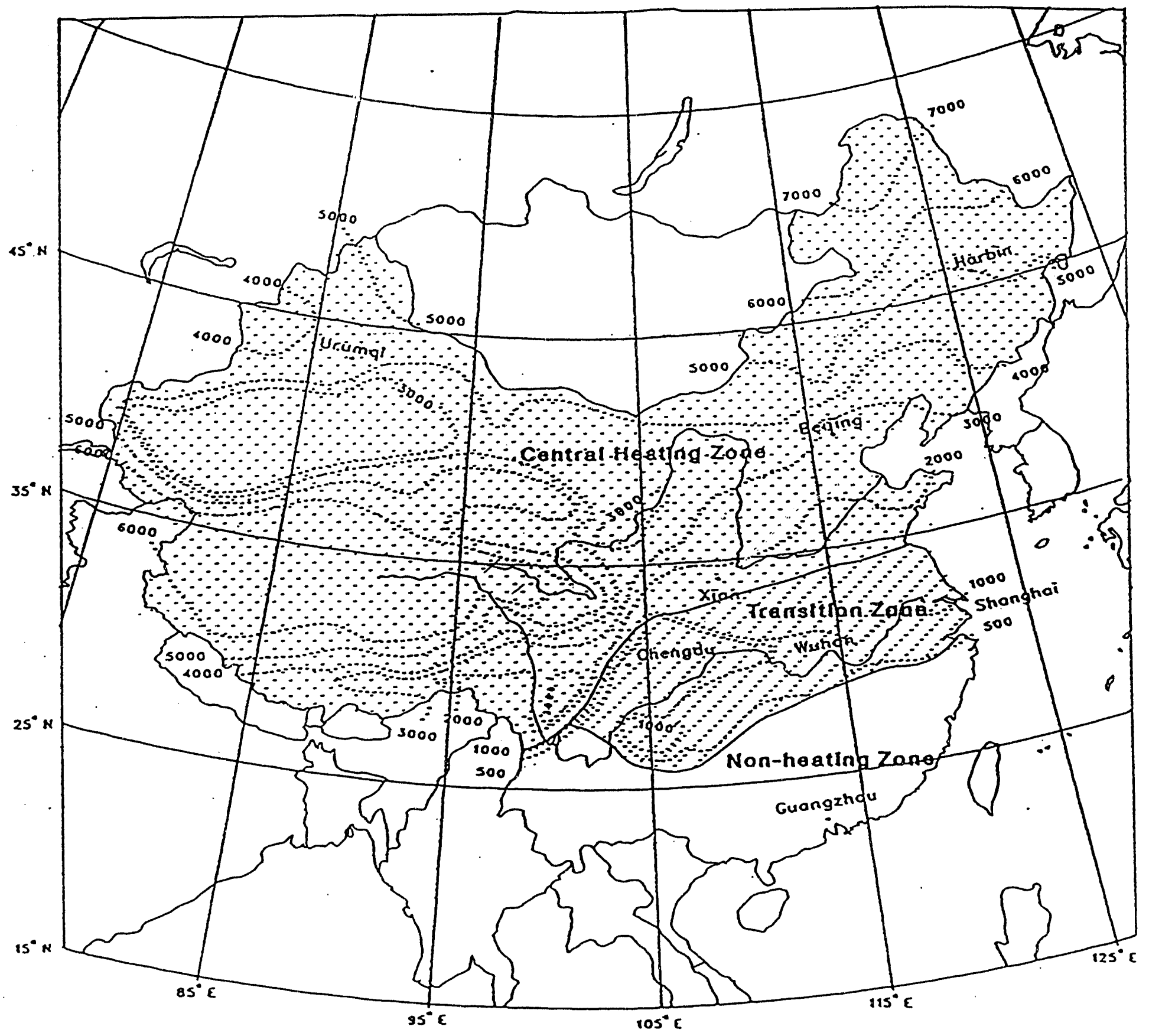

Heating Degree Days $\left(18^{\circ} \mathrm{C}\right)$ in Heating Period Only

Source: Lang and Huang, 1992 
which the average daily temperature is less than $8^{\circ} \mathrm{C}$ are classified as transition zones. The rest of the country falls into the non-heating zone. The heating zont occupies about two-thirds of China's territory and has about $50 \%$ and $40 \%$ of the nation's urban and rural populations, respectively. Figure 2-15 is a map of these zoning divisions.

Central heating facilities were not officially allowed if constructed outside of the heating zone, but restrictions have been loosened in recent years. It is rumored that the central government is considering lifting the ban on central heating systems in other areas of the country. Fuel subsidies are provided for heating-zone urban residents who have no access to central heating facilities during the heating season. The local governments or work units usually provide fuel subsidies for urban residents in the transition zone during the winter. Rural residents do not receive any governmental assistance in space heating. In southern China where the cold weather period is short and usually mild, heating requirements are at a minimum and space heating is not the norm. Because of the increasing wealth of the people, it is expected that space-heating energy demand will be driven up by both higher comfort standards and the expanding population.

Most areas in the transition zone and the non-heating zone have a very warm and humid summer season. At present, most households use electric fans to drive off summer heat. Since more than half of the nation's population lives in these areas, there is great market potential for room air conditioners.

\subsubsection{Residential and Commercial Building Stock}

No consistent historical statistics on the building stock in China are available. National urban building surveys were conducted in the mid-1980s and the end of that decade [SSB, 1989a; Tu and Li, 1991]. According to these surveys, by the end of 1989 , there were about 3543 million $\mathrm{m}^{2}$ of residential building floor area and 1019 million $\mathrm{m}^{2}$ of commercial building floor area in urban China. Urban residential and commercial buildings in the heating zone comprise floor areas of 1547 million $\mathrm{m}^{2}$ and 458 million $\mathrm{m}^{2}$ respectively, about $45 \%$ of the national total. ${ }^{14}$ Table 2-3 summarizes information and the author's estimates related to present building stock.

Commerce buildings i.e., those that house shops, restaurants, and other businesses, and office buildings comprise about $52 \%$ and $30 \%$ of the total commercial building stock; educational and academic buildings share about $3 \%$ of the total. The unclassified miscellaneous category is significant with a $15 \%$ share of the total commercial building stock.

14 Floor area or floor space here is actually the gross building area on which a room, an apartment, or a house sits. The Chinese official statistics also give another indicator called "living area" which only counts the area of bedrooms and living rooms. 
Table 2-3. Estimate of Residential and Commercial Building Stock, 1989

\begin{tabular}{lcccccc} 
& $\begin{array}{c}\text { Urban (a) } \\
\text { Population } \\
(\mathrm{Mn})\end{array}$ & $\begin{array}{c}\text { Rural (a) } \\
\text { Population } \\
(\mathrm{Mn})\end{array}$ & $\begin{array}{c}\text { Comm. (b) } \\
\text { Buildings } \\
\left(\mathrm{Mn} \mathrm{m} \mathrm{m}^{2}\right)\end{array}$ & $\begin{array}{c}\text { Urban Resi } \\
\text { Bldgs } \\
(\mathrm{b})\left(\mathrm{Mn} \mathrm{m}^{2}\right)\end{array}$ & $\begin{array}{c}\text { Rural Resi } \\
\text { Bldgs } \\
(\mathrm{b})\left(\mathrm{Mn} \mathrm{m}^{2}\right)\end{array}$ & $\begin{array}{c}\text { All Bldgs } \\
\text { Floor Area } \\
\left(\mathrm{Mn} \mathrm{m}^{2}\right)\end{array}$ \\
\hline Heating Zone & 146.5 & 338.5 & 458 & 1547 & 5755 & 7760 \\
Transition Zone & 87.7 & 280.2 & 330 & 1176 & 4763 & 6269 \\
$\begin{array}{l}\text { Non-Heating } \\
\text { Zone }\end{array}$ & 61.2 & 212.9 & 231 & 821 & 3619 & 4671 \\
Subtotal & 295.4 & 831.6 & 1019 & 3544 & 14137 & 18700 \\
\hline
\end{tabular}

Notes: (a) Population distribution is derived from the official 10\% sample data [SYC 1991]; (b) The subtotal figures and the heating zone figures for urban buildings are from Tu and Wang [1991]. Transition zone and non-heating zone figures are derived from the population ratio. Rural residential building stock is estimated from survey data of per capita floor space.

Source: SSB, 1991; Tu and Wang, 1991;

For both urban and rural residents, the largest increase in living space was achieved in the 1980s, which corresponded with the rapid economic growth in the same period. Per capita floor space for urban and rural residents was about 7 $\mathrm{m}^{2}$ and $9 \mathrm{~m}^{2}$ respectively in 1979 and increased to about $12 \mathrm{~m}^{2}$ and $17 \mathrm{~m}^{2}$ in 1989 [MoURC, 1987; SSB, 1991]. Although rural residents generally have greater floor space, the quality of housing is usually higher in urban areas.

One interesting thing about the data in Table 2-3 is that the total floor space of commercial buildings is relatively insignificant compared to that of residential buildings, which is a clear indication of the low level of urbanization. This also explains the insignificant energy share of commercial buildings in the residential and commercial sectors. The floor area of commercial buildings is only $6 \%$ that of residential buildings and energy use of commercial buildings is $8 \%$ that of residential buildings. By comparison, in the U.S. the floor area of commercial buildings is $29 \%$ that of residential buildings and energy use of commercial buildings is $65 \%$ that of residential buildings [DOE/EIA, 1987; DOE/EIA, 1987]. However, the urban building patterns in China do resemble those of the U.S. The present pattern of the distribution of floor areas has some important implications for building energy demands in the future. We have seen that commercial buildings disproportionally consume more electricity than residential buildings worldwide.

Two features of the urban building stock have a negative impact on building energy conservation. First, the urban building stock consists of mainly low-rise buildings. By the end of 1985, about $50 \%$ of the building stock was single-floor buildings and another $28 \%$ was two- or three-story buildings [SSB, 1989a]. There was no significant change in this situation by the end of 1989 [Tu and $\mathrm{Li}, 1991$ ]. Low-rise buildings tend to have a larger wall area per unit volume than high-rises. Other conditions being equal, such features increase a building's 
heating requirements. Second, the urban building stock consists largely of new, but poorly insulated, buildings constructed in the 1970s and 1980s. Close to $80 \%$ of the existing urban building stock has less than 20 years of service [SSE, 1989a]. These buildings pose serious problems for building energy conservation in the future.

\subsubsection{Building Energy Standards and the Construction Industry}

In the wake of a successful industrial energy-conservation program initiated in the early 1980s, the issue of building energy efficiency was brought up under the expectation that future demand in heating energy may put some heavy pressure on China's already strained energy supply. In 1986 the Ministry of Construction approved the "Energy-Efficient Design Standards for Residential Buildings (Heated Buildings)" (referred to as "the Standards") and began to experiment on demonstration projects. ${ }^{15}$ The Standards had set two goals for building energy conservation. The first goal was to reduce the space-heating fuel intensity (coal consumption per season per square meter floor space) of new buildings to a level $30 \%$ less than its 1981 value by 1990 . The second goal was to further reduce the space-heating energy intensity of new buildings to a level 30\% less than its 1990 value by 2000 . The total reduction goal from the 1981 fuel intensity level is $50 \%$. According to the Standards, the first-period goal is to be achieved through building envelope and heating system improvements, which, in turn, account for two-thirds and one-third of the energy-intensity reduction, respectively [Lang, 1988].

Local governments in the heating zore were required to formulate their own energy-efficient residential standards according to the national code. But it was not until 1990 that a few cities, including Beijing and Xian, announced detailed local standards.

So far, the first-period goal of the Standards aiming at improving the energy performance of the building envelope has not met expectations. Since the Standards is not mandatory, buildings built according to the Standards are very limited. For example, in Beijing, from 1987 to 1990, the floor space of new residential buildings built up to par of the Standards only accounted for about $10 \%$ of the total floor space of new residential buildings [ $\mathrm{Tu}$ and $\mathrm{Li}, 1991 ; \mathrm{SSB}$, 1991, 1992a]. The situation in other northern cities is worse. Lack of enforcement because of problems in technical support and shortages of insulacion materials are considered to be major reasons. Complacency in the construction industry is

15 It must be pointed out that the interpretation of "standard" in China is somewhat different from that in the western countries. Most government standards in China are actually reduced to mere guidelines in practice because of inadequate enforcement power. Some government standards are set to test the water and do not mean to be very stringent in terms of compliance in the early stage. The building standards have the bearings of both kinds. 
also a strong factor. The large stock of old buildings already poses a big challenge to the improvement of thermal integrity. The rapidly increasing new housing stock that is actually built in the same manner as the old stock creates even greater problems for future retrofits. That no stringent energy-efficient standards were carried through in the construction boom that has lasted for more than ten years may prove to be costly hindrances to urban development and energy-conservation .

Although the Standards are explicitly set for residential buildings in the heating zone, because apartment buildings are more or less similar in structure all over China, these suggestions could also apply to residential buildings in the transition zone or even the non-heating zone, with some revisions. At present, there are no energy-efficiency standards for rural residential buildings. This also is likely to become a serious problem in the long run. Most rural households in China enjoy single-family housing although the quality cannot be compared to its Western counterpart. Because of the lack of heating fuel and the unlikelihood of central heating for the dispersed rural housing, energy-efficient building design plays an essential role for curbing future rural heating-fuel demand, which in turn could either save coal or prevent the depletion of biomass. In recent years, with more and more wealthier farmers building large brick houses, the thermal integrity of rural houses has probably deteriorated in comparison to the older and smaller houses constructed with thick clay walls. The government could help itself in the long run by helping farmers now in selecting better housing design or even giving them some financial incentives for building energy-efficient houses. Passive solar heating in rural houses has been in an experimental stage for many years. Since most of China's cold areas are also solar-rich, passive solar represents a real opportunity for energy-efficient building design. However, in addition to probably significant incremental costs, there are many technical difficulties to overcome. Because of the nature of private ownership in rural housing, cost-effective conservation measures should work well as long as technical problems are eliminated.

Energy-efficient standards for commercial buildings are also very important considering the booming business in the coastal as well as inland areas. The demand for modern office buildings and fancy shops is high in large cities. Tourism also contributed to the large-scale construction of better hotels. It was found that many new hotels with expensive energy-consuming HVAC systems did not have better insulation than ordinary hotels [Wang, 1989]. Accelerated urbanization in China will bring more commercial buildings into cities and towns. Introducing and enforcing energy-efficient standard for commercial buildings is an effective way of reducing energy demand of commercial buildings.

The construction industry was and still is a major obstacle for the effective implementation of energy-efficient building standards. The construction workforce is a loose collection of state-owned companies and collective and private 
contractors from both urban and rural areas. Ad-hoc construction teams made up of friends and family members build most rural houses. The severe shortages of responsible and qualified building inspectors make the successful implementation of the Standards an impossible mission. The fragmentation of the construction industry easily dilutes the strength of enforcement power. A work-force made up of largely under-trained and undereducated rural workers makes the more skillful and detail-oriented efficiency measures harder to carry out.

The pressure of housing demand and the shortage of capital also give excuses to the local governments and the construction industry to resist the Standards, for the incremental capital cost of conservation measures could be used to put up more apartments. In addition, insulation materials and other energy-saving building products are not widely available and are priced relatively high. Policies that facilitate the improvement of the construction infrastructure are needed for a successful implementation of the Standards. Such policies may include technical training for both engineers and workers in the construction industry and financial incentives as well as capital investment for the manufacturing of energy-saving building materials and products. 


\section{RESIDENTIAL AND \\ COMMERCIAL SECTOR ENERGY EFFICIENCY}

Per capita consumption of residential and commercial energy (including biomass) in China was about $420 \mathrm{kgce}$ in 1988. Respective energy consumption in Japan was about $1300 \mathrm{kgce} /$ person [Schipper. 1993]. The figure for the U.S. was a high $4280 \mathrm{kgce}$ [DOE, 1989]. While it is unrealistic to expect Chinese consumption to reach that of the U.S., even a moderate increase in per capita residential and commercial energy use in China would translate into a significant amount of aggregate demand, which requires careful planning and management.

Chinese buildings not only consume great amounts of inferior energy sources such as solid biomass and coal, but also consume energy inefficiently compared with their Western counterparts, which result in more pollution and fewer energy services per energy unit consumed. In rural areas, firewood is often burned in stoves that have roughly only a $10 \%$ heat efficiency. In many urban households, raw coal is burned for daily use. Coal-fired stoves are still very popular for space heating. In addition, most buildings are simply constructed, with minimum insulation, which increases energy use and decreases comfort in both winter and summer.

Efforts have been made to improve energy services in the building sector in recent years. The massive efficient-stove program in rural areas and the promotion of honeycomb coal briquettes in urban areas are successful examples. [Xu and Zhang, et al., 1990; Jiang, 1991]. Many other conservation efforts, however, are still preliminary and experimental. Briquette supplies are inadequate. Central space-heating systems are inefficient and polluting because of the proliferation of inefficient coal-fired boilers. There has been little progress in building insulation since the release of energy-efficient residential building standards in 1986. Major appliances, although manufactured with relatively modern technologies, still lag behind similar products in the West in energy efficiency. Compact fluorescent lamps have had almost no penetration. Regulations designed to alleviate efficiency problems are insufficient and often not very effective. Little capital is available for improvements, while residential fuels are heavily subsidized by the government. All this suggests the great amount of conservation potential to be realized in Chinese buildings. The benefits extend to air pollution control and biomass conservation. Nonetheless, the economic and institutional difficulties of promoting energy conservation are also great. 
In 1988, total fuel use in buildings was about 430 Mtce of which space heating and cooking accounted for about $43 \%$ and $55 \%$, respectively. Table 3-1 shows the disaggregation of building fuel consumption by end use.

Table 3-1. Estimates of Building Fuel Use by End Use, 1988 (in Mtce)

\begin{tabular}{lrrrrrrc} 
& Biomass & Coal & Gases Kerosene & Oil & Total Fuel & Co-gen Heat \\
\hline Space Heating (a) & 122 & 64 & 0 & 0 & 0 & 186 & 3.1 \\
$\quad$ Residential & 122 & 53 & & & & 175 & 2.6 \\
$\quad$ Rural (stoves) & 122 & 26 & & & & 148 & 0 \\
$\quad$ Urban (b) & 0 & 27 & & & & 27 & 2.6 \\
$\quad$ Stoves & & 15 & & & & 15 & \\
$\quad$ Central heating & & 12 & & & & 12 & \\
Commercial (c) & 0 & 11 & & & & 11 & 0.5 \\
Cooking & 150 & 81 & 5.9 & 0.2 & 0 & 237 & \\
$\quad$ Residential & 150 & 72 & 5.4 & 0.2 & & 227.5 & \\
$\quad$ Rural & 150 & 32 & 0 & 0 & & 182 & \\
$\quad$ Urban & 0 & 40 & 5.4 & 0.2 & & 45.5 & \\
$\quad$ Commercial & 0 & 9 & 0.5 & 0 & & 9.5 & \\
Lighting & 0 & 0 & 0 & 1.6 & 0 & 1.6 & \\
Miscellaneous (d) & 0 & 0 & 0 & 2.1 & 3.1 & 5.2 & \\
Subtotal & 272 & 145 & 5.9 & 3.9 & 3.1 & 430 & \\
\hline
\end{tabular}

Notes: (a) The splits in biomass and coal consumption between space heating and cooking in residential buildings are based on survey data from Zhou, et al., [1989], p158-166. (b) Urban space-heating fuel use by heating mode is derived from estimates by $\mathrm{Tu}, \mathrm{Li}$, and Shen [1991]. (c) Derived from estimates by $\mathrm{Tu}, \mathrm{Li}$, and Shen[1991]. About $70 \%$ of the coal is used in heating stoves. (d) Oil use in commercial buildings, mainly diesel.

Source: SSB, 1990b; Xu and Zhang, et al., 1990; Tu, Li, and Shen, 1991; Zhou, et al., 1989.

Since more than $90 \%$ of the fuel use in buildings is in either coal-burning or biomass-burning stoves, fuel quality, stove efficiency, and the substitution of more efficient means of producing heat in households are prominent issues of fuel conservation. Boilers that provide heat for central heating and public bathhouses are also major fuel consumers in the urban areas.

\subsubsection{Cooking and Domestic Water Heating}

Cooking is the number one energy consumer in the Chinese residential sector, due, in part, to the inefficient use of solid fuels. Most rural households use 
firewood stoves and most urban households, coal-fired stoves. Only about $10 \%$ of the urban households use gaseous fuels for cooking [SSB, 1992b].1

Cooking fuels are more diverse in urban areas but coal is still predominant. For example, in 1988 , coal still made up more than $85 \%$ of urban residential cooking-fuel use. In rural areas, biomass contributes about $80 \%$ of the cooking fuel. These patterns suggest quite different strategies for supplying urban and rural cooking fuel demands. While the urban policy is to eliminate coal-burning for the sake of controlling air pollution, the rural problem is the lack of a convenient modern cooking fuel, namely coal. There is no easy solution for this seemingly complementary situation. For most urban households there simply are no other fuels; for the majority of rural households, coal is not available and adequate biomass fuel is not even guaranteed in some areas.

The usage of hot water in Chinese households is very limited. Households boil water (and store it in insulated bottles) for tea and cooking and other necessary daily uses. An adult may consume 4 liters of boiled water per day for such activities. Urban. residents usually go to public bathhouses for bathing. If such conditions do not exist, people take warm baths at home occasionally, often once a week. According to the Western standards, domestic hot water usage in Chinese households is negligible. This study does not separate water-heating fuel use from cooking fuel use.

With the penetration of gaseous fuels, compact, gas-fired, hot-water shower devices have rapidly gained popularity in recent years. They are considered to be very efficient for both energy and water usages. However, even if all households with natural gas or coal gas connections had gas-fired shower devices, they would make up only about $5 \%$ of the urban households. Analysts expect that domestic water-heating energy use will increase as the population uses more gaseous fuels.

The environmental impacts and health hazards of cooking fuel use are much higher in China than in Western countries because of massive indoor burning of coal and the excessive use of biomass. Fundamental changes in the structure of present cooking fuels will probably take a long time. Improving end-use efficiency is a sound alternative in the short to medium term and is also economically more attractive than some expensive fuel-switching programs. The Chinese government has been very active in supporting projects in cooking fuel conservation. This paper will review these projecis and examine further opportunities for cooking fuel conservation.

1 About 33.3 million people have access to either LPG, natural gas, or coal gas in 1990 [SSB, 1992b]. The actual gas-using population could be larger because the statistics do not include small cities. The official urban population figure in 1990 was 301.9 million. 


\subsubsection{Urban Residential Cooking Fuel Use}

In 1988 cooking fuel use in urban households was about 46 Mtce, of which coal accounted for about 40 Mtce and the rest included 2.3 Mtce LPG, 2.0 Mtce natural gas, 1.1 Mtce coal gas, and 0.2 Mtce kerosene. The uses of other types of fuel are negligible. LPG and gaseou's fuels are scarce and are available mostly in large cities or in places near the producers. Most urban households make do with a coal-fired stove, a zhao, a relatively large stove fixture in the kitchen.

Honeycomb Briquettes and Efficient Stoves. The promotion of honeyccmb briquettes has been a major residential coal-saving activity sponsored by the government. In 1988, about 20 Mtce of honeycomb briquettes were produced nationwide [Jiang, 1991]. The quantity of briquettes used for space heating is unknown, but even if we assume that all these briquettes were used for cooking, they would only equal about half of the cooking coal used in 1988. Inadequate briquette supplies for res lential use are evident. Production of pellet briquettes was about $6 \mathrm{Mt}$ (4.3 Mtce) and are inferior to honeycomb briquettes.

Residential coal is usually anthracite although quality may vary from region to region. But burning bituminous coal is not uncommon because of the constraint on local availability of anthracite. As a matter of fact, Shenyang, one of the largest cities in northern China, even produces bituminous honeycomb briquettes. In order to reduce smoke, this kind of briquette is designed to be toplit, but in practice it may not be used as designed because of the slowness of toplit combustion.

Presently, production of honeycomb briquettes is heavily subsidized by the government. Prices are even lower than for raw coal in many cities [SSB, 1990a]. Although these low prices for honeycomb briquettes encourage people to switch to this more efficient fuel, they cannot be sustained in the long term because of the disincentives for government investment. The cost-effectiveness of diffusing efficient stoves and honeycomb briquettes is discussed in Section 3.1.3.

An example of an efficient stove is a model designed in Xichong county, Sichuan province (this stove is actually designed for rural households). Its features are typical of an efficient stove, but its cost is lower since the shell is not cast iron. As shown in Figure 3-1, this stove is designed to burn honeycomb briquettes and is simply structured for easy operation. In addition to its adjustable circular hole at the side-bottom for controlling air intake, there is a separate small air entrance near the main entrance. Air taken in from this small hole is guided to the upper mouth of the combustion cylinder to enhance combustion of flue gases coming up. 
Figure 3-1. Efficient briquette-burning stove

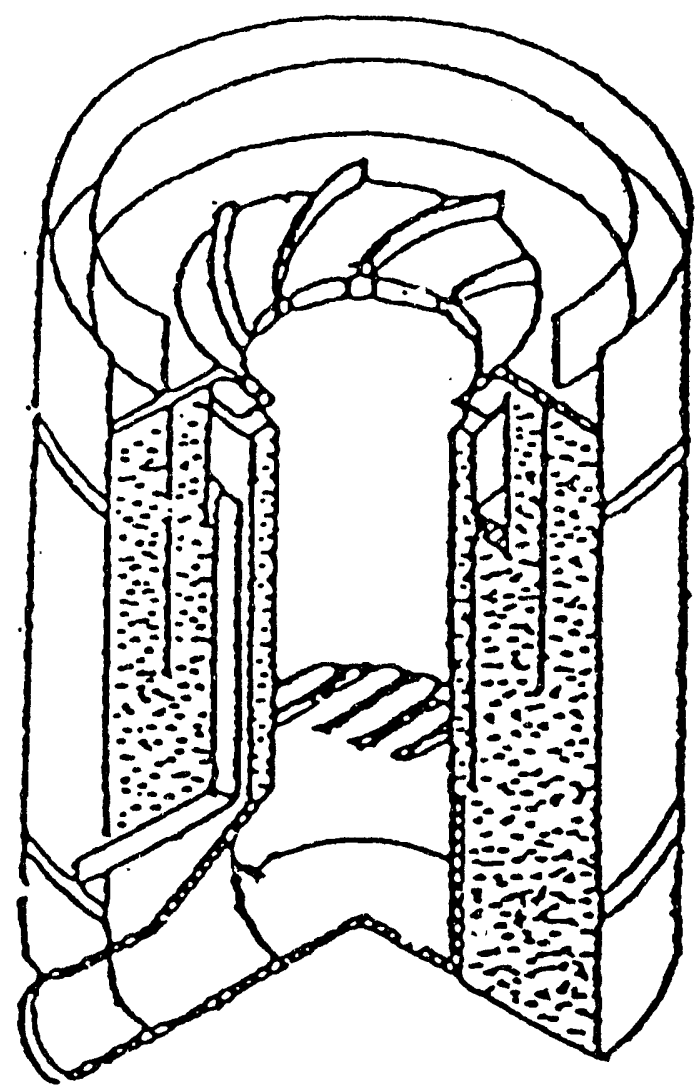

Average daily efficiency (including the time the stove is not in use but the fire is kept alive) is measured at $41 \%$. In 1987, local sales prices for this kind of stove were $¥ 12$ per unit [Liang and $\mathrm{Gu}, 1988$ ]. Better constructed stoves with a similar structure and efficiency are currently available to urban residents for arc and $¥ 50$. The incentive to buy a high-quality stove is low, considering that the average monthly income of a Chinese worker is only about $¥ 150$.

Efficient coal-fired stoves often burn honeycomb briquettes. Such a combination supposedly has a heat efficiency of around $40 \%$, three times that of stoves that burn raw coal. In daily practice, such measured efficiency is often not achieved because of less careful operation. Nevertheless, a household would be able to save about $20 \%$ of its cooking coal by switching from raw coal to honeycomb briquettes, other conditions being equal [MoGM, 1988]. Replacing the 20 Mtce raw coal consumption with honeycomb briquettes in urban cooking activity alone could save about $4 \mathrm{Mtce}$ coal per year.

Although the government has been very successful in promoting efficient stoves in rural areas, similar activity has not been reported in urban areas because of the low priority of coal (as opposed to gaseous fuels) in the urban residential-fuel strategy. From the author's point of view, promoting efficient 
stoves in urban areas is as important as producing honeycomb briquettes because many of the efficiency gains will be interdependent. In practice, however, promoting efficient stoves is more difficult. Without government subsidies or financial incentives, efficient stoves may appear to be too expensive for consumers. In most cases, people can build their own stoves at a minimum cost. This situation will continue as long as government subsidies depress briquette prices. Instead of creating low prices for briquettes, subsidies should be placed on the price of efficient stoves. Higher fuel prices should also reinforce the incentives to acquire energy-efficient stoves. In the case of home-built stoves, the government should provide information and technical assistance to the builders.

Another problem of cooking-coal conservation (this also applies to stove use for space heating) is the shortage of anthracite in the residential market. While anthracite resources in China are plentiful and the quality is generally high, there are some major problems with the coal-allocation system, which traditionally serves industry, not residential users. But the low price of residential coal is also to blame. Currently, there are only about $30 \mathrm{Mt}$, or 21 Mtce, of anthracite supplied to the residential market each year, while the anthracite production is about $200 \mathrm{Mt}$ per year [Jiang, 1991; SSB, 1992b]. The supplied residential anthracite is about $50 \%$ short of urban residential cooking use, not even taking into account the space heating needs and the rural demand. Allocating adequate high-quality anthracite to the residential market should be a top priority in promoting efficient and low-pollution uses of coal in the residential sector.

Promoting the Use of LPG, Natural Gas, and Coal Gas. The most notable progress in urban cooking fuel use in the 1980s has been the rapid penetration of gaseous fuels, i.e., LPG, natural gas, and coal gas. The combined annual growtin rate of these three fuels was $14 \%$ from 1980 to 1990 . The heat efficiency of gas stoves is usually around $50 \%$. Most significantly, the use of gaseous fuels greatly reduces air pollution and many health hazards of burning coal indoors. Unfortunately, gaseous fuel supplies are still limited to about $10 \%$ of the urban population. Because of the shortages of both capital and resources, gaseous fuels are unlikely to contribute a sizable share of the urban residential energy supply in the near future.

Although the gas-using population has been growing rapidly (from 18 million in 1985 to 33 million in 1990), it is mainly in center cities (large, im-ortant provincial capitals or highly populated cities) or cities located close to producers. Gaseous fuels are used almost exclusively for cooking. If uses expand to activities such as water and space heating, the growing demand will meet serious challenges. LPG is now the most popular gaseous fuel used in China. Its future role will be determined by the scale of the oil-refining industry. It is unlikely that China's refineries, which are primarily supplied by domestic oil, will experience a substantial increase of production because of the sluggish crude oil production in recent years and a similar situation expected for the future. For this reason, 
the role of LPG in the long-term development of urban residential fuel supply is limited. In addition, the rising demand for transportation fuels puts the production of LPG against that of gasoline and diesel fuel.

Natural gas supplies are also restrained by the availability of resources. At present, more than $80 \%$ of China's natural gas is used in the industrial sector, either as fuel or for feed stock. In spite of efforts in recent years to provide more natural gas to households, only about $10 \%$ is consumed in the residential sector. The estimated ultimate natural gas resource in China is far smaller than that of the U.S. [Liu, et al., 1992], and it is unlikely that China's natural gas production could reach present U.S. levels. Official projection of production by the year 2000 is 30 billion $\mathrm{m}^{3}$-slightly more than twice the present production. Other than providing for industrial feed stocks, residential use of natural gas should be a priority, considering the benefits of replacing dispersed coal use. High connecting costs and low gas prices to industry have been the major barriers to increased residential natural gas supply. There has been an initiative to construct a major pipeline from Shaanxi province, where a large gas field was recently discovered, to Beijing for residential use in order to mitigate the city's worsening air pollution. However, such special and expensive treatment may be unlikely for other cities unless the prices for natural gas (and other fuels) are freed of controls and consumers are given a choice.

Because of China's huge coal reserves, coal gasification is probably the only source of a residential gaseous fuel supply that has no serious resource constraint. But it is probably the most expensive way of supplying residential fuel. For China, it is not only a problem of high financial costs but also an issue of practical technological difficulties. Domestic gasification technology produces a low-quality gas and often lacks pollution control. Large-scale gasification facilities have to be imported and will be very costly. The economy of importing such facilities will net be justified with the prevailing low gas prices. Although coke-oven gas is a high-quality and low-cost fuel (byproduct), its use is limited by location and scale. Other high-heating-value and low-cost gases such as blast furnace gas and refinery gas from industrial processes, also have similar problems that prevent their wider applications. People's Daily recently reported that Harbin, the seventh largest city in China, had embarked on a project based on large-scale coal gasification that would eventually provide coal gas for the city's three million residents [People's Daily, 1992c]. This project bears watching to see how costs and benefits are evaluated and if its goals are met. Because Harbin is also the coldest of the ten largest cities in China, more investigation is warranted to ascertain if the local government has plans for gas heating in such a large-scale gasification project.

Increasing gaseous fuel supplies for residential use, at least for cooking, is the future trend of urban energy development. But resource constraints, financial and institutional barriers, and technological difficulties hinder this 
development. The Harbin coal-gas project may provide some good experiences in this regard.

\subsubsection{Rural Residential Cooking Fuel Use}

While cooking fuel is basically guaranteed for urban households, many rural families still suffer from shortages. Rural cooking fuel supply and consumption differ by region, depending on the local natural resources. In general, biomass dominates and coal is the only available modern fuel. The estimated rural cooking fuel use in 1988 was about $180 \mathrm{Mtce}$, of which $150 \mathrm{Mtce}$ was biomass and about 30 Mtce was coal.

One thing that may be unique to the rural households is that cooking animal feed is a significant or even the primary fuel use, because raising pigs is usually the major side activity of rural families, especially in the southern areas. However, this issue has not been explicitly raised in the rural fuel-use survey. Consequently, the data on rural residential energy use in this report probably include cooking energy use for both humans and animals.

The major problem of rural cooking-fuel consumption is the unsustainable use of biomass. Including space-heating usage, rural biomass consumption in 1988 was about 270 Mtce. Firewood and crop residues each contribute about half of this amount. The consumption of about 230 million dry ton of firewood ( 1 dry ton of firewood $=0.571 \mathrm{tce}$ ) per year exceeds the sustainable level by 100 million dry ton. And the consumption of about 270 million dry ton of crop residues per year consumes half of the available crop residues [ $X \mathrm{u}$ and Zhang et al., 1990]. The excessive use of biomass adds stress to an ecosystem that is already vulnerable and burning crop stalks reduces the amount of organic materials that needs to be returned to the soil. These issues have been vigorously addressed by the Chinese government over the past decade. Projects to improve end-use efficiency and increase firewood supplies have been actively promoted.

Because ordinary firewood stoves have only about $10 \%$ heat efficiency, the demand for firewood and crop residues in rural areas is often excessive. Seeing the danger of chronic rural fuel shortages and unsustainable firewood consumption, the Chinese government launched efficient-stove and tree-planting programs in the early 1980 s. By 1987 , about $45 \%$ of rural households had beeit equipped with energy-efficient stoves with a rated heat efficiency of $25-30 \%$. The efficient-firewood stove program was estimated to have been able to save about 20 Mtce (or 35 million dry ton) of firewood per year as of 1987 [Liang and Gu, 1988].

Firewood stoves are actually quite different from briquette-burning stoves illustrated in the previous section. The former are usually largie fixtures in kitchens. A model made for on-site assembling and installation is illustrated in Figure 3-2. 
Figure 3-2. Rural firewood-fired cook stove

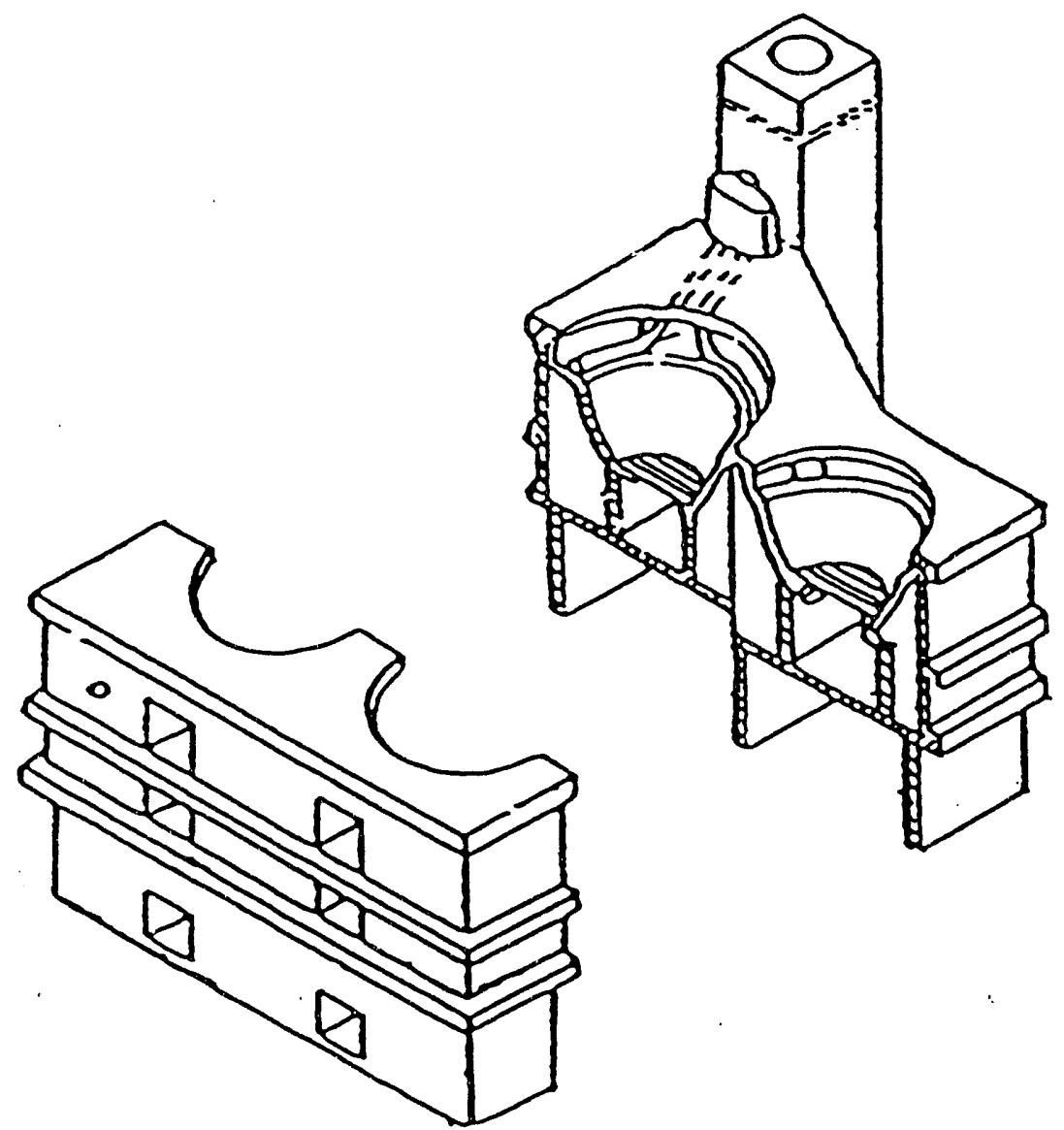

This twin fireplace-firewood stove with $42 \%$ heat efficiency was commercially available at about $¥ 60$ in 1987 [Liang and Gu, 1988].

For rural households that have arcess to coal, the use of efficient coal stoves is also encouraged, although use may be limited because briquettes are generally not very accessible. Small briquetting facilities may be needed to accommodate the sparsely populated rural areas. The economics of such small facilities are unknown.

One other energy-efficient and much cleaner option for rural cooking is the utilization of biogas. In fact, biogas has been used in large-scale experiments in rural China for about two decades and is perhaps the first governmental attempt to mitigate the rural fuel crisis. The biogas digester program was at its peak in the late 1970s but lost it., momentum entering the 1980 s because of quality problems. By the end of 1987, there were total of 4.5 million biogas digesters in China; most were located in the southwestern Sichuan province. The initial cost of digesters, usually around $¥ 400$ per unit in the late 1980 s [ $\mathrm{Xu}$ and Zhang et al., 1990], is extremely high compared to that of efficient stoves. But if well managed, the later savings and benefits could be larger than those of firewood stoves [Qiu et al., 1991]. Biogas digesters not only provide households 
with a clean fuel but also produce an excellent organic fertilizer, which is badly needed in the fields. In southern China, where the climate is warm and humid and feed stock is plentiful because of intensive farming and animal husbandry, diffusion of biogas digesters should be very attractive. From historical experience, it is often the technical problems that discourage potential users. Designing reliable and easy-to-operate digesters is the key to future success in biogas projects.

\subsubsection{Commercial Cooking and Water-Heating Fuel Use}

Commercial use of cooking and water-heating fuels is significant because of the popularity of restaurants, work-unit cafeterias, teahouses, and public bathhouses. The fuel usage is estimated at about $10 \mathrm{Mtce}$ and is basically all raw coal. There have been attempts to use large honeycomb briquettes in these commercial activities, however many commercial users such as restaurants prefer raw coal because they usually need fast combustion and high flames. For these users, gaseous fuels may be the only favorable substitution. In other settings, boilers are usually the end-use equipment. There are many types of energy-efficient teahouse boilers available now. Using briquettes in such boilers could be effective. The bigger boilers used in many public bathhouses are usually small capacity industrial boilers, and there is a wide selection of efficient boilers for such applications on the market.

\subsubsection{Space Heating}

Because of fuel shortages and the lack of central heating facilities, space heating in China is basically for urban people who need it most. The heated population is presumably in the official heating zone, although the transitionzone residents also need significant space-heating services. Space-heating activities are considered to be much lower in the rural areas because of fuel shortages. This discussion therefore, will focus on buildings in the heating zone. Space-heating issues in the transition zone are also briefly discussed.

Urban building floor space in the heating zone is 1547 . million $\mathrm{m}^{2}$ for residential buildings and 458 million $\mathrm{m}^{2}$ for commercial buildings. Chinese experts usually quote these figures as half of their respective national totals. According to the author's estimate, heating-zone rural residential buildings have about 5755 million $\mathrm{m}^{2}$ floor area, about $40 \%$ of the total rural residential building area (see Table 2-3).

Energy demand for space heating is a function of at least six variables: climate, building shell characteristics, efficiency of energy-conversion devices and systems, operation of energy systems, control devices and systems, and income level. All are a combination of social, economical, managerial, and technological factors. Even within the official heating zone, there are great 
differences among regions and between the urban and rural areas with respect to these factors. The discussion here only addresses the most common issues of space heating in the heating zone. Specific regional differences and details are subjects for further study.

There are three modes of space heating in urban areas: coal stoves, central heating from small boilers (usually heating a single building or several buildings), and district heating systems (relying on either large heat-only boilers or co-generation power plants, and sometimes industrial surplus or waste heat). Rural households use either firewood or coal-fired stoves for space heating. Table 3-2 provides some basic data on space heating in urban residential and commercial buildings in the heating zone in 1989.

Table 3-2. Basic Data on Urban Buildings in the Heating Zone, 1989

\begin{tabular}{llcc} 
& Heating Mode & $\begin{array}{c}\text { Floor Space } \\
\left(\text { million } \mathrm{m}^{2}\right)\end{array}$ & $\begin{array}{c}\text { Fuel Intensity (d) } \\
\left(\mathrm{kgce} / \mathrm{m}^{2}\right)\end{array}$ \\
\hline Residential & Central (c) & 1547 & 30 \\
& Stove & 387 & 18 \\
Commercial & & 1160 & \\
Commerce(a) & Central & 458 & 20 \\
& Stove & 54 & 15 \\
Other Public(b) & Central & 163 & 30 \\
& Stove & 85 & 25 \\
\hline
\end{tabular}

Notes: (a) Stores and restaurants and the like; (b) Includes office buildings, school buildings, and other public buildings; (c) Central heating includes dispersed small boilers and district heating; (d) Estimated average heating-season (150 days for heating zone) value. The differences in the listed fuel intensities may reflect different levels of thermal comfort rather than energy efficiency. For example, people who use stoves usually get by with lower room temperatures than those who enjoy central heating services. Less floor area is heated in the former case as well.

Source: Tu, Li, and Shen, 1991

\subsubsection{Space Heating through Stoves}

Estimates indicate that about $75 \%$ of the floor area of urban residential and commercial buildings in the heating zone is heated by coal-fired stoves. All space heating in urban buildings in the transition zone is presumably supplied by stoves because the use of central heating facilities is not officially permitted.

Commercially available heating stoves are usually larger versions of cooking stoves and are equipped with flue-gas pipes. In the northern rural areas, brick sleeping beds, kang, are heated by passing flue gases from stoves under them. 
A significant health hazard stemming from stove heating is $\mathrm{CO}$ poisoning. Even though households are careful about this matter, insufficient ventilation and poor flue-gas pipe conditions do result in tragedies each heating season. Other types of pollution such as $\mathrm{SO}_{2}$ and particulates are thought to be at high levels because of the use of low-quality coal and poor ventilation. The indoor air quality issue is certainly worthy of investigation. Readers interested in indoor air pollution caused by stoves in China can find more information in Sinton's study of this matter [Sinton, 1992].

The efficiency of stove heating depends on the type of stove, fuel (briquettes, raw coal, or firewood), and utilization of the heat in the flue gas (with flue pipe). Since all heat radiated from the stove is utilized for heating (except heat that leaves the house through the flue-gas pipe), the energy efficiency of stoves for space heating should be considerably higher than in the case of cooking only.

Stove heating is unhealthy and low in comfort levels. Households with heating stoves often have lower indoor temperatures and shorter heating time. Usually only one room is heated instead of all rooms, as in central heating. The indoor temperature is usually in the range of $10-14{ }^{\circ} \mathrm{C}$ during the day and even lower at night when the stove is either kept at slow combustion or moved out of the apartment to avoid CO poisoning. For these reasons, households that use stoves for space heating usually have much lower seasonal heating-fuel intensities than those using central heating facilities $-18 \mathrm{kgce} / \mathrm{m}^{2} \mathrm{vs} .30 \mathrm{kgce} / \mathrm{m}^{2}$ per heating season, as indicated in Table 3-2. The situation in rural areas is even worse because of fuel shortages. The kang, is often heated when cooking during the day and before sleeping.

For health and comfort, heating stoves should be replaced with either central heating or gas heating. But neither is easy to obtain because of capital and technological difficulties. Most stove-heated urban families live in one-story row houses or low-rise apartment buildings (usually two to three stories). These buildings are generally old and dispersed. Stove-heated commercial buildings have similar characteristics. Providing central heating for occupants of these buildings not only requires the construction of new heating systems but also the construction of new buildings that can use these systems efficiently. This goal can only be achieved gradually as these old buildings are replaced. The alternative option of gas heating is difficult both financially and technologically because of the lack of natural gas supplies and the likely requirement of largescale coal gasification.

Although the government has announced ambitious plans to develop district heating systems, central heating systems (including dispersed boilers) are not expected to surpass urban space-heating stoves in the near future. In the next 10 or 20 years, therefore, improving the efficiency of heating stoves is still 
the most realistic target for saving energy and reducing air pollution. This is especially true in rural areas where stoves are the only heating devices.

\subsubsection{Space Heating through Dispersed Small Boilers}

In 1989 , central heating systems provided space heating to about $25 \%$ of the floor area of urban residential buildings and $30 \%$ of the floor area of commercial buildings in the heating zone (Table 3-2). However, centrally-heated buildings are mostly serviced by small boilers with typical capacities of 1-4 ton of steam/hour (ts/h). ${ }^{2}$ According to a 1989 survey of ten large northern cities (each with a population of more than 1 million), heating boilers in the 1-4 ts $/ \mathrm{h}$ range accounted for about $75 \%$ of total heating boiler capacity. This percentage is presumably higher in smaller cities. One ts $/ \mathrm{h}$ boiler carnacity typically heats a floor area of about $4000 \mathrm{~m}^{2}$ [Wen, 1991]. So we would expect a single $4 \mathrm{ts} / \mathrm{hr}$ boiler to heat about $16,000 \mathrm{~m}^{2}$, or about 400 households (typical Chinese apartments have about $40 \mathrm{~m}^{2}$ floor area).

The popularity of small boilers may be attributable to their low cost and easy installation. But the lack of consistent and integrated urban housing planning and management is commonly considered to be the origin of the proliferation of small boilers. Most Chinese work units, especially the stateowned units, provide housing for their employees. Such apartment buildings are usually constructed near the work units. Under such circumstances, selfsufficient small boilers are naturally chosen for space heating. Even when building locations allow several work units to pool together for larger boilers, bureaucratic and financial difficulties often prevent this from happening.

Small-boiler central heating systems have two major energy-efficiency problems: low load factor and poor boiler-heat efficiency. While the former is usually related to the design and operation of the heating system, the latter is basically due to outdated boiler manufacturing technology.

The load factor of a boiler is defined as the ratio between actual heating load and its rated heating capacity. We have seen that the average heating load in many cities is $1 \mathrm{ts} / \mathrm{h}$ per $4000 \mathrm{~m}^{2}$. But the rated heating capacity for $1 \mathrm{ts} / \mathrm{h}$ is $10,000 \mathrm{~m}^{2} .3$ Thus, the average load factor of small boilers is a low 0.4 , which indicates that many of the boilers are running far below their rated capacities.

The mismatch of heating load and boiler capacity is considered to be the main reason for the low load factor. Since the distribution networks usually do not have stable working conditions due to problems of hydraulic balance of hot water and the lack of flow-control valves, building designers have routinely used

$21 \mathrm{ts} / \mathrm{h}=0.7 \mathrm{MW}$

3 At the heat intensity of $70 \mathrm{~W} / \mathrm{m}^{2}$, one ts $/ \mathrm{hr}(=0.7 \mathrm{MW})$ would heat $10,000 \mathrm{~m}^{2}$. 
a higher-than-normal heating intensity value to calculate the heating load and set the desired boiler capacity in order to have a larger safety margin. ${ }^{4}$ This practice results in an oversized boiler station with a significant back-up boiler capacity. For example, apartment buildings in Beijing usually only need $46-58 \mathrm{~W} / \mathrm{m}^{2}$ heating intensity to satisfy the official heating requirement (room temperature at $18{ }^{\circ} \mathrm{C}$ ), if the heating system operates smoothly. In practice, heating-intensity values in the range of $70-80 \mathrm{~W} / \mathrm{m}^{2}$ are often chosen to avoid underheating when heating systems fail to perform well [Wen, 1991]. When boilers do not run at their full load, their heat efficiency is reduced because of suppressed combustion.

Under normal operations, the average heat efficiency of all boilers in China is about $60 \%$, a result of the huge stock of operating small boilers. Boilers with capacities of 1-2 ts $/ \mathrm{h}$ often have a dismal efficiency of 45-50\% [Qin and Xin, 1989 ]. Domestically manufactured large coal-fired boilers ( $210 \mathrm{ts} / \mathrm{h}$ ) usually have about a $70-80 \%$ heat efficiency.

With the combined problems of the distribution network and the boiler itself, small-boiler central heating systems usually have $50 \%$ or even lower overall efficiency. Some low-cost measures, such as feeding system improvements, air preheating, thermal insulation, and air flow controls, were demonstrated to be able to enhance small-boiler efficiency by as much as $15 \%$ [Qin and Xin, 1989].

The skills of boiler operators also contribute to the performance of boilers. Differences in operators' skills may result in variations of up to $15 \%$ in boiler efficiency [World Bank, 1991]. Boiler operating is considered a low-prestige job in China and is therefore often hard to find contented workers who perform at a professional level. Adequate training in combustion-control techniques and maintenance is also needed to promote good boiler operations.

Different boilers require specific types of coal for maximum heat conversion. Coal blending, which mixes coals of different quality and chemical natures in order to match the requirements of different types of boilers, is designed for such a purpose. In the mid-1970s, the Chinese began to use blended steam coal in industrial boilers and found that, in general, boiler efficiency could be raised by $4 \%$ and the carbon content of bottom ash could be reduced by $6-10 \%$ with this rather simple and low-cost measure [MoGM, 1988].

Some important issues need to be resolved with respect to the continuing existence of small-boiler central heating systems. Although quite a few costeffective conservation measures can be applied to existing small boilers, major improvements in the efficiency of small-boiler central heating systems must come from a new generation of efficient boilers and control equipment. In recent

4 Heating intensity $\left(\mathrm{W} / \mathrm{m}^{2}\right)$ is defined as heat consumption per unit time per unit floor area during the heating season at the average indoor-outdoor temperature difference and is assumed to be the heat supply needed in order to maintain the desired indoor temperature. 
years, environmental concerns seem to have become an increasingly important reason for policy makers to disfavor small-boiler heating systems and favor district heating systems. Average industrial boilers may last 10 to 15 years. Thus, the retiring of the present stock of small boilers in the next 5 to 10 years represents an important opportunity to integrate small-boiler heating systems into large district heating systems when conditions are suitable. This proposition underlines the importance of reforming boiler manufacturing technology and infrastructure in the immediate future. The benefits of new technology in boiler manufacturing extend far beyond the residential and commercial sectors. In fact, industrial boilers alone consume about one-quarter of China's total modern energy.

\subsubsection{District Heating-Large Boilers and Co-Generation}

Central heating systems provide space heating for about one-quarter of the floor area of the urban residential and commercial buildings in the heating zone. District heating is only a small part of China's central heating systems. Considered a cleaner and more efficient heating mode than the dispersed small boiler system, district heating has been heavily promoted by the government since the early 1980s. District heating systems now supply about $5 \%$ of the urban residential and commercial building area in the heating zone. ${ }^{5}$

China's district heating systems utilize heat from large heat-only boilers and co-generation plants. Heating stations with large boilers seem to have become increasingly important in the last ten years because of the higher costs of co-generation plants. It is not clear what percentage of district heating is provided by co-generation plants at present. Fifty percent may be a reasonable guess. 6

There are different definitions of district heating systems (the boiler station type). For large and medium cities (with populations of 500,000 or more), the criterion is a minimum heated floor area of $40,000 \mathrm{~m}^{2}$ (about 1000 households) with boilers having a unit capacity of at least $10 \mathrm{ts} / \mathrm{h}$. For smaller cities, the criterion is a minimum heated floor area of $40,000 \mathrm{~m}^{2}$ with boilers having a unit capacity of at least $4 \mathrm{ts} / \mathrm{h}$.

District heating not only utilizes the more efficient, large boilers but also aids pollution control. Boilers used for district heating in large or medium cities usually have three different capacities: 10,20 , and $40 \mathrm{ts} / \mathrm{h}$. The $10 \mathrm{ts} / \mathrm{h}$ model is the most popular, with a usual $70-80 \%$ rated heat efficiency. Problems, such as partial loads, operation by unskilled personnel, and the use of low-quality coal,

5 The percentages of $75 \%, 20 \%$, and $5 \%$ for stoves, small boilers, and district heating are derived from data in Table 3-2 and Wen's estimate [Wen, 1991].

6 In Beijing, it is estimated that heated residential floor areas supplied by big boilers and co-generation plants are 13.45 million $\mathrm{m}^{2}$ and 15.72 million $\mathrm{m}^{2}$ respectively [Wen, 1991]. 
that already exist in small-boiler systems also impair the energy efficiency of large-boiler heating systems. Conservation measures may yield significant economic benefits in the case of large boilers because of the high replacement costs. Automatic control systems can also be amortized on large boilers with the resulting energy savings.

Co-generation has been placed high in the government's plan for developing district heating systems. It not only has the highest energy efficiency among present heating modes but also provides the best solution for air pollution control. But progress so far has been moderate because of the high cost of installing power-generation units. By the end of 1987, there were 6680 MWe of co-generation capacity in China, about $8 \%$ of the thermal power capacity installed then. However, most of the existing co-generation plants only supply heat to industrial users [MoE, 1990b]; The residential and commercial sectors do not benefit much from the existing co-generation capacity. With the present situation of severe electricity shortages, heat supply may be sacrificed for electricity generation in co-generation plants.

From the way it promotes district heating systems, the Chinese government seems to preemptively favor this heating mode. However, it is not clear if this bias is based on solid socio-economic and environmental assessments or is more of a technocratic intuition. Large district heating systems can be operated very efficiently theoretically, but in practice, difficulties are often encountered when these systems try to meet expectations. Reports indicate that some of the newly built systems actually run less efficiently than many of the well-operated small-boiler systems because of insufficient hook-ups or the slowness in making new hook-ups [Wen, 1991]. The average length of the heating season in the heating zone is about 150 days and many northern cities have heating seasons longer than six months. Also, most Chinese cities are quite densely populated and apartment buildings are often clustered together. These factors should make large-scale heating systems attractive. Extensive economic analyses that consider the optimal allocation of resources and air-pollution control are needed for evaluating district heating projects. China may look at the experiences of Northern European countries for help in planning future developments for district heating.

Central heating systems may not help save much coal if we compare their fuel intensity to that of stoves themselves (see Table 3-2). But using central heating facilities instead of coal-burning stoves represents a major improvement in the standard of living for urban households in northern China with respect to both thermal comfort and indoor air quality. By applying district heating, the government would also have much easier control over the emissions of effluents. In this author's view, promoting district heating in China may result in more environmental and health benefits than direct energy-saving benefits. 


\subsubsection{Heat-Distribution Networks}

The efficiency of China's central heating systems is significantly impaired by the poor quality of heat-distribution networks, which are often not well-insulated and are operated with malfunctioning equipment. The average heat loss of Chinese distribution networks is about $15 \%$, while $10 \%$ is considered to be appropriate [Wen, 1991].

A typical Chinese heat-distribution network circulates hot water through insulated steel pipes by means of pumps located at the boiler station or at the heat-production unit. Co-generation systems also have substations connected by large insulated steel pipes. A set of main valves is located at each individual building to control the water flow. Most mains are buried underground. Poor construction often results in ground water flooding in pipe ditches, which contributes to significant heat loss. Each heated apartment is connected with single-string type radiators with neither automatic nor manual control valves. Apartments at the far end of the network are usually compensated with larger or additional radiators. Occupants have no control over the amount of heat received; when rooms become overheated, the only option is to open the windows.

The unbalanced hydraulic working state and the lack of flow-control valves create problems such as overheating for occupants close to mains or boilers and underheating for those far from the mains or boilers. In order to ensure enough heat for people who live at the end of the distribution network, the common practice is to increase the capacity of pumps at the boiler station. The latter practice tends to derate boilers because of the reduced temperature differences of outgoing and returning water as the result of the increased volume of hot water flow. Poor insulation and faulty maintenance further reduce the heat efficiency of the heating system. According to a survey in nine northern cities in 1988, the average seasonal heat efficiency of 50 dispersed boiler heating systems was only about $42 \%$ [Lang, 1991]. Malfunctioning distribution networks are one of the major reasons for such mediocre heating efficiency.

In a dernonstration project to resolve problems of the distribution networks, Lang [1991] adopted the following procedures: Install a newly developed flow-control valve at all mains and at the entrance pipe of each building. At the beginning of the heating season, adjust each valve, starting from the mains and ending at each individual building, to match the actual hot water flow with the designed flow. In order to guarantee the overall performance of the heating system, a computer system is installed for better combustion control at the boiler station. Boiler operation is guided by a table of indoor-outdoor temperature differences and outgoing-returning water temperature differences with corresponding coal-consumption data. Boiler operators are also trained in technical details. With all these measures, the experimental heating system (a single $10 \mathrm{ts} / \mathrm{hr}$ boiler that originally heated 57.5 thousand $\mathrm{m}^{2}$ ) was able to handle 
an additional 29.7 thousand $\mathrm{m}^{2}$ floor area without adding new boiler capacity. Seasonal coal consumption was reduced from $28 \mathrm{kgce} / \mathrm{m}^{2}$ to $22 \mathrm{kgce} / \mathrm{m}^{2}$, a $21 \%$ reduction. Seasonal electricity use also decreased from $3.6 \mathrm{kWh} / \mathrm{m}^{2}$ to 2.4 $\mathrm{kWh} / \mathrm{m}^{2}$ because of less pumping activity. And the seasonal boiler efficiency was improved from $55 \%$ to $64 \%$. The quality of heating service was also improved significantly with new room temperatures ranging from $15-19{ }^{\circ} \mathrm{C}$ compared to $9-28^{\circ} \mathrm{C}$ before the measures. These measures are also inexpensive with an estimated cost of $¥ 0.3 / \mathrm{m}^{2}$. This translates into a fuel-saving cost of $¥ 50 /$ annual tce, far beicw the coal supply cost of $¥ 700 /$ annual tce (see Section 3.1.3.3 - (3) for calculation details).

From this example, it is clear that $\mathrm{m}$ iderate equipment improvements can significantly improve the efficiency and service of many medium-sized central heating systems. But careful adjustment of the distribution network and efficient operation of boilers are also prerequisites, as are teams of professional technicians to carry out the task and policies that promote scientific management of central heating systems.

Most Chinese central heating systems are operated intermittently. Heat is often not supplied during the night or during the middle of the day. This practice is intended to save coal, but it also sacrifices thermal comfort to some extent. With intermittent heating, room temperatures are usually lower than desired. And apartments at the end of a heating system often rereive insufficient heat because of the delayed heat supply. "Warm-up" heat is significant each time the system is turned on. Identified problems with the present intermittent heat supply include: (1) More boiler capacity is required. Because intermittent heating requires large boi er output in a short time, extra boiler capacity has to be installed. For example, for a $100,000 \mathrm{~m}^{2}$ heating area, five $4 \mathrm{ts} / \mathrm{hr}$ boilers are usually required for 12-hour intermittent heating. But if continuous heating were adopted, only three would be needed. This may partially explain the low load factor of the central heating systems. (2) Boiler operation is unstable and derated. Intermittent heating results in frequent suppression of combustion. An efficient combustion temperature is difficult to maintain. Often, by the time efficient stable combustion is reached, it is the time to suppress the fire [Wen, 1991].

According to a study in Beijing, continuous heating is concluded to be superior to the present 12-hour intermittent heating for the following reasons: (1) a stable and warmer indoor environment, (2) reduced boiler capacity installation and related operation and maintenance costs, and (3) improved boiler efficiency, $73 \%$ vs. $55 \%$. However, compared to 12 -hour intermittent heating, 24 -hour heating uses about $20 \%$ more coal per heating season. $\mathrm{NO}_{\mathrm{x}}$ emissions are found to have increased by $30-60 \%$ in continuous heating, while $\mathrm{SO}_{2}$ emissions are unchanged and $\mathrm{CO}$ emissions are reduced by $20-40 \%$. The acuteness of air pollution is mitigated because the morning and evening peaks are avoided [Wen, 1991]. 
While sleeping, people usually prefer a cooler room temperature than when they are active. This practice should contribute to the feasibility of reducing the heat supply in the late night. Further research will be needed to determine tiri optimal intermittent heating procedures that save fuel, require less boiler capacity, ind compromise little comfort.

\subsubsection{Thermal Integrity of Heated Residential Buildings}

In addition to coal-burning stoves and central heating systems, the thermal integrity of buildings s:gnificantly affects the demand for heating fuel. Improving building thermal integrity reduces heating intensity, and thus, downsizes heating systems and saves coal. Unfortunately, until recently housing and building construction practices in China have mostly been concerned with putting up sufficient floor space to mitigate the severe housing shortages rather than creating a more comfortable living environment for dwellers. Procedures that improve building thermal integrity are usually considered to be costly because they use capital that would otherwise be available for more housing units. Low-cost insulation materials are often not widely available. If energyefficient residential building standards were universally enforced, the manufacturing capacity for insulation materials would probably be inadequate to meet the demand. Regulations or building codes are usually looked upon as guidelines rather than enforced rules because of resistance from builders and the lack of solid enforcement procedures. This section will discuss some common problems identified with residential buildings in the heating zone in order to achieve a better understanding of the thermal integrity of Chinese residential buildings.

Walls and Roofs. Solid bricks are the predominant wall material in China. Heat loss is substantial through exterior walls and roofs that have only minimum insulation. For example, exterior walls of typical six-story residential buildings in Beijing are mostly brick with a thickno s of $370 \mathrm{~mm}$. The inner side of the wall is usually coated with a 20-mm layer of cement or lime mortar. Residential buildings in regions further north have thicker exterior walls. But the heattransfer coefficient does not decrease very much. Table 3-3 compares some heatperformance features of typical apartmient buildings in northern China with those of Canadian residential buildings in areas of similar heating degree-days. The differences are striking. Since Canadian residential buildings are mostly wooden structures, a low he transfer coefficient is achieved more easily. Better insulation should reduce much of the heat loss through the walls and roofs in Chinese buildings. 
Table 3-3. Heat-Transfer Coefficients of Typical Multi-Story Chinese Apartment Buildings vs. Those of North American Houses

\begin{tabular}{lccc} 
& $\begin{array}{c}\text { Exterior Wall } \\
\left(W / \mathrm{m}^{2}-{ }^{\circ} \mathrm{C}\right)\end{array}$ & $\begin{array}{c}\text { Window } \\
\left(W / \mathrm{m}^{2}-{ }^{\circ} \mathrm{C}\right)\end{array}$ & $\begin{array}{c}\text { Roof } \\
\left(W / \mathrm{m}^{2}-{ }^{\circ} \mathrm{C}\right)\end{array}$ \\
\hline $\begin{array}{l}\text { Beijing } \\
\text { Present Status }\end{array}$ & 1.57 & 6.40 & 1.26 \\
$\quad$ New Standards & 1.28 & 6.40 & 0.91 \\
Harbin & & & \\
$\quad$ Present Status & 1.28 & 3.26 & 0.77 \\
$\quad$ New Standards & 0.73 & 3.26 & 0.64 \\
Canada & & & \\
$\quad$ Comparable to Beijing & 0.36 & 2.86 & $0.23-0.40$ \\
$\quad$ Comparable to Harbin & 0.27 & 2.22 & $0.17-0.31$ \\
\hline
\end{tabular}

Source: Tu and Wang, 1991

Many measures for improving the heat resistance of walls and roofs are known to be effective at reasonable costs. They are still not widely practiced because of shortages of insulation materials and the unwillingness of builders. Research has found that, in Beijing, using $20 \mathrm{~cm}$ aerated concrete board for exterior walls and roofs in a typical six-story 48-unit apartment building reduced heat-transfer coefficients of the exterior wall, the roof, and the stairway-facing wall from their original $1.57,1.26$, and $1.83 \mathrm{~W} / \mathrm{m}^{2}{ }^{\circ} \mathrm{C}$ to $0.95,0.95$, and $0.91 \mathrm{~W} / \mathrm{m}^{2}$ ${ }^{\circ} \mathrm{C}$, respectively. This single measure can reduce heating load $\left(\mathrm{W} / \mathrm{m}^{2}\right)$ by about $20 \%$. If $30 \mathrm{~cm}$ aerated concrete boards are used, heat-transfer coefficients of the exterior wall, the roof, and the stairway-facing wall can be further reduced to $0.58,0.58$, and $0.56 \mathrm{~W} / \mathrm{m}^{2}$, resulting in a total reduction of heating load by about $32 \%$ [Yang and Bai, 1991]. Cost data of buildings constructed with aerated concrete boards are not available, although the author suspects that it would not be significantly higher than that of brick buildings. The price of bricks in 1991 was $¥ 120 / \mathrm{m}^{3}$ while the price of aerated concrete (not the board) was $¥ 90 / \mathrm{m}^{3}$. The lack of building designs based on aerated concrete boards is also a problem [Qin and Shen, 1991]. Low mechanical strength, especially in multi-story, highrise buildings, is one major hinderance to the application of aerated concrete board.

Using hollowed bricks for exterior walls should also be a low-cost improvement. Since most bricks in China are produced by small rural brickyards, some practical and technical difficulties in promoting hollowed bricks may still exist. Another widely used method in present conservation practices is to pave the interior of an exterior wall with a layer of pearlite mortar that has a low heat-transfer coefficient. The cost effectiveness of these measures is examined in Section 3.1.3.

Windows. In a typical six-story apartment building in Beijing, about one-third of the heat lost through the apartment envelope is through windows (see Table 3-4). 
Newly constructed residential buildings in the heating zone usually have singleglazed steel-frame windows. Only in the most northern areas, like in Liaoning province and regions further north, are double-glazed, wood-frame windows. Steel-frame, single-glazed windows maximize heat losses in the winter and heat gains in the summer and are the worst kind of energy peiformer. They are usually poorly manufactured and installed, which adds to ivven greater heat losses because of infiltration. The trend of increasing the area ratio of window/wall also increases the amount of heat lost through windows. In winter, northern residents usually go to such lengths as installing thick window curtains and sealing leaks in the windows with paper.

In a typical Beijing apartment building, double-glazing can almost cut the heat-transfer coefficient of windows by half. This measure alone can reduce heating loads by about $24 \%$. However, double-glazed windows are not universally welcomed because of their high cost.

Table 3-4. Heat Losses of Typical Apartment Buildings in Beijing ${ }^{\dagger}$

\begin{tabular}{lcc} 
& $\begin{array}{c}\text { Heat Transfer Coefficient } \\
\left(W / \mathrm{m} 2-{ }^{\circ} \mathrm{C}\right)\end{array}$ & Heat Loss (\%) \\
\hline Envelope & & $76.9 \%$ \\
Exterior wall & 1.57 & $25.6 \%$ \\
Window & 6.40 & $23.7 \%$ \\
Roof & 1.26 & $8.6 \%$ \\
Balcony door & 6.40 & $3.1 \%$ \\
Entrance door & 2.91 & $2.8 \%$ \\
Stairway wall & 1.83 & $10.8 \%$ \\
Floor & 0.34 & $2.3 \%$ \\
Infiltration & & $23.1 \%$ \\
\hline
\end{tabular}

+ Six-story brick wall buildings.

Source: Tu and Wang, 1991

As Table 3-4 indicates, heat loss through infiltration in apartment buildings is a very large factor, contributing $23 \%$ to the total heat loss. Major channels of air infiltration are windows and doors. For centrally heated buildings where $\mathrm{CO}$ poisoning is not an issue, tighter seals on windows and doors should be encouraged during the heating season. Providing residents with sufficient sealing materials could prove to be an inexpensive way to save coal.

Building Shape and Structure. One other factor that contributes to a building's thermal integrity is the structure of the building, i.e., whether the building is single- or multi-storied and what kind of shape the building takes. Chinese building scientists have made extensive studies on this subject and have summarized the impact of a building's structure on its thermal integrity in an 
indicator called shape coefficient. ${ }^{7}$ High-rise buildings usually have lower shape coefficients, which correspond to better thermal integrity, while low-rise or single-story buildings have higher shape coefficients. It is estimated that popular five- to six-story buildings usually have a shape coefficient of $0.28-0.30$. Singlestory buildings can have a shape coefficient as high as $0.5-0.6$. This indicates that low-rise residential buildings may have much poorer thermal integrity than high-rise buildings. Measurements have shown that, everything else being equal, an increase of $1 \%$ in the shape coefficient will result in about $0.5 \%$ of increase in heating load. A higher shape coefficient directly results in higher construction costs if equal thermal integrity standards are to be maintained [Yang and Bai, 1991]. Studies in building shape coefficient provide some guidelines for residential building design.

The majority of Chinese buildings are single-story or low-rise (2-3 stories) buildings. Even in Beijing, the most modernized city in China, single-story buildings account for about $41 \%$ of the floor area of all residential buildings and buildings with four or more stories account for about $44 \%$. The respective figures in medium or small cities are usually more than $60 \%$ and less thian $30 \%$ [Tu, Li, and Shen, 1991]. Four-story and higher buildings, for the most part, were built in the past 10 or 15 years. Because of the large number of low-rise older buildings, the poor thermal integrity of the majority of buildings due to their high shape coefficient will not be easily improved in the short term. Other things can be done to improve a building's energy performance such as installing better insulation; however, retrofitting old buildings is both expensive and inconvenient, as discussed in Section 3.1.3.

\subsubsection{Space Heating in the Transition Zone}

Space heating in the transition zone may have significant impact on residential energy demand in the future. All areas in the transition zone actually need extensive space heating to achieve the Western standards of comfort. Many urban households in the transition zone deny themselves space heating because they want to avoid the health hazards and the nuisances of coal-burning stoves. However, for residents living in areas close to the heating zone, heating is of an absolute necessity and stove heating is widely practiced. And many higher income households may turn to electric heaters for space heating.

The problem with the transition zone is that it is often economically infeasible to construct central heating systems because of its much shorter heating season. At the same time, gas heating is simply not available because of the lack of a gas supply. However, if the government overlooks this spaceheating issue, it may well pose some serious problems in the long run. Possible

7 Defined as the ratio between the outer surface area and the enclosed volume of a building. Since heat loss is positively related to the envelope area, heating energy increases with the shape coefficient. 
outcomes could be the spread of electric heaters and small-boiler central heating systems. While the use of electric heaters may be an expensive alternative, smallboiler systems can be inefficient and polluting if no stringent measures are applied.

The option of gas heating in the transition zone is not unrealistic. The economic costs of such a plan need to be carefully weighed. It would be desirable for cities in the transition zone to incorporate the gas-heating option in their town gas projects. Putting aside technological issues of gas heating (such as large-scale gasification), it is vital to introduce free-market rules for developing urban gas heating. Present subsidized gas prices (for cooking only) give no incentives to providers-local governments or enterprises-to even consider a gas space heating option. In the long run, it may also be difficult to prevent households from tapping gas for space heating if it is cheap and readily available (at present gas is not officially allowed for space heating). Of course, gas heating should not be the only mode for all urban areas in the transition zone. Industrial surplus or waste heat can be utilized and electric heating might be justified in hydro-rich areas.

To accommodate the heating needs of the transition zone and to make the best efforts at energy conservation, better building design and better insulation perhaps provide the most cost-effective and environmentally sound options. Buildings with excellent thermal integrity not only save much of the spaceheating energy in the winter but also save space-cooling electricity in the summer. Demonstration projects of passive solar heating have shown that significant improvements in thermal comfort can be achieved with moderate incremental costs [Lang, Fan, and Xu, 1991]. Such projects will provide technical information for the formation of an energy-efficiency standard for residential buildings in the transition zone.

\subsubsection{Other Issues of Space-Heating Energy Conservation}

According to a 1990 survey of 35 cities in the heating zone, heating fuel intensities $\left(\mathrm{kgce} / \mathrm{m}^{2}\right)$ in most of the surveyed cities have risen over their respective 1981 values [ $\mathrm{Tu}, \mathrm{Li}$, and Shen, 1991]. This rise seems to contrast with the government's efforts since the early 1980 s of improving boiler efficiency. The introduction of the energy-efficient building standard also seems to have had no tangible results. There are, however, some cities, like Beijing and Shenyang, that actually reduced their heating fuel intensities. The general rising trend of heating fuel intensities is exacerbated by two factors: a rising demand for thermal comfort and lack of an energy-conservation consciousness. These two factors reinforce each other and drive up fuel intensities.

Lack of Conservation Consciousness. The lack of an energy conservation consciousness is evident when Beijing is compared to most other Chinese cities. Heating coal supplies in Beijing have been historically stringent. This situation 
forced Beijing to adopt strict heating management rules, which effectively reduced waste or over-quota heat supplies but probably sacrificed comfort as well. On the other hand, in coal-rich cities, usually cities adjacent to coal-mining areas, intensive and inefficient space heating is encouraged by the inexpensive and handy coal supply. For example, Datong, which sits in China's largest coalmining area, has an average fuel intensity twice as high as that of Shenyang, a city that has about the same number of heating degree-days. Even within the same city, heating fuel intensities can vary by as much as $300 \%$, indicating vast differences in the provision of space heating among heat providers $[\mathrm{Tu}, \mathrm{Li}$, and Shen, 1991]. With the prevailing distorted coal prices and many other institutional problems, it is difficult to build a consciousness of energy conservation. In addition, most coal produced in the country is from northern China, so coal shortages generally have less impact on most of the heating region.

Poor management of heating facilities adds to the mediocre performance of the central heating systems. China's central heating systems are either managed by the local housing bureaus or by the work units themselves, depending on ownership of the heated buildings or the heating system. The housing bureau generally is a better manager of facilities than the work units. In Beiiing and Shenyang, where housing bureaus have a very strong presence, the central heating systems perform much better than those in most other cities (although at some cost to comfort due to intentionally depressed heat supply). Many work-unit heating facility managers lack basic knowledge about energy management and the heating system itself. Rarely do cost analyses or management-improvement programs figure into operations. Investigation has shown that many work-unit managers know nothing about the details of coal consumption or water consumption of their heating systems, let alone other matters. According to the survey of ten big cities, average seasonal fuel intensity of the housing-bureau heating systems is $35 \%$ lower than that of the work-unit heating systems [Wen, 1991]. This represents a significant potential for energy savings through an almost cost-free management improvement. To match the housing bureaus' performance, however, there might have to be some sacrifice in residential comfort.

Comfort $v$ s. Conservation. The government has regulations concerning the length of the heating season for different regions in the heating zone. For example, the heating season in Beijing starts on November 12 and ends on March 16, while the heating season for Harbin lasts from October 15 to April 14. These prescribed heating periods are usually stringent rather than generous, and consequently, heating coal supply is allocated accordingly. The official average heating temperature is $18^{\circ} \mathrm{C}$ but is infrequently achieved either because of intention or poor performance of the heating system. The actual average room temperature provided by central heating systems is about $16^{\circ} \mathrm{C}$. 
Work-unit apartment dwellers, however, have recently begun to experience higher comfort levels. In the wake of loosening central control and prosperity of the local economies in recent years, many work units are trying harder to satisfy their employees' demands for higher heating temperatures and longer heating periods. In addition to coal allocated from the state channel, freemarket coal is readily available at various prices. Rich enterprises or work units that have access to coal can lengthen the heating period and increase heat supply as long as they can afford it. These out-of-plan operations may well be the major factor that caused the rise of the average heating fuel intensity in recent years.

Compared to the comfortable room temperatures of $20^{\circ} \mathrm{C}$ in the U.S. and in Europe, the Chinese practice of $16^{\circ} \mathrm{C}$ is indeed not up to par. Comfort will be a significant contributing factor to future heating-energy demand not only because it increases fuel demand in the heating zone but also because it creates a new heating population in the transition zone and even in parts of the nonheating zone. The effort made toward conservation is thus bound to be offset to some extent by this rising comfort demand.

Another important issue is the transition from stove heating to central heating in urban areas. The room temperature from stove heating is significantly lower than that of central heating, and correspondingly, the fuel intensity is also much lower in stove-heated households, a seasonal average of $18 \mathrm{kgce} / \mathrm{m}^{2} \mathrm{vs.} 30$ $\mathrm{kgce} / \mathrm{m}^{2}$ for central heating. With more and more central heating systems being built, it is likely that without conservation policies in place, the average fuel intensity of residential and commercial buildings will increase. But in fact, Chinese energy-efficient building standards have set a goal of reducing heatingzone residential heating-fuel intensity to $15 \mathrm{kgce} / \mathrm{m}^{2}$ by the year 2000 . Compared with the residential building standards of Western countries, there is still further potential for energy conservation in the Chinese residential buildings. The reduction of space-heating fuel intensity not only calls for new policy initiatives but also requires cost-effectiveness in order to be successful. China also needs to foster international cooperation to acquire building-energy technologies and the transfer of advanced conservation measures.

\subsubsection{Assessment of Fuel-Conservation Measures}

As we have observed in previous sections, energy efficiency of residential and commercial fuel use in China suffers from the use of inefficient equipment, the provision of low-quality fuel, and the mediocre thermal integrity of buildings. It would be worthwhile to discuss some of the popular conservation measures and to examine their cost-effectiveness. This section presents only an incomplete survey of possible measures. The assessment of cost-effectiveness is also preliminary since data may not be accurate and economic indicators are often distorted. 


\subsubsection{Criteria of Conservation Assessment}

The cost-effectiveness of fuel conservation is measured in two ways. First, the cost of annual fuel savings is calculated and compared with the cost of fuel supply capacity. The calculation of the cost of saved capacity (CSC) is performed with the following formula:

\section{$\operatorname{CSC}(¥ /$ annual tce $)=$ Measure Cost $/$ Annual tce Savings}

In the case of saving coal, for example, the CSC is compared with the cost of supplying coal by investments in new mining and transportation capacities, or even washing capacities if washed coal is saved. The implicit assumption here is that both alternatives have equal lives, which makes the comparison somewhat weak if the measure's life is considerably shorter than the supply facilities. This problem can be resolved by calculating annualized costs, which will be defined explicitly later. The exclusion of operation and maintenance costs also adds uncertainty to the comparison. The operation and maintenance costs in coal mining are often high while conservation measures usually do not add much in costs and, sometimes, even save operation and maintenance costs.

The second measure of cost-effectiveness is the comparison of cost of conserved fuel (CCF) and the fuel prices, or presumably, the long-run marginal cost of the fuel. CCF is calculated with the following formula:

\section{CCF $(¥ /$ tce $)=$ Measure Cost $\bullet$ Capital Recovery Factor / Annual tce Savings}

The capital recovery factor (CRF) is considered the annual payments on a loan used to finance an efficiency measure, assuming an interest rate equal to the discount rate, and a measured life equal to the loan term (this is a conservative assumption because measured life should, in general, be longer than the loan term). In this case, the operation and maintenance cost of conservation measures is implicitly assumed to be zero.

The CCF measure is preferred to the CSC measure because the useful life of conservation measures and the time value of money are explicitly dealt with. However, coal prices in China are greatly distorted since the controlled prices are often below production costs and the market prices in industrial regions are usually extremely high. Using the official price is obviously unrealistic. But the market price may also be significantly distorted because of arbitrage. In practice, the CSC measure and CCF measure should both provide useful information and insights for judging cost-effectiveness. In the author's view, the feasibility or cost-effectiveness of conservation measures should be judged case-by-case, taking into account regional differences. This section intends to provide a national perspective on some of the popular conservation measures. 


\subsubsection{Coal Prices and Investment Costs of Supplying Coal}

According to the State Bureau of Prices, in 1989 the average market price of raw coal was about $¥ 170 /$ ton, while the controlled price for residential raw coal was about $¥ 60 /$ ton [SSP, 1990]. Here both prices are considered distorted and inappropriate for this assessment. It was also reported that in 1989 the Beijing Housing Bureau purchased raw coal (presumably for space heating) at about $¥ 110 /$ ton [Liu and $\mathrm{Zhu}, 1991$ ]. This figure represents a somewhat reasonable coal price and will be used in this study. For simplicity, I assume the 1990 coal price of $¥ 110 /$ ton, or about $¥ 150 /$ tce. For comparison, the controlled price for residential coal is about $¥ 85 /$ tce.

There is no uniform value for investment costs of supplying coal. Capital costs can be very low for rural collective mines because of their simple and crude construction. The investment costs of larger mines are generally quoted at about $¥ 400$ \%tce (including the transportation investment) for the mid-1980s [Qin and Xin, 1989]. This cost, according to the author's communications with experts from the Energy Research Institute in Beijing, reached about $¥ 700 /$ tce in the early 1990 s. Consequently, the $\$ 700 /$ tce figure will be used as the comparison against conservation investments because most of future coal supply is planned to come from large mines.

\subsubsection{Conservation Measures and Their Cost-Effectiveness}

\section{(1) Honey comb briquettes and energy-efficient stoves (for space heating and cooking)}

Honeycomb briquettes can save $20-30 \%$ coal consumption, depending on whether pellets or raw coal were used previously [MoGM, 1988]. In this section, a $20 \%$ savings is presumed achievable by switching to honeycomb briquettes from either pellets or raw coal.

From 1986 to 1990 , total investment in honeycomb-briquetting facilities was $¥ 200$ million (in then current prices), resulting in 5 million ton per year new production capacity [Jiang, 1991]. This figure would translate into an investment cost of $¥ 40 /$ annual ton, presumably at 1990 prices (the figure may be higher; but adjustment to the 1990 prices is not possible). Thus the cost of saved capacity would be $¥ 280 /$ annual tce. ${ }^{8}$ The cost of new stoves may range from around $¥ 20$ to more than $¥ 50$ per unit depending on the material used in construction and the level of sophistication. Even if honeycomb briquettes are not used, a stove is still needed. It is not essential that households purchase a new stove in order to use honeycomb briquettes. Some kind of retrofit is more likely. To be conservative, including the cost of a $¥ 50$ stove, the CSC of investing in both briquettes and stoves is $¥ 330 /$ annual tce. This can be compared to a coal-supply cost of

8 Investing $¥ 40 /$ annual ton in honeycomb briquettes would save 0.2 ton coal per year (20\% savings). Thus CSC $=¥ 40 / 0.2=¥ 200 /$ annual ton $\approx ¥ 280 /$ annual tce. 
700/annual tce. There is a clear advantage to investing in honeycomb briquettes and efficient stoves. In addition, operation and maintenance costs of coal production are supposed to be high and are not reflected in the initial investment cost. The external cost of producing and consuming an extra ton of coal is not included either.

The CCF of investing in honeycomb briquettes and efficient stoves would be $¥ 87 /$ tce, if a loan term of 5 years and an interest rate of $10 \%$ are assumed (this translates into a capital recovery factor of 0.2638 ). 9 The CCF is far lower than the market raw coal price of $¥ 150 /$ tce and is about the same as the present controlled raw coal price. The honeycomb briquettes option is clearly a winner in this case. Coal prices can also be adjusted to make investing in honeycomb briquettes more attractive.

\section{(2) Construction of district heating systems}

One of the major energy-conservation measures in central heating is the construction of district heating capacity instead of dispersed small boiler systems. In the sixth Five-Year Plan (1981-1986), investments in district heating was about $¥ 210$ million and the newly increased district heating building floor area was about 15 million $\mathrm{m}^{2}$. This expansion was achieved through a combination of heat, and construction or expansion of co-generation plants. Estimated annual coal savings achieved through such projects were about 578 thousand tce per year [Liu and Qin, 1988]. This translates to a rough conservation cost of $¥ 360$ /annual tce at 1986 prices. 10 If adjusted for inflation, the CSC would be about $¥ 490$ /annual tce at 1990 prices, ${ }^{11}$ which compares favorably with the supply cost of $¥ 700 /$ tce. Since the above CSC figure is a gross average of a combination of projects, the comparison here is less informative. I would not calculate the CCF by using the given CSC.

\section{(3) Improving the hydraulic balance of heat-distribution networks}

As previously discussed, a common problem of heat-distribution networks in China is the overflow of hot water and an uneven heat supply to customers caused by malfunctioning flow-control valves and water pumps. These hydraulic problems not only derate boilers but also result in low-quality heating services. According to a pilot project conducted by the Air Conditioning Research Institute of the China Academy for Building Sciences, fixing hydraulic problems on the distribution network can be achieved at low cost (see Section 3.1.1.4). The estimated cost of the measures is about $¥ 0.30$ yuan $/ \mathrm{m}^{2}$ for most boiler-heating distribution systems. And the typical fuel savings are about 6

9 Interest rates vary with loan term. In China, short-term loans may have interest rates of more than $10 \%$, while long-term loans may have interest rates of $7 \%$ or even lower. Usually, the government gives special low-interest rates for conservation loans (about $3 \%$ in the early and mid-1980s) or subsidizes the normal interest rates. For simplicity, the $10 \%$ interest rate is chosen in this report. 
$\mathrm{kgce} / \mathrm{m}^{2}$ [Lang, 1991]. The cost of saved fuel is a low $¥ 50 /$ annual tce ${ }^{12}$ which is substantially lower than the coal-supply investment.

(4) Improving the quality of coal (for heating boilers)

Supplying better quality coal to boilers is important for efficient combustion. Coal washing is a widely used procedure. While coal washing is a capitalintensive investment, the coal-blending process discussed previously is a much cheaper measure for improving boiler efficiency. It is, of course, desirable to have coal both washed and properly blended for specific end uses. But in China's case, capital constraints often make coal blending an attractive single investment rather than a contingent project to coal-washing facilities. The CSC was about $¥ 170 /$ annual tce from coal-blending in 1986 [Qin and Xin, 1989]. At 1990 prices it would be about $¥ 230$ /annual tce. Compared to the cost of coal supply, saved coal from constructing coal-blending facilities is a low-cost alternative.

The CCF in this case is about $¥ 60 /$ tce, if a loan term of 5 years and an interest of $10 \%$ are used. This figure would compare favorably to the controlled coal price of $¥ 84 /$ tce and the market price of $¥ 150 /$ tce.

(5) Improving the thermal integrity of the building envelope

Here we consider a typical six-story, 72-unit Beijing apartment building. The basic statistics of the building are

- Gross areas of exterior walls- $175 \mathrm{~m}^{2}$ east and west, $855 \mathrm{~m}^{2}$ north and south;

- $\quad$ Roof area-570 $\mathrm{m}^{2}$;

- Areas of windows per story- $-5.4 \mathrm{~m}^{2}$ east, $1.8 \mathrm{~m}^{2}$ west, $24.4 \mathrm{~m}^{2}$ south, and $31.6 \mathrm{~m}^{2}$ north; all single-glazed and steel-framed;

- Gross floor space per story- $570 \mathrm{~m}^{2}$;

- $\quad$ Structure of exterior wall- $-370 \mathrm{~mm}$ thick brick structure plus 15 $\mathrm{mm}$ lime mortar layer on the inner side;

- Structure of interior wall-15 mm cement mortar plus $240 \mathrm{~mm}$ brick structure plus $15 \mathrm{~mm}$ cement mortar; and

- Structure of roof-from bottom up, $130 \mathrm{~mm}$ hollow concrete slab, $70 \mathrm{~mm}$ pumice stone concrete, $100 \mathrm{~mm}$ aerated concrete, and a layer of asphalt for water-proofing.

The seasonal heating load is calculated, using the DOE-2 simulation program, at $34.1 \mathrm{~W} / \mathrm{m}^{2}$ [Lang and Huang, 1992]. This figure translates to about $23.4 \mathrm{kgce} / \mathrm{m}^{2}$ of seasonal coal consumption assuming a heating-system efficiency

$12 ¥ 0.3 / 6=¥ 0.05 /$ annual kgce $=¥ 50 /$ annual tce. 
of about $51 \%$ (boiler $60 \%$, distribution $85 \%$ ). In reality, seasonal coal consumption in Beijing ranges from 17 to $26 \mathrm{kgce} / \mathrm{m}^{2}$.

Two types of envelope improvement are proposed here for evaluation: one for new buildings and one for retrofitting old buildings.

\section{Conservation measures for new buildings:}

- Exterior walls-240 mm brick structure plus $20 \mathrm{~mm}$ air layer plus $30 \mathrm{~mm}$ polystyrene boards plus $12 \mathrm{~mm}$ gypsum boards;

- Stair-facing walls-30 mm pearlite cement mortar plus $140 \mathrm{~mm}$ reinforced concrete plus $30 \mathrm{~mm}$ pearlite cement mortar;

- Roof-130 mm hollow concrete slab plus $170 \mathrm{~mm}$ pumice stone concrete plus $20 \mathrm{~mm}$ cement mortar plus a layer of asphalt;

- Windows-double-glazing north, west, and east windows; south windows remain single-glazed.

With these measures, a new seasonal heating load is calculated at $\mathbf{2 2 . 6}$ $\mathrm{W} / \mathrm{m}^{2}$ assuming an air-change rate of $0.6 / \mathrm{hr}$. This would translate to a seasonal coal consumption of $15.5 \mathrm{kgce} / \mathrm{m}^{2}$ [Lang and Huang, 1992]. Compared to the baseline fuel intensity of $23.4 \mathrm{kgce} / \mathrm{m}^{2}$, these conservation measures would result in a fuel savings of $7.9 \mathrm{kgce} / \mathrm{m}^{2}$ per heating season.

The incremental materials costs are exterior walls, $¥ 15965$; stair-facing walls, $¥ 3500$; roof, $¥ 2394$; and windows, $¥ 15132$. The total incremental cost is $¥ 36,991$, or about $¥ 11 / \mathrm{m}^{2}$ gross floor space, compared with the original design (for detailed information, see Appendix A).

According to these figures, the CSC would be $¥ 1392$ /annual tce. This is far higher than the coal supply investment of $¥ 700 /$ annual tce. However, in this situation, such a comparison is less meaningful, because buildings usually last much longer than coal mines. The CCF would be $¥ 164 /$ tce assuming a 20 -year loan term and a $10 \%$ interest rate, compared to the market price of coal at $¥ 150 /$ tce. Consequently, these measures of envelope improvement appear to be unattractive. This situation may be improved when production of insulation materials has expanded and their prices have lowered. On the other hand, the simple payback time is about nine years at market coal prices. This is reasonable for buildings that last decades.

\section{Conservation measures for old buildings:}

- $\quad$ Replacing old insulation layer of exterior walls and stairway walls with a $30 \mathrm{~mm}$ layer of cement pearlite mortar; 
- Insulating the opaque part of balcony doors;

- Double-glazing all windows.

After these adjustment, seasonal heating load can be reduced to 25.0 $\mathrm{W} / \mathrm{m}^{2}$ and seasonal coal consumption can be reduced to $17.2 \mathrm{kgce} / \mathrm{m}^{2}$, resulting in a fuel savings of $6.2 \mathrm{kgce} / \mathrm{m}^{2}$ [Lang and Huang, 1992].

The incremental materials costs in this case are walls, $¥ 27,456$; windows, $¥ 24,648$. Neglecting the cost of door insulation, the total cost of materials would be $¥ 52,104$, or $¥ 15 / \mathrm{m}^{2}$, an even higher incremental cost than the new building case (See Appendix A).

With the above cost figures, the CSC would be $¥ 2419 /$ annual tce. The CCF would be $¥ 284 /$ tce assuming a 20 -year loan and a $10 \%$ interest rate. Retrofitting old buildings with these measures seems to be a worse investment choice than building of new ones, which, to some extent, indicates that in many cases retrofitting old and low-value buildings may not be worthwhile.

Conclusion. This demonstrative analysis shows that energy-efficient improvements for residential buildings may not always be justified under conventional economic criteria, either because of distorted prices or because of an inappropriate choice of measures. In more elaborate analyses, external costs such as air pollution and waste disposal and benefits such as downsized heating systems should be considered. Measures should be designed to consider both the efficiency goal (reduction of heating load) and its cost-effectiveness. Since new efficient buildings do pay back their incremental costs in the long run (in the above fictitious example, a nine-year simple payback time), special policies should be designed to encourage investments. In fact, demonstration projects have shown promise for energy-efficient residential buildings. A case study of such a project is presented in Appendix B.

\section{(6) Firewood conservation}

Estimating the costs and benefits of promoting energy-efficient firewood stoves in rural areas is difficult because most rural households gather their own firewood or crop stalks instead of buying them. The production cost of firewood is estimated at $¥ 40-140 /$ tce at 1987 prices depending on regional differences in fuel resources [ $X_{i i}$ and $Z$ hang et al., 1990]. At 1990 prices, firewood may cost $¥ 60$ $215 /$ tce.

The cost of converting an ordinary firewood stove to a fuel-efficient one is estimated at about $¥ 50 /$ unit [ $X u$ and Zhang et al., 1990] After conversion, a $100 \%$ increase of heat efficiency is normally expected, i.e., from $10 \%$ to $20 \%$. In practice, it may be lower. On average, an ordinary firewood stove consumes about 3 tce of firewood or crop stalks a year (estimated from 1979 rural biomass consumption). Thus, the new stove would save 1.5 tce per year. If households 
buy firewood from the market at $¥ 40 /$ tce, the investment would be a very attractive one. Although, most people in rural areas do not currently buy firewood, using efficient stoves and production firewood would save people the time that is otherwise spent on collecting fuel. Furthermore, the benefit of more efficient stoves extends beyond just saving fuels. Conserving firewood and crop residues is very important for alleviating overuse of these materials in rural China and relieving fuel shortages found in many rural areas.

\subsection{ELECTRICITY USE AND CONSERVATION}

Residential and commercial electricity use has been increasing rapidly since the late 1970s. From 1980 to 1990 , the annual grow th rate of electricity demand in the residential and commercial sectors was $15 \%$, while that of other sectors was about $7 \%$. The explosive increase in residential electricity use (averaging over $16 \%$ per year from 1980 to 1990) has been fueled by the very rapid growth of electric appliances. For example, the stock of refrigerators increased from 0.2 million units in 1980 to 30.0 million units in 1990; the stock of television sets increased from 9.0 million units in 1980 to 185.5 million units in 1990; and electric fans, from 13.7 million units in 1980 to 201.3 million units in 1990 [SSB, 1992b]. The increase of electricity use in commercial buildings may have a great deal to do with the boom in trade and business that accompanied the proliferation of modern commercial buildings in this perind. In major cities, newly constructed luxury hotels can draw up to $15 \%$ of a city's residential and commercial electricity supply. ${ }^{13}$

Table 3-5. Per Capita Residential and Commercial Electricity Use in Selected Countries, 1989

\begin{tabular}{lcccc} 
& \multicolumn{2}{c}{ RESIDENTIAL } & SECTOR & \multicolumn{2}{c}{ COMMERCIAL SECTOR } \\
\cline { 2 - 5 } & $\begin{array}{c}\text { Total } \\
\text { (billion } \mathrm{kWh} \text { ) }\end{array}$ & $\begin{array}{c}\text { Per Capita } \\
\text { (kWh/year) }\end{array}$ & $\begin{array}{c}\text { Total } \\
\text { (billion } \mathrm{kWh} \text { ) }\end{array}$ & $\begin{array}{c}\text { Per Capita } \\
\text { (kWh/year) }\end{array}$ \\
\hline Chinat & 48 & 42 & 28 & 24 \\
India & 28 & 35 & 10 & 13 \\
Brazil & 44 & 296 & 39 & 265 \\
S. Korea & 18 & 418 & 16 & 387 \\
Japantt & 127 & 1033 & 143 & 1163 \\
USA & 904 & 3660 & 724 & 2931 \\
+ 1990 data & & & & \\
+ 1988 data & & & &
\end{tabular}

Sources: SSB, 1991; Sathaye. 1993; DOE, 1991. Beijing.

13 Ihformation from Mr. Wang Xunchang of the Institute of Air Conditioning Research, 
In spite of the ten-year phenomenal growth of residential and commercial electricity demand, the absolute amount of electricity used in these sectors is still low. In 1990, residential and commercial electricity use totaled 76 billion $\mathrm{kWh}$ (48 billion $\mathrm{kWh}$ for residential buildings and 28 billion $\mathrm{kWh}$ for commercial buildings), which accounted for over $15 \%$ of total electricity end use in the nation, compared with its share of $7 \%$ in 1980 [SSB, 1992b]. Per capita consumption was about $67 \mathrm{kWh} /$ year, 3.5 times as much as that in 1980 . As Table 3-5 reveals, per capita residential and commercial electricity use in China is substantially lower than that of the developed countries and is also lower than that of many peer developing countries, indicating great growth potential. With the present population, every $5 \mathrm{kWh} /$ year increase of per capita residential electricity use would require the addition of a 1-GWe thermal power plant.

Table 3-6. Estimates of Residential Electricity End Uses

\begin{tabular}{|c|c|c|c|c|}
\hline & $\begin{array}{c}\text { Rated Power } \\
\text { (W) }\end{array}$ & $\begin{array}{c}\text { Operating Time } \\
\text { (hrs/day) }\end{array}$ & $\begin{array}{c}\text { Annual Elec Use } \\
(\mathrm{kWh} / \mathrm{yr})\end{array}$ & $\begin{array}{l}1990 \text { Saturation } \\
\text { (per } 100 \text { urban hh) }\end{array}$ \\
\hline \multicolumn{5}{|c|}{ Urban Household } \\
\hline Lighting (a) & 60 & 4 & 88 & 100.0 \\
\hline Refrigerator (b). & 122 & 24 & 400 & 42.3 \\
\hline Color TV (18") & 75 & 3 & 82 & 59.0 \\
\hline B \&W TV (12") & 30 & 3 & 32 & 52.4 \\
\hline Fan $(400 \mathrm{~mm})$ & 66 & $500 \mathrm{hrs} / \mathrm{yr}$ & 33 & 135.5 \\
\hline Clothes washer & 230 & $80 \mathrm{hrs} / \mathrm{yr}$ & 18 & 78.4 \\
\hline Rice cooker & 600 & 0.8 & 175 & $10 \sim 30(c)$ \\
\hline Air conditioner & 1500 & $600 \mathrm{hrs} / \mathrm{yr}$ & 900 & $<1(c)$ \\
\hline Rural Household & & & & (per 100 rural hh) \\
\hline Lighting & -40 & 4 & 58 & 70.0 \\
\hline Refrigerator & 122 & 24 & 400 & 1.2 \\
\hline Color TV & 75 & 4 & 110 & 4.7 \\
\hline B \&W TV & 30 & 4 & 44 & 39.7 \\
\hline Fan & 70 & $400 \mathrm{hr} / \mathrm{yr}$ & 26 & 41.4 \\
\hline Clothes washer & 230 & $80 \mathrm{hrs} / \mathrm{yr}$ & 18 & 9.1 \\
\hline Rice cooker & 600 & 0.8 & 175 & $<<1$ (c) \\
\hline Air conditioner & 1500 & $500 \mathrm{hr} / \mathrm{yr}$ & 750 & $\ll 1$ (c) \\
\hline
\end{tabular}

(a) Operating power. Installed lighting power could be a lot higher than that indicated here. (b) A two-door 1701 model manufactured by the Xuehua Electronics, Inc.. (c) Guessed number.

Source: Zhou, et al., 1989; SSB, 1991.

Residential and commercial electricity use has yet to become a serious problem of electricity management because of the predominance of industrial use (more than $70 \%$ of the total electricity end use). Thus far, the government has been preoccupied with industrial power shortages and has not paid attention to the issue of demand-side management of residential and commercial electricity use. Restrictions on residential electricity uses have always been stiff in order to contain the demand, while active conservation measures such as efficient 
appliances and efficient lighting devices have not been seriously pursued. The increased use of electricity in the residential and commercial sectors is a direct result of the rapid improvement in the standard of living during the last decade. This momentum is likely to be maintained for a long period of time if the Chinese economy continues to excel. Increases in residential and commercial electricity use create peak load problems that result in substantial economic costs and management headaches. It is therefore important to address this issue in the early stages of growth.

Since detailed electricity consuription data are not available, estimates of electricity consumption in each of the major residential and commercial end uses may vary from the actual uses. Table 3-6 assembles some essential information for understanding electricity end uses in urban and rural households. Major end uses are discussed in the subsequent sections.

\subsubsection{Lighting}

Because of the rapid increase in appliance ownership in the last decade, lighting has become a much less important component of residential and commercial electricity use today than it was ten years ago. For an above-average urban family that owns a refrigerator, a color television set, and a clothes washer, lighting may only contribute about $10-15 \%$ of the annual electricity use of the household. On the other hand, for an average rural houselold, lighting would account for most of the electricity use since appliance ownership is still at a very low level. It has been estimated that about $25 \%$ of rural households still had no access to electricity by the end of 1980s [Xu and Zhang et al., 1990].

Residential lighting electricity use in 1989 is estimated at about 15 billion $\mathrm{kWh}$, or about $35 \%$ of total residential electricity use.14 For commercial buildings, I estimate that 18 billion $\mathrm{kWh}$, about $70 \%$ of electricity used in commercial buildings, was used for lighting in 1989.15 The figure for commercial buildings is at best a guess, because knowledge about lighting patterns in different types of commercial buildings is lacking. The result is considered reasonable since HVAC systems are still rare in China.

Fluorescent fixtures are widely used in office buildings, classrooms, and shops while in the residential sector incandescent lamps are still the dominant lighting device. Domestically manufactured compact fluorescent lamps are also

14 Urban total $=88 \mathrm{kWh} / \mathrm{yr}-\mathrm{HH} \bullet 82.1$ million $\mathrm{HH}=7.2$ billion $\mathrm{kwh}$; rural total $=58$ $\mathrm{kwh} / \mathrm{yr}-\mathrm{HH} * 169.7$ million $\mathrm{HH} * 75 \%=7.4$ billion kwh.

15 Commercial total $=($ schools $) 5 \mathrm{~W} / \mathrm{m}^{2} \cdot 25.24$ million $\mathrm{m}^{2} \cdot 6 \mathrm{hrs} /$ day $\bullet 250$ days + (offices) $5 \mathrm{~W} / \mathrm{m}^{2}$ • 304.01 million $\mathrm{m}^{2}$ • $6 \mathrm{hrs} /$ day $\bullet 300$ days + (commerce) $10 \mathrm{~W} / \mathrm{m}^{2} \cdot 533.96$ million $\mathrm{m}^{2}$ • $8 \mathrm{hrs} /$ day $\bullet 320$ days + (other) $5 \mathrm{~W} / \mathrm{m}^{2} \cdot 155.84$ million $\mathrm{m}^{2} * 4 \mathrm{hr} /$ day $\bullet 310$ days $=$ 17.6 billion kwh. 
available on the market at prices ten times higher than those of incandescent lamps, but the quality is inferior to similar types found in the U.S.. Private purchases of compact fluorescent lamps are very limited.

There are no previous estimates of the stock of operating incandescent, fluorescent, and other types of lamps. The only information available is the annual production figure of light bulbs, which gives no indication of shares by lamp type and lamp power. In 1989, total production of light bulbs was 2 billion units (figures do not indicate if all are incandescent lamps) [SSB, 1991]. The production of fluorescent lamps (unit power range of 4-40 W) was reported at about 200 million units in 1990 [Economic Report Daily, 1991]. If the life of an incandescent bulb is assumed to be $700 \mathrm{hrs}$, the turnover of stock would be about twice a year, and estimates would put about one billion incandescent lamps in use in 1989. Fluorescent lamps usually last over 3000 hours. If average replacement time is assumed to be twice every three years, the stock of fluorescent lamps in use in 1989 would be about 300 million units $(=200 / 0.67)$. How many of each kind and what wattages are used in the residential, commercial, and industrial buildings is not clear. Residential buildings probably have the largest share of incandescent lamps and commercial buildings the largest share of fluorescent lamps.

Assuming three incandescent lamps per urban household and two incandescent lamps per rural (electricity-using) household, a rough estimate for the stock of residential incandescent lamps would be about 500 million in 1989. Rated power of incandescent lamps used in residential buildings usually ranges from $15 \mathrm{~W}$ to $60 \mathrm{~W}$, while those used in commercial or industrial buildings usually have $100 \mathrm{~W}$ or more. High wattage fluorescent fixtures (usually 20-40 W) are not widely installed in residential buildings, but low wattage (6-15 W) fluorescent table lamps or portable screw-in fixtures are quite popular in urban areas.

Because of high residential electricity prices (usually twice that of industrial electricity), Chinese households used to be very frugal with lighting electricity use when metering was imposed. Since the income of average families has increased significantly in the 1980s, the attitude toward lighting may have changed somewhat. Since ordinary households carefully monitor electricity use, it is not obvious that substantial lighting electricity savings can be achieved in the residential sector. However, compact fluorescent lamps (CFLs) could find a huge market in residential buildings if quality is established and an innovative promotion policy adopted. Even if electricity is not saved, without doubt, using more luminous fluorescent lamps would improve lighting services.

Great lighting electricity savings exist in commercial buildings (and industrial buildings) where high-wattage lamps are used. Introducing electronic-ballast fluorescent lamp systems and CFLs can be very cost-effective for commercial lighting. 


\subsubsection{Appliances}

\subsubsection{Refrigerators}

Refrigerators are by far the largest electricity-consuming appliance in most households. They are also the greatest driving force behind the surge of residential electricity demand in the last ten years-about $35 \%$ of the increase in residential electricity demand in the 1980s-by this author's estimate (see Figure 2-10). Refrigerator saturation data from several representative cities are shown in Figure 3-1 to illustrate the speed of saturation in major metropolitan areas.

Figure 3-3. Refrigerator Saturation in Selected Major Cities

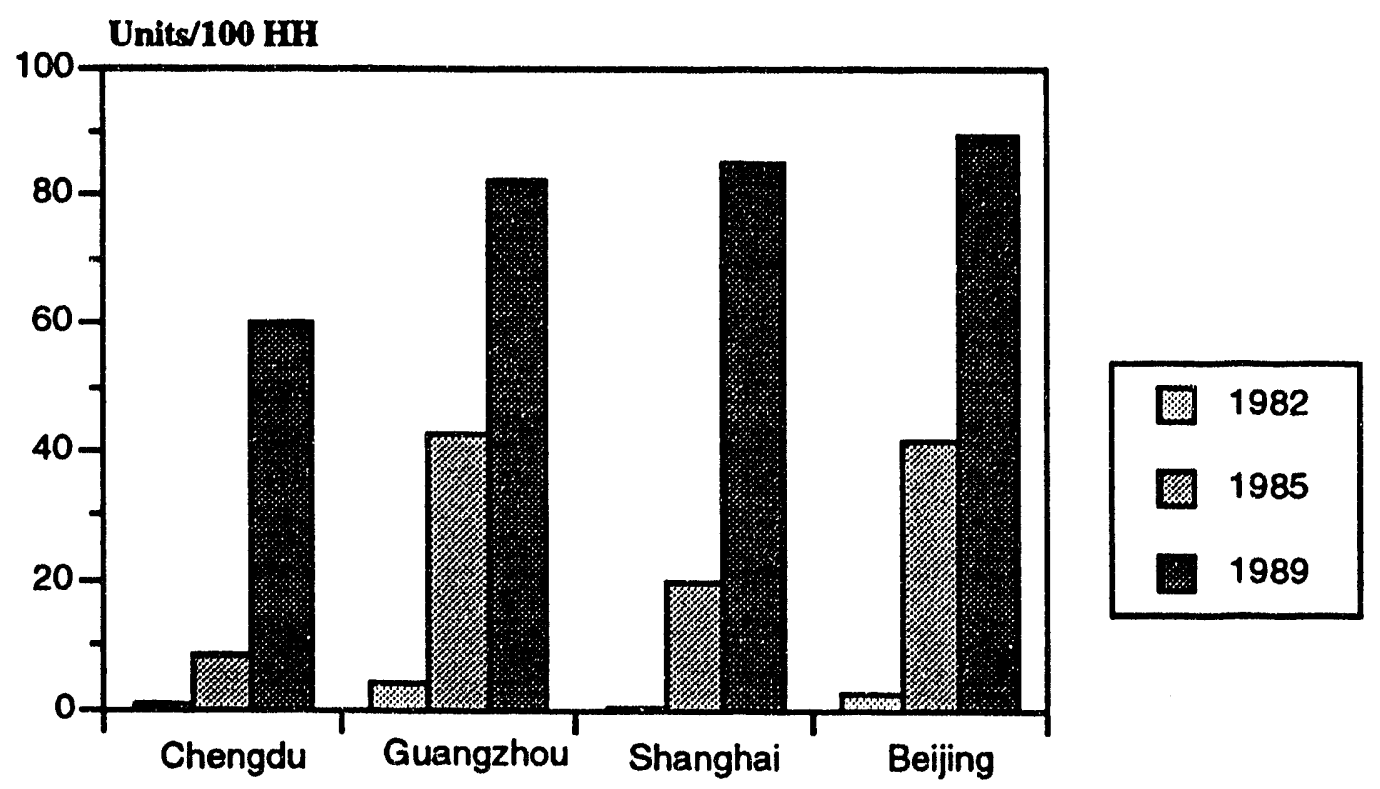

Source: SSB, $1989 \mathrm{~b}$.

Refrigerator manufacturing is a new industrial trade in China. Japan and Italy are the two most influential suppliers of hardware and technologies, and the manufacturing lines that China imported in the mid-1980s represent the technologies of exporting countries at that period. In 1989, China produced 6.7 million units of refrigerators, a massive production by any standard. Most domestically produced refrigerators are in the volume range of 160-200 liter. The popularity of two-door and larger models has been increasing rapidly.

The stock of refrigerators by the end of 1990 was about 30 million units, which may include some non-residential stock. Since the stock of refrigerators was only 4 million in 1985, most of the present operating refrigerators will probably be in use for another ten years or more. Because the manufacturing technology is at early or mid-1980s levels, energy efficiency is better than average 
compared to other large developing countries such as India and Brazil, where refrigerator penetration started much earlier.

Electricity consumption of refrigerators is difficult to estimate because few measurement data are available for popular Chinese models. Refrigerator electricity use also depends on how refrigerators are operated and the location of a refrigerator in a room. It is not rare for Chinese families, especially for those living in the northern region, to run their refrigerators only partially in the winter. According to a researcher at Tsinghua University who has made preliminary measurements of refrigerator electricity use, 160-170 liter single-door models use slightly less than $1 \mathrm{kWh} /$ day. A popular two-door 170 liter refrigerator model (BCD-170A) manufactured by Xuehua Electronics, Inc. in Beijing is reported to have an electricity consumption of $1.1 \mathrm{kWh} / 24$ hours according to the manufacturer's menu. In comparison, a typical 165 liter Indian model uses about $1.78 \mathrm{kWh} /$ day [ACEEE, 1991]. Larger models are expected to have higher electricity consumption. For example, a 230-liter two-door model (Yangzi BCD-230, manufactured by Yangzi Electronics, Inc.) has input power of $160 \mathrm{~W}$. If 9 hour/day of refrigerating time is assumed, the electricity use would be $1.44 \mathrm{kWh} /$ day, or an annual electricity use of $525 \mathrm{kWh} /$ year. On average, electricity usage of the present stock of refrigerators would be about on the level of the Xuehua model just mentioned, i.e., $400 \mathrm{kWh} /$ unit-year. Without taking into account unusual operating patterns, a estimate of annual electricity use of 1989 stock of refrigerators is roughly 10 billion $\mathrm{kWh}$.

Developing a new generation of energy-efficient refrigerators may take a long time for a fledgling domestic industry. Many problems may hinder the industry's ability to tackle energy-efficiency issues. Currently, there are still too many manufacturers (a few dozen of them) in the refrigerator market. Economies of scale are rarely the case. In addition, the entire industry depends on foreign suppliers for key technologies such as compressors. This situation in many cases strains manufacturers' financial capabilities to do their own R\&D. Nonetheless, some manufacturers have begun to pay more attention to refrigerator efficiency in recent years, but most work is still in the experimental stage.

The Shanghai-based Hangtian Refrigerator Factory reports that by modifying a two-door 177-liter model (Hangtian BCD-177A) it is able to produce a new model that consumes $0.8 \mathrm{kWh} /$ day of electricity, which results in an annual electricity use of $292 \mathrm{kWh} /$ unit. This is a $27 \%$ electricity savings compared with the Xuehua 170-liter model. The incremental cost of this new model has not been released. The modifications the factory has performed include: (1) reversing the refrigerant flow pattern of the original model by letting the refrigerant pass through the evaporator of the freezer compartment first and then the evaporator of the refrigerator compartment. This redistribution of cooling capacity works best for two-door direct-cooling refrigerators because of the better match-up of cooling capacity and cooling load. (2) Modifying the 
original built-in condensers in both sides of the refrigerator body to a shutter type condenser placed on the rear side (exposed) to improve the efficiency of heat dissipation. The condensing temperature is also lower after modification. (3) Rearranging the tubes of the evaporators and the distribution of the evaporating area to optimize the efficiency of the refrigeration system [Zhang, et al., 1990]. The Hangtian report did not mention anything related to insulation improvement, which is usually inexpensive and effective.

A more revolutionary case is also reported. A newly invented refrigerant in China aimed at minimizing CFC emissions is also found to be electricitysaving. It is said that prototype refrigerators using this new refrigerant can save $33 \%$ of electricity used compared with the original models [People's Daily, 1991]. Unfortunately, data are still not available.

\subsubsection{Televisions}

Similar to the pattern of refrigerator sales, television saturation has been strongly supported by large-scale domestic manufacturing that utilizes Japanese technologies almost exclusively. In 1980, China produced about 2.5 million television sets, mostly black and white (B/W) sets. In 1990, China produced more than 10.3 million color television sets and about 16.5 million $B / W$ sets, outnumbering any other major television-producing country in the world. Domestically made sets are so far exclusively the portable types, which use less electricity than those with large screens.

The stock of television sets by the end of 1990 was about 185 million units (including some non-residential stock). The share between color and $\mathrm{B} / \mathrm{W}$ sets is unknown. The most popular $B / W$ sets are usually 12 to 14 -inch models that have a rated power of about $30 \mathrm{~W}$; the most popular color sets, 18 to 20-inch models with a rated power of about $75 \mathrm{~W}$.

The electricity consumption of television sets is very much influenced by the watching behavior of households. In China, television time is regulated by the central or local stations with programs running intermittently and with most entertainment programs concentrated in the evening hours from 6 to 11p.m. Rural households presumably spend more time watching television than their urban counterparts. Assuming that daily watching time for urban households and rural households averages about 3 hours and 4 hours respectively, estimates of annual electricity use of televisions sets is put at around $7-8$ billion $\mathrm{kWh}$ in 1989.16

Recent developments in the television market have been the proliferation of color sets and the growing demand for larger screen models. With an

16 There were about 165.9 million television sets in China in 1989. Assuming a quarter of them are color sets, electricity use can be calclulated by using data in Table 3-6. 
increasing length of programming time, we may also expect people to spend more time watching television-as is usually the case in other countries. These factors will certainly add to the rise of electricity use in the future. Because television viewing time is quite concentrated, peak load impact will be a major concern of demand-side management.

Video cassette recorders (VCRs) are beginning to find a place in urban families in recent years. Like the proliferation of television sets in the 1980s, VCRs will undoubtedly become highly saturated in urban areas in a matter of a few years.

\subsubsection{Electric Fans}

Because of their relatively low cost and the necessity of having one in the summer in most regions of China, ownership of electric fans has increased greatly in the $1980 \mathrm{~s}$. Urban saturation had reached 135 units per hundred households in 1990, compared with about 40 units per hundred households in 1980. Rural saturation in 1990 was 41 units per hundred households. Total stock of electric fans was 201 million in 1990 (including non-residential stock).

Table fans or floor fans with a $400 \mathrm{~mm}$ diameter are among the most popular models. They usually have about $60-70 \mathrm{~W}$ rated power. In recent years, ceiling fans have also become popular because they generate a wider and more gentle circulation pattern. Unlike other major electric appliances, most fans are manufactured with domestically developed technologies. Fan manufacturing (design and product quality) has reached a very sophisticated level in China because of a sharply competitive market that has squeezed out poor quality products. Energy efficiency has actually become a selling ticket in promoting certain brands in recent years, which is not very common in the refrigerator or television markets. The intensive use of fans in the summer is perhaps viewed as a good reason for buying a more efficient fan. And technological maturity also allows manufacturers to produce energy-efficient products with low costs.

Assuming 400 hours/year operating time for each fan, at an average $60 \mathrm{~W}$ per unit, we estimate an annual electricity use of about 4 billion $\mathrm{kWh}$ for the 1989 stock. Since the saturation of fans in urban areas is already high, future increase of electricity demand from electric fans would mostly come from rural areas, where saturation is still low. Because fans are mostly used in the summer, they also contribute to summer peak loads.

\subsubsection{Rice Cookers}

No national data exist on stocks of electric cookware. To some extent, this gap reveals the lack of attention paid to these important household appliances. Electric cookers, mostly rice cookers, have been rapidly spreading all over the 
country since the mid-1980s. Recent survey data show that electric cookers have reached high saturation in many central cities. For example, the saturation rate in Guangzhou, capital of Guangdong province, was as high as 119 units per hundred households in 1989. Harbin, capital city of Heilongiang province, is one of the other six large cities that have over 80 units per hundred households saturation rate [SSB, 1989a]. It is somewhat surprising that in the three largest cities of China-Shanghai, Beijing, and Tianjin-electric cooker saturation is actually very low, registering 17,7 , and 1 per hundred households respectively in 1989. This is probably the result of stricter residential electricity control in these cities. Another major reason is the high percentage of gas-using households.

Although electric cookers may not use as much electricity as refrigerators because they often are used in a short time period, they are indeed big power machines compared to other major appliances. This again raises the issue of peak load contribution. Average rice cookers usually need $600 \mathrm{~W}$ or more power input and cook rice in about 20 minutes. The peak load pressure is high if a great many rice cookers are turned on at about the same time in the evening. The annual electricity consumption of a rice cooker is estimated at about $175 \mathrm{kWh}$, the second most important electricity user for a household that has every major appliances except an air conditioner.

\subsubsection{Clothes Washers}

Clothes washers used in China are small compared to their American counterparts. A popular model manufactured by Beijing Washing Machine Factory, Baiju XPB20-2S, has a washing capacity of $2 \mathrm{~kg}$ dry clothes and a power input of $230 \mathrm{~W}$ for the washer and $140 \mathrm{~W}$ for the spinner (an attached centrifugal spinning cylinder that extracts water from clothes). Dryers are not used by Chinese households. Like many other home appliances, clothes washers became a common commodity only recently. Production of clothes washers started at the late 1970s and reached its peak in 1988 at about 10 million units annual production. Weaker market demand had driven down the production to about 7 million units in 1990. Again, manufacturing technologies were almost exclusively imported from Japan.

The total stock of clothes washers in 1990 was 96 million units. Saturation rates for urban and rural households were 78 units and 9 units per hundred households, respectively. Assuming each household uses the clothes washer about 80 hours per year, annual electricity consumption of 1989 stock of clothes washers would be about 2 billion $k W h$.

\subsubsection{Other Items}

Other home electric appliances worth mentioning include electric irons, electricity-heated blankets, and electric water heaters. Electric irons are very 
popular now although no statistics are available. Electricity-heated blankets have a large market in southern provinces where people have to endure cold winters without space heating. Related information is not available, but electricity use for these blankets is presumably considerable.

Another major appliance yet to become popular in China is the microwave oven. Its availability in the future will depend on the scale of domestic manufacturing, which is still very limited at present. The stock of microwave ovens could rise rapidly if an increased consumers' appreciation is accompanied by expanding production-much like what was experienced in the television and refrigerator markets in the $1980 \mathrm{~s}$.

Estimates of residential electricity end uses are summarized in Table 3-7. To see the impact of the sharp increase of appliances stock, estimates for 1989 are compared to those from 1981. Since the data are not well-documented, the table only intends to show a rough division of electricity end uses in China's residential sector (including both urban and rural areas). The estimates for 1989 have each been discussed in the previous paragraphs. The estimates for 1981 have followed the rules of calculation for 1989 except for the estimate of lighting electricity use. 17

Table 3-7. Estimates of Residential Electricity End Uses, 1981 vs. 1989 in Billion kWh

\begin{tabular}{lcccccc} 
& Lighting & Refrigerators & TVs & Fans & Clothes Washers & Other \\
\hline 1981 & 10 & 0.1 & 0.5 & 0.6 & 0 & 0.6 \\
1989 & 15 & 10 & 7 & 4 & 2 & 2 \\
\hline
\end{tabular}

Table 3-7 (also see Figure 2-10) indicates a drastic change of electricity end-use structure in the 1980s brought about by the proliferation of home appliances. Most increases in electricity use came from refrigerators, televisions, and fans. Air conditioning electricity use is considered to be negligible and is lumped into the "other" category.

\subsubsection{Residential Air Conditioning}

Room air conditioners are rare in residential buildings. In addition to their high price, high operation cost is an important factor that keeps people from installing them. Various types of room air conditioners are widely available in China at a price of around $¥ 4000$ or more per unit. In contrast, the average price of a

17 Urban household lighting use in 1981 is assumed to be higher than in 1989 because until the late 1980 s meters had not been widely installed and electricity was mostly charged by counting the number of bulbs (wattage). Cheating was considered to be common. So the operating lighting power in urban households is considered to be $70 \mathrm{~W}$ instead of $60 \mathrm{~W}$. Also, rural electrification rate is considered to be lower in 1981, i.e., assumed at $60 \%$. 
popular color television set or refrigerator is about $¥ 2000$ per unit. With a few thousands watts of power input, an air conditioner could cost a family hundreds of yuans per year in electricity. In most urban areas, saturation of air conditioners is not measurable even on the scale of units per thousand households. Nevertheless, there are several cities that have shown some significant figures. Shengzhen, a prosperous southern city in the Guangdong province, has a saturation rate of 18.0 units per hundred households $(\mathrm{HH})$. Xian, a large city in the northwest, has a saturation rate of 1.3 units per $\mathrm{HH}$, and Wuhan, another large city in central China, has a saturation rate of 1.0 unit per HH [SSB, 1989b].

A recent market investigation shows that production as well as the sales of air conditioners has been increasing rapidly in recent years. For example, in Hangzhou, a city of about 1.5 million people, statistics show that in 1989 the sales volume of air conditioners was 200. The figure rose to 500 in 1990 and 13, 000 in 1991. Sales of 20,000 air conditioners were expected in 1992. According to the survey of the Ministry of Light Industry, sales volume of air conditioners reached 1 million in 1991 (including 600,000 Chinese-made and 400, 000 imported units). The figure for 1992 was estimated at 1.5 million pieces [ $\mathrm{Li}, 1992]$.

It is perhaps true that there are more room air conditioners in commercial buildings than in residential buildings because many up-scale hotels and restaurants as well as some new office buildings have installed room air conditioners.

At present, electricity demand of room air conditioners is insignificant and may not increase sharply in the near future. But the previously mentioned market survey seems to signal that the new wave of economic reforms in China has already brought about the beginning of an era in building air conditioning. The potential market for air conditioners in the residential sector is huge because the central and southern provinces, mainly the Yangzi river basin and the southern coastal areas, have very unpleasant summer weather. These provinces are the most densely populated areas in China. They also lead the country in prosperity and economic growth. By the end of this century, many urban households will have the financial means to install air conditioners if the economy continues its present growth.

Because of the acute electricity shortages in China, this trend may pose serious problems for the tightly stretched power supply sector. The government has drafted stipulations that those who want to install air conditioners must get approval by local authorities and pay an additional tax. The Ministry of Energy has suggested that air conditioner producers manufacture "energy-saving" models. The Ministry of Light Industry regards the efficient models as the key target to be supported [Li, 1992]. 
HVAC systems are rare in commercial buildings in China. They have been installed only in tourist hotels, up-scale department stores, and western-style modern office buildings, and they are not without problems. The following discussion is drawn from a study by the Institute of Air Conditioning Research of the China Building Science Academy [Wang, 1989].

Inspections of tourist hotels in the cities of Beijing, Guangzhou, and Shanghai, found that, depending on the season and location, non-lighting systems used $60-85 \%$ of the hotel's electricity. Air conditioning and ventilation are dominant electricity users in this category, comprising 50-60\% of a hotel's annual electricity use.

In this survey, the ventilation and air conditioning facilities were all imported Japanese or American products of 1970 s and 1980 s vintages. The following are some of the major energy-efficiency problems identified:

(1) Mismatches of the capacity and the load of the chillers. In designing buildings, engineers often calculate only the maximum heating or cooling load in order to have a large safety margin. Dynamic analysis of year-round energy-use patterns has not been introduced to HVAC system design, so in practice, even though a single chiller's rated efficiency is high, partial-load operation still results in a significant waste of electricity. In order to enhance the energy performance of chillers, it is important to choose the number of urits and unit capacity according to maximum cooling loads and operating times of various partial loads.

(2) Poor maintenance and management. The common operation standard among the owners of HVAC systems is based on whether the facility is working or not. It is often true that maintenance occurs only if and when the machine breaks down. Routine maintenance is important for efficient operation of chillers. It is also desirable to practice economic operation based on knowledge of indoor-outdoor temperature, humidity, and the load patterns of air conditioning during the day and the night.

(3) Lack of speed control for cooling-water pumps and the control of the numbers of operating pumps. Most present cooling systems use extra electricity because of the common problem of large cooling-water flows and small temperature differences of returning water. This problem is caused by a mismatch of cooling-water flow and cooling load. It is desirable to automatically adjust water flow when the cooling load changes. The adjustment can be achieved by installing a variable-frequency speed-control instrument on the secondary pump, which allows for continuous speed regulation. The device senses the temperature difference of returning water and responds by regulating the pump speed. Units of operating pumps can be controlled by the pump's 
upper and lower speed limit. With these adjustments, the flow of secondary cooling-water circulation is regulated according to the cooling load.

(4) Recycling heat or cold air in the vented air to pre-heat or pre-chill fresh air could be cost-effective in some cities. The cost-effectiveness of the recycling facilities varies significantly among the three cities studied. Simple pay-back times for hotels in Beijing, Shanghai, and Guangzhou are estimated at six, four, and two years. A major factor is the climatic differences among these cities.

(5) Excessive ventilation electricity use. Air compressors are the second largest electricity users after chillers in hotel HVAC systems. In general, smaller ventilation systems are more efficient than larger ones. Most of the surveyed hotels, hotel ventilation systems are small- to medium-sized, and use compressors with rated power under $20 \mathrm{~kW}$. It is estimated that, by installing dual-speed air compressors, ventilation electricity use could be reduced by onehalf, assuming two-thirds of the operating time is in an off-peak period:

(6) Excessive space conditioning. One common problem in tourist hotels is overcooling in the summer and overheating in the winter in order to avoid customer complains. A practical standard based on an international comfort scale would give better guidance to energy management in hotels. Another related problem with overheating and overcooling is the common use of old mechanical thermometers with limited temperature-adjustment ranges and insensitivity to small temperature changes. In addition, mechanical thermometers also lack self-adjustment functions that save energy when the room is not occupied or when an occupant is asleep. Saving electricity would be relatively easy if hotel management set more practical indoor temperature and humidity standards and installed multi-function. electronic thermometers.

(7) Mismatch of the capacity of transformers and the load of electric equipment. Most transformers in the studied hotels are found to be in operation at $20-30 \%$ load, which results in a large waste of energy. This again requires more careful design and operation.

(8) Insufficient insulation. Many hotels with HVAC systems do not have any better insulation than ordinary hotels. Electricity can be saved by improving the thermal integrity of the building envelope, which includes window improvement, wall and roof insulation, and other measures.

\subsubsection{Assessment of Electricity-Conservation Measures}

Because the economic evaluation is often distorted by the controlled-price system, this assessment should be considered a preliminary investigation of the cost-effectiveness of some of the major electricity-conservation measures. 


\subsubsection{Criteria of Conservation Assessment}

The same evaluation methodology used in the previous case of fuel conservation is followed here. Two kinds of evaluations are used. For each conservation measure, the cost of saved peak generating capacity (CSC) is calculated using the following formula:

$\operatorname{CSC}(¥ / \mathrm{kW})=$ Measure Cost $/(\mathrm{KW}$ Savings $\bullet$ Peak Coincidence Factor/Capacity Factor $)$

Peak coincidence factor is the proportion of equipment that is actually operating during the peak demand hours of the electric utilities, presumably from 7 A.M. to 7 P.M. (empirical data are needed for more accurate estimates). The peak power demand is also adi-usted for a capacity factor of the power plants since they may only operate wider partial capacity. The typical capacity factor for Chinese thermal power plants is about $60 \%$ and less for hydropower stations.

CSC can be compared to the cost of new power plants. Investment costs of new generating capacity vary by the fuel type and location of power plants. This study uses a composite cost often quoted in Chinese official documents that is presumably a weighted-average cost of hydro capacity, thermal capacity, and transmission lines. Nuclear power is excluded because of its insignificant share to date.

In another method, the cost of conserved electricity (CCE) is calculated by using the following formula:

CCE $(¥ / \mathrm{kWh})=$ Measure Cost $\bullet$ Capital Recovery Factor / Annual kWh Savings

The capital recovery factor (CRF) is the annual payments on a loan used to finance an efficiency measure, assuming an interest rate equal to the discount rate, and a measure life equal to the loan term (this is a conservative assumption because measure life should generally be longer than the duration of the loan). The operation and maintenance costs of conservation measures are implicitly assumed to be zero. The CCE is directly compared to residential or commercial electricity prices.

\subsubsection{Electricity Prices and the Investment Cost of Generating Capacity}

Most residential and commercial electricity users are charged a price ranging from $¥ 0.20$ to $0.28 / \mathrm{kWh}$ [SBP, 1990]. Electricity in this price range is called "lightin?" electricity because, historically, residential and commercial buildings used electricity primarily for lighting. In-plan industrial electricity or "power" electricity is often priced at less than half the residential electricity price. In this study, the electricity price of residential and commercial sectors is assumed to be approximately $¥ 0.25 / \mathrm{kWh}$ in 1990 . 
Estimates put investment costs for thermal, hydro, and nuclear power $p^{\prime}$ nnts at $¥ 1270 / \mathrm{kW}, ¥ 2250 / \mathrm{kW}$, and more than $¥ 5000 / \mathrm{kW}$, respectively, in the late 1980s. Transmission line costs were about $¥ 510 / \mathrm{kW}$ [Xia, 1989]. Costs of new power plain's have been increasing rapidly in recent years. According to a China Ministry $c$ Energy report, the composite construction cost of new power plants rose from $¥ 1746 / \mathrm{kW}$ in 1985 to $¥ 3000 / \mathrm{kW}$ in 1990 [MoE, 1991].

\subsubsection{Conservation Measures and their Cost-Effectiveness}

\section{Lighting Improvement}

Three possible electricity conservation measures-compact fluorescent lamps (CFLs), efficient fluorescent tubes, and electronic ballasts-are examined for lighting.

Compact Fluorescent Lamps. CFLs are not widely available in China at present. There are a few joint ventures produc.ng CFLs for export. Selling prices of various domestic brands are usually in the range of $¥ 30-50 /$ unit, depending on quality and additional accessories, (most come with decorative fixtures). The lamp itself (including the ballast) may only cost $¥ 20-30 /$ unit, compared with the price of an incandescent bulb at under $¥ 1 /$ unit and the cost of a fluorescent fixture at about $¥ 20 /$ set ( $¥ 5-7 /$ tube, $¥ 5 /$ ballast, $¥ 6 /$ capacitor, $¥ 1 /$ starter). Retail prices of CFLs in the U.S. range from $\$ 9$ to $\$ 20$ per unit and are dropping because of new technologies and the realization of economies of scale. If manufactured domestically, equal quality CFLs would probably sell in China for less than $¥ 50 /$ unit, which translates to about $\$ 9 /$ unit at present exchange rates and could be significantly cheaper if the economies of scale are realized. In this study, the unit price of $¥ 50 /$ unit is used. ${ }^{18}$

The author proposes that CFLs of $16 \mathrm{~W}$ (13W in the lamp and $3 \mathrm{~W}$ in the ballast) with 900 lumen be introduced into use. A $16 \mathrm{~W}$ lamp is equivalent to incandescent lamps of $60 \mathrm{~W}$. A CFL operated on a standard test cycle ( 3 hours on, $1 / 2$ hour off) lasts for 10,000 hours (up to 24,000 hours if left on continuously), 19 which translates into seven years of useful life if 4 hours/day is assumed. Thus, one CFL would be able to replace about 14 incandescent lamps (of 700 hours of life) in its lifetime. However, the very unstable voltage of China's residential and commercial electricity may shorten a CFL's life.

As Table 3-8 reveals, the cost-effectiveness of this measure ciepends on what wattage of incandescent lamps the CFLs replace. The best result is

18 Since the quality of CFLs currently sold (at relatively low price) in China is not up to par with those in the U.S., a higher price is assumed in this calculation. This makes my estimate conservative. Laboratory.

19 Information obtained from the Center for Building Science, Lawrence Berkeley 
achieved if $60 \mathrm{~W}$ incandescent lamps are replaced, which has a CCE $=¥ 0.12 / \mathrm{kWh}$ and a CSC $=¥ 545 / \mathrm{kW}$, compared to the electricity price at $¥ 0.25 / \mathrm{kWh}$ and the peak capacity cost at $¥ 3000 / \mathrm{kW}$. If only $25 \mathrm{~W}$ incandescent lampu are replaced, the cost-effectiveness is questionable, although lighting services are vastly improved. Because the production of CFLs in China is very limited at present, prices should drop significantly with increased production. In which case, introducing CFLs could be an inexpensive conservation measure. Because of the present price levels, it is hard to imagine a household spending $1 / 5$ to $1 / 4$ of its monthly income on a CFL. Innovative policies are needed to promote private installation [Gadgil and Jannuzzi, 1990].

Table 3-8. Cost-Effectiveness of Introducing 16W CFL

\begin{tabular}{lcccccc} 
& Prices & Net First Cost & $\begin{array}{c}\text { Electricity } \\
\text { Saved (a) }\end{array}$ & CSC (b) & CCE (c) & SPT (d) \\
\hline 1 CFL & $¥ 50$ & & & & & \\
14 Incandescents & $¥ 14$ & & & & & \\
$25 \mathrm{~W}$ & & $¥ 36$ & $13 \mathrm{kWh}$ & $¥ 3143 / \mathrm{kW}$ & $¥ 0.47 / \mathrm{kWh} 10 \mathrm{yrs}$ \\
$40 \mathrm{~W}$ & & $¥ 36$ & $35 \mathrm{kWh}$ & $¥ 1179 / \mathrm{kW}$ & $¥ 0.17 / \mathrm{kWh} 3.8 \mathrm{yrs}$ \\
$60 \mathrm{~W}$ & & $¥ 36$ & $64 \mathrm{kWh}$ & $¥ 643 / \mathrm{kW}$ & $¥ 0.10 / \mathrm{kWh} 2.1 \mathrm{yrs}$ \\
\hline
\end{tabular}

(a) Operate 4 hours per day and 365 days per year; (b) Peak coincidence factor $=0.9$, capacity factor $=0.6$; (c) Assume a measure life of 7 years and an interest rate of $10 \%$ per year; (d) Simple pay back time. Residential electricity price $=¥ 0.25 / \mathrm{kWh}$.

Another alternative to incandescent lamps is the screw-in, circular fluorescent lamp, which costs less than a CFL but is also less efficient. Because of the inconvenience caused by its shape and size, I consider the circular fluorescent lamps an inferior option to CFLs.

If 100 million of the estimated 500 million incandescent lamps in the residential buildings are $60 \mathrm{~W}$ units, then replacing them with the $16 \mathrm{~W}$ CFLs would save over 6 billion $\mathrm{kWh}$ of electricity per year. That is equivalent to a 1GWe thermal power plant. The potential electricity savings in commercial buildings from CFLs are considered great because hirh-wattage incandescent lamps are popular.

High-Efficiency Tubes. In commercial buildings, there is pro ably not much room left for further penetration of fluorescent fixtures. However, considerable electricity savings can still be achieved by introducing more efficient fluorescent tubes and high-efficiency ballasts. In residential buildings, fluorescent fixtures are not as attractive as CFLs because they are not much cheaper and lack versatility.

The standard fluorescent tube used in China has a rated power of 40W. There are also 20W, 25W, and $30 \mathrm{~W}$ tubes available. More efficient "TLD" type fluorescent tubes have been produced by many countries. Production scale of TLD tubes in China is unknown. A TLD fluorescent tube of $36 \mathrm{~W}$ puts out the 
same amount of lumens as a 40W TL tube. The production cost of the TLD tubes is reported to be either the same as or slightly higher than that of the older type tubes [ACEEE, 1991]. The major obstacle to wide application of TLD tubes in China where voltage variation is large-is that TLD tubes require a steady voltage of around 165 or higher.

Electronic Ballasts. Fluorescent lamps are more efficient at higher frequencies because the voltage drop at the positive electrode is reduced. Electronic ballasts have been developed for this application. In addition, the electronic ballast itself is more efficient than its magnetic predecessor. Estimates rate the electronic ballast/fluorescent lamp system $25 \%$ more efficient than the electromagnetic/fluorescent lamp system. ${ }^{20}$ The ballast/lamp system has the added benefits of reducing flicker and resisting low voltage (i.e., it can be turned on at $130 \mathrm{~V}$ ).

Since electronic ballasts can now be produced at low cost, electricity savings from this measure are presumably very cost-effective. According to one Chinese manufacturer's report, a standard fluorescent fixture (40W) that uses the electronic ballast can save $29 \mathrm{kWh}$ of electricity per year (17\% more efficient) in comparison to one that uses an electromagnetic ballast operating 10 hours a day [Zhang 1988]. The wholesale price of the electronic ballast mentioned by Zhang was $¥ 12.5$ /unit in 1986 , about $¥ 2$ more expensive than the electromagnetic ballast and capacitor set of the old fixture. At this cost, the simple payback time of installing electronic ballasts would be less than four months. The current 1993 cost of electronic ballasts is probably even lower, given that electronic products usually have had downward price trends in recent years. This would make electronic ballasts a very attractive conservation investment for users of fluorescent fixtures.

\section{Refrigerator Improvement}

Average annual electricity use of the present stock of refrigerators in China is about $400 \mathrm{kWh} /$ unit-year, which is actually a much better figure compared to typical refrigerators used in India (165-liter, $650 \mathrm{kWh} /$ unit-year) [ACEEE, 1991]. Recent imported technologies have certainly helped. The example of the Shanghai refrigera cor plant indicates that significant efficiency improvements can be achieved even with some simple measures. The measures that the Shanghai plant adopted are basically rearrangements of the original refrigerating system and should not result in significant incremental costs.

Other conservation measures include better insulation, tighter door seals, larger evaporator surface areas, more efficient compressors, and.so on. At what

20 Information obtained from the Center for Building Science, Lawrence Berkeley Laboratory. 
scale Chinese manufacturers are practicing these measures is not clear. The cost of these improvements is likely to be modest.

The success of refrigerator efficiency improvement is best illustrated by the South Korean experience. It also illustrates how rapidly improvements can take place. In 1980, the annual electricity use of a typical Korean 200-liter refrigerator was $672 \mathrm{kWh} /$ unit-year; by the end of 1986, annual electricity consumption of new 200-liter models had been reduced to $240 \mathrm{kWh} / \mathrm{unit}$ [Meyers, et al., 1990]. This reduction was achieved by a close working relationship between the Korean industry and the Korean government without any deliberate regulations or standards.

Average domestic annual sales of refrigerators in China from 1988 to 1991 was over 5 million units. If such a trend continues, by 2000, 45 million new refrigerators will be added to the present stock (fewer than 35 million in 1991). This is a major opportunity for electricity conservation. As long as conservation measures are encouraged or enforced by government policies, great efficiency improvements can be expected in a matter of a few years. After ten years of learning and imitating, it is time for the Chinese refrigerator industry to put technological renovation in the front and commit itself to energy-efficient products. The government can play an important role in guiding and helping the industry to make such an adjustment.

\section{Efficient Television Sets}

According to the U.S. experience, replacing surge protection resistors and installing additional output taps on the power supply can reduce screen power of a 13-inch B/W television set by $5 \%$ with an incremental cost of $\$ 1$ (in 1988) [Koomey, et al., 1991]. Popular Chinese sets have a screen size of 12-14 inches. Similar measures are presumably applicable to the Chinese models and would result in $1.5 \mathrm{~W} /$ unit power savings or $1.6 \mathrm{kWh} /$ unit electricity savings per year (refer to Table 3-6). If the peak coincidence factor is 0.9 for televisions and the measure cost is $¥ 6,21$ CSC of this measure would be about $¥ 2667 / \mathrm{kW}$, not a bargain if the measure cost is indeed close to $¥ 6$.

For 19 to 20 -inch color sets, the U.S. experience also shows that about $15 \%$ power reduction is achievable with an incremental cost of $\$ 7$ (in 1988) [Koomey, et al., 1991]. If the same measures are applied to similar Chinese models, we could expect about $11 \mathrm{~W} /$ unit power savings or $12 \mathrm{kWh} /$ unit electricity savings per year (refer to Table 3-6). In this case, CSC is $¥ 2545 / \mathrm{kW}$ (assuming a measure cost of $¥ 42$ ). At ten years of useful life and a 10\% discount rate, CCE would be $¥ 0.57 / \mathrm{kWh}$. Again, the cost-effectiveness of this measure depends on the actual measure cost and the time the television set is on.

21 Official exchange rate $\$ 1=¥ 5.5$. Converting the U.S. costs to Chinese costs at official exchange rate probably overestimates the real costs, so the calculation here is less informative. 


\section{POLICY ISSUES OF BUILDING ENERGY CONSERVATION}

Early attempts at energy conservation in the residential and commercial sectors were characterized by the introduction of honeycomb briquettes for use in residential buildings and fluorescent fixtures in commercial buildings. As the 1980 s began, environmental protection became a very strong incentive to diminish coal use in urban buildings and biomass use in rural buildings. The government began to allocate special funds for urban district-heating development and briquette production and for the diffusion of energy-efficient stoves in the rural area. The introduction of Energy Conservation Designing Standards for Residential Buildings (Heated Buildings) in 1986 signified the central government's serious concerns about building energy efficiency. However, our observations in the previous sections of this report reveal that Chinese residential and commercial sectors still have much to do to achieve high levels of energy efficiency. This chapter reviews past experiences in promoting building energy efficiency and discusses policy options that could strengthen this movement in the future.

\subsection{CONSERVATION POLICIES FOR RESIDENTIAL BUILDINGS}

\section{Rural Fuel Conservation}

Problems with rural residential energy-problems that the government has been continuously addressing for the past 20 years-revolve around the issue of fuel shortages. The first attempts at a solution were the waves of biogas development and small hydropower projects in the early to mid-1970s. Both have survived until the present day, but the scale and the amount of government commitment has been reduced significantly because of a more practical approach that takes into account the project's cost-effectiveness. Another solution (since the early 1980s) has been the program of diffusing efficient stoves and planting firewood trees. Improving end-use efficiency has been recognized as an important way of resolving the rural residential fuel crisis.

The early use of family biogas digesters was characterizec as a political campaign which eventually failed to produce the desired services. Many digesters were abandoned because of poor quality construction and inconvenient operating procedures. Since the mid-1980s, the design and quality of biogas digester construction have been continuously improved. With improved technical support and better materials and parts supply, the number of operating biogas digesters rebounded. Because of their multi-beneficial functions, digesters 
many cases would be an attractive investment for rural families in the southern provinces where weather conditions are favorable and feeding materials can be easily collected.

From pas: experiences, it appears unlikely that, without heavy government subsicies, rural households would invest in biogas digesters just for the sake of cooking fuel, if alternative fuels such as firewood and coal are available. The long-term strategy for biogas development should rest on its multi-objective function that brings fuel supply, sanitary improvement, and soil fertility preservation together. The practice of eco-farming that uses a biogas digester to convert wastes into organic fertilizer while also providing energy has quite a few successful examples in China [Li, 1987]. So, the evaluation of rural biogas projects has to take into account other benefits besides providing fuel.

The rural fuel crisis in China is characterized, to a large extent, by constant firewood shortages. Firewood deficits run as high as 100 million dry ton per year (actual use of 232 million ton versus sustainable harvest of 135 million ton) and contributes to soil erosion [ $\mathrm{Xu}$ and Zhang, 1990]. In addition, excess consumption of crop stalks in firewood-scarce areas also contributes to the depletion of organic matter in the soil. In the wake of the costly and, at that time, troubled biogas program, the government realized that conservation was also an alternative energy supply and launched the successful efficient-stove and treeplanting programs in the early 1980 s. By the end of that decade, about $50 \%$ of the rural households were equipped with efficient stoves of different sorts. Estimated annual savings of firewood and crop stalks were about 30 million dry ton [ $\mathrm{Xu}$ and Zhang, 1990] The future plan is to install efficient stoves (biomassburning or coal-burning) in every rural household by the end of this century.

Although the efficient-stove program has been successful, quota-driven low-quality construction appears to be a major problem in some areas. New stoves also often require more careful operation and some functions may not fit the needs of every household. In biomass-rich areas, these factors may discourage households from acquiring efficient stoves. There have been reported cases of switching back to old-fashioned stoves [Liang and $\mathrm{Gu}, 1988$ ].

A generic problem in the diffusion of efficient stoves is the lack of service support. Routine inspection and parts replacement may be needed to achieve the desired conservation levels. Commercializing the design and production of efficient stoves and marketing stoves that suit the needs of rural households in different areas would help facilitate acceptance. Stoves having multiple functions (cooking, water heating, and so forth) achieve higher efficiency and would be ideal for rural households. Research should reveal benefits such as cheaper and easier installation and more convenient operation. Development of technology for economical, small-scale briquette production is important for rural briquette programs. 
Although end-use efficiency is of great importance to China's rural energy development, it is unlikely that conservation alone can solve the problem of fuel shortages. History has shown that while people have been using more efficient equipment, they are also using more energy as the standards of living rise and their lifestyle changes. This trend of increasing energy-using activities is especially evident in the developing countries. Population growth further enforces the demand for additional residential energy supply. Thus, it is essential to develop other alternative fuel supplies. The Chinese government has shown a strong interest in planning a sustainable energy strategy for rural areas that takes into consideration regional resource distribution and puts renewable energy sources such as firewood trees, solar energy, and small hydro power at the top of alternatives for rural energy development [Xu and Zhang, 1990]. There are great challenges in transforming a rural fuel system that abounds in shortages and degrades the environment into an efficient and sustainable one that supports hundreds of millions of people. This transition would be a showcase of the strength and commitment of the government's policy toward sustainable development. International corporations are needed to bring in greater capital investment and more technological transfers.

\section{Urban Residential Fuel Conservation}

Cooking Fuel Conservation in urban areas was initially aimed at saving coal. During the 1980s; it was more and more motivated by improving indoor air quality and ambient air pollution control. The focus has been on developing town gas (either through natural gas connections or coal gasification and industrial gas) and promoting LPG. Investment in honeycomb-briquette production has also increased significantly. While gaseous fuels are now popular in many center cities, coal (in many remote urban areas, raw coal) is still the dominant cooking fuel.

Major problems in promoting gaseous fuels have been the difficulty of allocating the limited gas supply and the high costs of bringing in new supplies. Heavy price subsidies to residential gas users further deter capital investment. Honeycomb-briquette production also suffers from low prices, which has increasingly become a burden on the local governments. Also, anthracite allocation to the residential sector has been inadequate. Since fuel saving and air pollution control can be most effectively achieved through fuel switching, the long-term strategy for an urban cooking fuel supply should rest on gaseous fuels. Considering the importance of honeycomb briquettes in the near to medium term, the following options are suggested for an urban cooking-fuel policy that, in most cases, also apply to heating fuel:

- Residential anthracite should be the top priority of in-plan coal allocation. The major benefit would be reduced urban air pollution. The government should establish appropriately mandated quality standards for residential coal supply (purchased directly by householders) and an effective 
way of preventing high-sulfur and low-grade coal from entering into massively dispersed uses.

- The prices of honeycomb briquettes should be increased in order to generate enough revenue for self-supportable production expansion. Higher briquette prices will also give incentives to consumers to install more efficient stoves. Price adjustments for coal and coal products is a systematic reform. It would be difficult to raise briquette prices without raising raw coal prices.

- For urban areas where there is a high portion of residential coalusing households and where gasification is unlikely in the near future, an efficient-stove program similar to the rural model should be initiated.

- Local governments should initiate extensive studies to identify the best combination of residential fuel supplies that are both environmentally sound and economically justifiable. Attention should be given to the utilization of combustible industrial gases available in local factories.

- The prices of gaseous fuels, especially natural gas and coal gas, should be increased. Higher prices would attract more natural gas supplies to the residential sector and make some gasification projects affordable.

- The central government should help identify and support local long-term gaseous fuel supply projects. This task includes the siting of oil refineries, the routing of natural gas pipelines, and the introduction of large-scale coal gasification projects.

Heating Fuel Conservation in urban residential buildings is more economically and politically complicated than saving cooking fuels. For households that use coal stoves for space heating, saving coal complements cooking coal conservation: it depends on the householders' behavior and how much incentive they may receive from the marketplace. But for centralized space heating, energy conservation has never been an easy task although it may look more manipulative. Problems with energy conservation in centralized space heating can be attributed to two aspects, i.e., problems of the heating systems themselves (both technical and managerial) and problems of the heated buildings (heat loss because of too little insulation and other envelope defects).

Central heating management is entangled with the existing housingmanagement systems. Residential buildings that are connected to central heating facilities have three types of ownership: housing bureaus (reporting to local governments), state-owned work units, and collectively owned work units. The importance of the housing-bureau buildings has been shown in their positive performance in achieving space-heating energy efficiency. Housing bureaus in large and old cities such as Beijing and Shenyang control a large share of residential buildings while in many newly established industrial cities (constructed after 1949) they play only minor roles. 
Like housing, residential central heating in China is heavily subsidized for dwellers, who are usually employees of the state-owned work units. In cases where the work units do not have their own heating facilities, they pay for or subsidize their employees for space-heating services provided by either the local housing bureaus or co-generation companies. Residential space heating is not metered. Service charges are calculated on the basis of the number of square meters of floor space in the apartments. Residential space-heating charges range from $¥ 6-18 / \mathrm{m}^{2}$ per heating season. Residents usually pay less than $¥ 1 / \mathrm{m}^{2}$ per heating season and the rest is paid by the user's work unit [Tu and Wang, 1991]. Since residents do not pay much for heating services, there is little incentive for them to conserve. The only pressure that consumers put on the heat suppliers, whether they are housing bureaus, co-generation plants, or work units, is complaints about the insufficient heat supply. In cases where there is too much heat, residents quietly open the windows. On the other hand, heat suppliers are usually beleaguered by low heat prices and increasing operational costs caused by the rising prices of coal, electricity, and water. Tightened environmental regulations also put pressure on many boiler stations because they may have to pay various pollution fees.

Because there are no market forces to regulate inefficient practices, promoting energy efficiency of the central heating systems relies solely on administrative orders of local governments. But the effectiveness of such administrative orders has become very limited after a decade of decentralization and it is more problematic in a central heating business that has three different management systems. Housing bureaus that are sub-departments of local governments certainly take the administrative orders most seriously. This may partly explain the better energy efficiency of heating systems operated by housing bureaus. On the other hand, work units and co-generation stations, usually having their own respective central administrations, have less or little involvement with local governments, and therefore may not take administrative orders seriously. This entangled management of central heating systems is not expected to perform well when cooperative efforts are needed to achieve efficiency. For example, in many cases, work units may often need technical and managerial assistance from local housing bureaus. Also, in order to maintain a certain level of performance, local housing bureaus may send out inspection teams regularly to check on boiler stations. These practices may be difficult to carry out if present self-governed parallel management systems prevail.

In response to the energy-efficiency and air-pollution issues of space heating, the government has selected coal-fired district heating as a priority for urban space-heating development. From the experiences in the 1980s, construction of district heating systems (especially co-generation systems) is quite expensive and sometimes not able to meet the cost-effective criteria under present pricing systems and evaluation standards. A wise choice of technology for decision makers should be the one that has the greatest social, environmental, energy-efficient, and economic benefits. From the aspect of providing equal 
services with minimum pollution and high efficiency, district heating systems do have advantages over small coal-fired central heating systems and coal-fired stoves in China's heating zone. But future technological development may also make small coal-fired central heating systems attractive.

Regarding the above issues related to central heating systems, the following suggestions are considered to be helpful for improving space-heating efficiency:

- Central and local governments should allocate appropriate funds to local housing bureaus to conduct routine inspection and maintenance of the central heating systems. As we have seen in Section 3.1.1.4, scheduled repairs of malfunctioning parts or equipment in the central heating systems are essential for efficient heat supply and quality services.

- The current heat-charge system should be reformed by linking end users directly to heat suppliers. Since heat meters are very expensive at present (over $¥ 1000$ per unit), meters should be installed at the building level. Although this practice does not resolve the common-pool property problem, it is still better than the current charge scheme. A certain level of subsidy may still be needed for heat users in the short term.

- District heating systems are usually expensive projects. In considering future space-heating options, local governments should thoroughly study the costs and benefits of all available alternatives and their respective impact on the local environment. In cities that already have or are constructing extensive gas pipelines, gas heating may be a feasible choice in the long run. In the case where district heating is chosen, co-generation may have greater longterm benefits than heat-only boiler stations.

- It is important to invest in energy-efficient technologies and hardware development such as high-efficiency boiler technologies and new control devices. The government should provide adequate funds for research and development and selectively introduce advanced roreign technologies.

\section{Energy-Efficient Building Standards and Conservation Policy}

One of the major problems in complying with residential building codes is that additional funds for improving thermal performance are not often made available. Developers only want to build as many apartments as their money allows. They get no direct benefit at all from building energy-efficient buildings. Property owners such as work units, are usually swamped with demands for quantities of apartments rather than for the quality of apartments. With no mandated regilations and no explicit punishment for violations, building codes, either national or local, have had little success except in the few demonstration projects. 
Upon review, available local enforcement codes appear to be strict and sometimes creative. For example, the regulations for Beijing, which were said to be effective starting January 1,1991, require all new residential buildings constructed in the Beijing metropolitan area to conform to the local standards. Otherwise, no construction license will be issued to contractors. If field inspections identify any non-conforming practice, construction must be halted and defects fixed in a required period. If the finished buildings violate the code, the housing bureau or the property owner is not allowed to acquire them. In Xian city, a fee $\left(\because 6 / \mathrm{m}^{2}\right)$ is collected from the developer or the property owner before building construction. If the building passes the energy-efficiency inspection, the money will be returned. Otherwise, part or all of the money will be used as building energy-conservation funds depending on how many defects the building has.

There are also various kinds of tax incentives for factories that produce new building materials, such as aerated concrete and hollowed bricks, which have a better thermal performance.

In many smaller urban areas where air pollution control is not as stringent as in large cities and cities with easy access to coal, there is not as much urgency to invest in energy-efficient buildings. Enforcement of building codes in such areas will be more problematic.

Another important issue is that the present infrastructure of the construction industry is inadequate to support a full enforcement of new residential building standards. Few energy-efficient building designs are available, and architects are still catching up. Materials used in new buildings construction are either not widely available or not being produced at affordable costs. The quality of products also varies greatly. Building science research and development are still in the start-up stage. Other than residential building codes, there are almost no technical support documents or handbooks available nor inperson technical instruction at a local level. The construction industry has been performing relatively simple tasks for decades. Sudden demands to perform more complex and detailed tasks are not easily accepted nor practiced well. All these may need some time for adjustment and adaptation.

In response to problems encountered in promoting energy-efficient residential building standards, the following suggestions may need to be considered in formulating new policy measures:

- In order to provide an adequate technical and material basis for the enforcement of residential buildir.g codes, policy should help generate varieties of new energy-efficient building designs and introduce new building materials and products that fit local conditions and needs. There is much work to be done in training and instructing constructors to adopt practices required by the new designs and to use new materials. 
- Since additional funds are often hard to collect or squeeze out of constrained budgets, the central government should provide some kind of matching funds in order to attract local money to invest in efficiency measures in residential buildings. There have been some successful experiences of this kind in the industrial energy-conservation programs. Tax incentives of all sorts should be used when applicable.

- Special support should be given to the production and marketing of energy-efficient building materials. Financial and regulatory incentives are needed for this industrial subsector to become a market force and achieve economies of scale.

- Each local government should establish an inspection and enforcement body for residential building codes, (which should extend to all types of buildings in the future). Since administrative punishment is usually not very effective, violations of building codes should be explicitly tied to economic or legal responsibilities.

- Both central and local governments should significantly increase their su, pport of building sciences and technology research and development. Financial support should not be restricted to hardware development. Educational and training programs are also very important for the successful enforcement of residential building codes.

- Energy-efficient standards should be extended to buildings in the transition zone and adjusted to local climatic conditions. Special building codes for rural housing construction should also be established.

- While new building construction in the heating zone should be strictly guided by the standards, retrofitting old buildings cannot be overlooked. Government should provide householders with instructions and inexpensive materials for some basic and simple insulation work.

- There are many advanced building technologies that Chinese scientists could learn from their colleagues in the U.S. and other Western countries. Government policy should promote international exchanges and attract foreign investment in new building technologies, such as gas-filled glazing panels and super windows.

Tl.ere is a strong possibility that, on the national level, improved residential buildings will not save much energy, but will definitely improve comfort.

\section{Residential Electricity Conservation}

Residential electricity consumption was very limited until the early 1980 s. A rapid increase in appliance ownership, mostly in urban areas, has resulted in a 
three-fold growth in residential electricity use in one decade. Although residential electricity use is still less than $10 \%$ of total end-use electricity supply, it is increasing at a rapid pace. Introducing vigorous electricity-conservation measures will have a large preventive effect on future residential electricity demand, which is expected to be driven mainly by appliances. The following recommendations are considered to be important for electricity conservation in the residential sector:

- Establish national appliance-testing centers that research and formulate appliance-efficiency standards. Enforcement should be strictly carried out through the corresponding industrial ministries or departments. Many industrial products, such as boilers and electric motors, have been improved with the help of energy-efficiency standards.

- Search for innovative ways to promote residential compact fluorescent lamps (CFLs). To achieve this, large-scale domestic manufacturing of CFLs is necessary. Joint ventures with other countries should be encouraged.

- Government should actively support research and development of residential electricity-saving technologies such as efficient lighting and advanced refrigeration and cooling technologies and facilitate their transfer to industries.

\subsection{CONSERVATION POLICIES FOR COMMERCIAL BUILDINGS}

Until recently there have been limited energy-conservation efforts in commercial buildings and there is no specific conservation policy aimed at commercial buildings. For space heating, commercial buildings bear similar characteristics to residential buildings because most of them are heated by stoves. For electricity use, lighting is so far the predominant end use. However, since modern hotels and office buildings have begun to appear in major cities and in the rapidly developing coastal areas, HVAC systems could emerge as an important end use in the next 10 or 20 years. There has also been a steady increase in the use of room air conditioners in offices in recent years, so electricity use for air conditioning will increase dramatically.

In order to save coal and slectricity, there is an urgent need to improve the thermal integrity of commercial buildings. Energy-efficient commercial building codes should be established and enforced as soon as possible. Rapid economic growth in the last decade has initiated waves of construction for commercial buildings. But because of the lack of standards, even many modern hotels with HVAC systems were constructed with no better thermal insulation performance than ordinary commercial buildings found everywhere in China. If this trend continues, the high-volume construction will have a significant impact on energy demand of commercial buildings in the decades to come. Retrofitting old commercial buildings is often costly. 
Presently, there is a large stock of operating fluorescent fixtures that uses magnetic ballasts in commercial buildings. Replacing the old ballasts with the new generation electronic ballasts will result in great electricity savings. It was reported that a factory producing one million sets of electronic ballasts and efficient lamps per year was put into operation in May 1992 [People's Daily, 1992a]. Another similar factory started production in June 1992 [People's Daily, 1992b]. As shown in previous analyses, electronic ballasts have good economic benefits. Installation can be speeded up with the participation of local energyconservation centers.

Alternative fuel sources should be provided for tens of thousands of urban restaurants and cafeterias that burn raw coal directly. LPG and town gas should suit cooks' desire for a high-temperature flame and reduce air pollution as well. 


\section{CONCLUSIONS}

This report has examined major issues concerning energy use and energy efficiency in China's residential and commercial sectors. As our discussions have revealed, shortages and waste co-exist in the residential and commercial energy sectors. While many of the issues-shortages of rural residential fuel and an inadequate supply of electricity and gaseous fuels-appear to be supply-side problems, resolutions of such problems are not restricted to increasing supply. Demand-side management that stresses end-use efficiency and quality of energy services often provides cost-effective alternatives to complement the expansion of supply capacity and contributes to a better environment.

If a Western lifestyle is what China can expect in the future (trends in the last 15 years seem to support this assumption), it is quite certain that residential and commercial energy use will be greatly increased in the coming decades. Without comprehensive policies that target energy efficiency in the residential and commercial sectors, there is good chance that future energy demand will not be met at reasonable costs. In addition, there will be dangers of a continuing degradation of farm lands and forests and exacerbated urban air pollution.

As we have seen, residential conservation policy has been focused on fuel conservation-measures such as efficient stoves and district heating. This is understandable because of rural fuel shortages and serious urban air pollution. Equal emphasis should also be given to electricity conservation. When people use electricity they often see it as a clean and convenient alternative and forget the other end of the line. Electricity conservation in the residential and commercial sectors can have a great preventive effect if it deters inefficient appliances and equipmient from entering a huge, but still minimally saturated, market. Policy makers should not be hesitant about phasing in strict energyefficiency standards for appliances and other electrical equipment for buildings. Programs for diffusing efficient lighting devices should also be actively pursued.

Energy-conservation efforts in residential and commercial sectors have exposed some fundamental problems that require institutional reforms or reconstruction. There is an urgent need to pursue energy-pricing reforms that bring market forces to bear on energy conservation. To be specific, prices of briquettes and gaseous fuels should be raised as high as consumers' tolerance allows. Streamlining the management system, abolishing the welfare-like subsidizing scheme, and introducing new charging systems-besides hardware improvement-are all needed for a more efficient central heating system.

We have also seen the importance of enforcing energy-efficient building standards in the residential and commercial sectors. The effectivcness of such standards has been seriously weakened because of the lack of enforcement 
agencies and inadequate technological and building materials support. These problems have to be resolved without anymore delay. The ever-increasing building stock-with its chronically poor thermal integrity-can only create more problems in the future.

Investment in cost-effective energy-conservation programs in the residential and commercial sectors and implementing policies and regulations that overcome market barriers would bring great economic and environmental benefits to the country. Electricity conservation reduces the need to construct more power plants. Reduced direct use of coal and biomass improves indoor and ambient air quality. Capital savings come not only from reduced mining and transportation activities but also from reduced end-use energy expenditure and health-care bills. Reductions in effluent emissions also contribute to regional and global environmental protection.

There is much room for improvement in international cooperation in buildirg science research and technology transfer. It is important that the industrialized countries not only help China identify opportunities in building energy conservation but also be actively involved in capital investment that brings in cost-effective technologies and products.

The Chinese government has demonstrated its willingness to pursue economic development that minimizes environmental destruction and uses energy and other natural resources most efficiently. The successful industrial energy-conservation program and rural efficient-stove program have provided strong evidence of effective conservation policies. Future success in residential and commercial sector energy conservation will depend on continuing commitments to improving energy efficiency and innovative policies that overcome past mistakes and institutional barriers. 


\section{APPENDICES}

\section{APPENDIX}

\section{A. COSTS OF ENERGY-EFFICIENT MEASURES FOR BUILDING ENVELOPE IMPROVEMENT}

Here we consider a typical six-story 72-unit apartment building in Beijing. The basic characteristics of the building are:

- Gross area of exterior walls: $175 \mathrm{~m}^{2}$ east and west, $855 \mathrm{~m}^{2}$ north and south.

- Roof area: $570 \mathrm{~m}^{2}$.

- Areas of windows per story: $5.4 \mathrm{~m}^{2}$ east, $1.8 \mathrm{~m}^{2}$ west, $24.4 \mathrm{~m}^{2}$ south, and $31.6 \mathrm{~m}^{2}$ north; all single-glazed and steel-framed.

- Gross floor area per story: $570 \mathrm{~m}^{2}$.

- Structure of exterior wall: $370 \mathrm{~mm}$ thick brick structure plus $15 \mathrm{~mm}$ thick cement mortar layer on the inner side.

- Structure of interior wall: $15 \mathrm{~mm}$ cement mortar plus $240 \mathrm{~mm}$ brick structure plus $15 \mathrm{~mm}$ cement mortar.

- Structure of roof: from bottom up, $130 \mathrm{~mm}$ hollow concrete slab, 70 $\mathrm{mm}$ pumice stone concrete, $100 \mathrm{~mm}$ aerated concrete, and a !ayer of asphalt for water-proofing.

\section{CONSERVATION MEASURES FOR NEW BUILDINGS}

- Exterior walls: $240 \mathrm{~mm}$ brick structure plus $20 \mathrm{~mm}$ air layer plus 30 mm polystyrene boards plus $12 \mathrm{~mm}$ gypsum boards;

- Stair-facing walls: $30 \mathrm{~mm}$ pearlite cement mortar plus $140 \mathrm{~mm}$ reinforced concrete plus $30 \mathrm{~mm}$ pearlite cement mortar;

- Roof: $130 \mathrm{~mm}$ hollow concrete slab plus $170 \mathrm{~mm}$ pumice stone concrete plus $20 \mathrm{~mm}$ cement mortar plus a layer of asphalt;

- Windows: double-glazing north, west, and east windows; south windows remain single-glazed. 
1991 Budgetary Prices of Selected Building Materials: ${ }^{\dagger}$ $¥ 8 / \mathrm{m}^{2}$;

Polystyrene boards $(30 \mathrm{~mm}): \because 17 / \mathrm{m}^{2} ;$ gypsum boards $(12 \mathrm{~mm})$ :

Single-glazed window: $¥ 79 / \mathrm{m}^{2}$; double-glazed window: $¥ 144 / \mathrm{m}^{2}$;

Aerated concrete: $¥ 90 / \mathrm{m}^{3}$; pumice stone concrete: $¥ 110 / \mathrm{m}^{3}$ ；

Reinforced concrete: $¥ 260 / \mathrm{m}^{3}$; bricks: $¥ 120 / \mathrm{m}^{3}$;

Cement pearlite mortar: $¥ 220 / \mathrm{m}^{3}$; cement-sand mortar: $¥ 110 / \mathrm{m}^{3}$.

Incremental Material Costs: H

Exterior walls:

Measure Costs - Original Costs

$=\left(0.24 * 2060 \mathrm{~m}^{3} * ¥ 120 / \mathrm{m}^{3}+2060 \mathrm{~m}^{2} * ¥ 17 / \mathrm{m}^{2}+2060 \mathrm{~m}^{2} * ¥ 8 / \mathrm{m}^{2}\right)$

$-\left(0.37 * 2060 \mathrm{~m}^{3} * ¥ 120 / \mathrm{m}^{3}+0.015^{*} 2060 \mathrm{~m}^{3} * ¥ 110 / \mathrm{m}^{3}\right)=¥ 15965$.

Stair-facing walls:

Measure Costs - Original Costs

$=\left(2^{*} 0.03^{*} 200 \mathrm{~m}^{3} * 220 / \mathrm{m}^{3}+0.14^{*} 200 \mathrm{~m}^{3} * ¥ 260 / \mathrm{m}^{3}\right)-\left(2^{*} 0.015^{*} 200 \mathrm{~m}^{3} *\right.$ $\left.¥ 110 / \mathrm{m}^{3}+0.24 * 200 \mathrm{~m}^{3} * ¥ 120 / \mathrm{m}^{3}\right)=¥ 3500$.

Roof:

Measure Costs - Original Costs

$=0.1 * 570 \mathrm{~m}^{3} * ¥ 110 / \mathrm{m}^{3}+0.02 * 570 \mathrm{~m}^{3} * ¥ 110 / \mathrm{m}^{3}-0.1 * 570 \mathrm{~m}^{3} * ¥ 90 / \mathrm{m}^{3}=$ $¥ 2394$.

Windows:

Measure Costs - Original Costs $=6 * 38.8 \mathrm{~m}^{2} *\left(¥ 144 / \mathrm{m}^{2}-¥ 79 / \mathrm{m}^{2}\right)=¥ 15132$.

The total incremental cost is $¥ 36991$, or about $¥ 11 / \mathrm{m}^{2}$ gross floor area.

$\mathrm{CSC}=\left(¥ 11 . \mathrm{m}^{2}\right) /\left(7.9 \mathrm{kgce} / \mathrm{m}^{2}\right.$ savings per heating season $)=¥ 1392 /$ annual tce.

$\mathrm{CCF}=¥ 164 /$ tce, assuming a 20 -year loan term and a $10 \%$ interest rate.

Simple Payback Time (SPT) = Measure Cost/Annual Value of Saved Energy $=¥ 36991 /\left(¥ 150 / \mathrm{tce} * 7.9 \mathrm{kgce} / \mathrm{m}^{2}-\mathrm{yr}^{*} 6 * 570 \mathrm{~m}^{2 *} 0.001\right) \approx 9$ years.

+ Source: Air-Conditioning Research Institute, China Academy of Building Sciences, Beijing.

+ Source: Lang, S., 1992

t+ Other costs are omitted in this calculation. 


\section{CONSERVATION MEASURES FOR OLD BUILDINGS}

- Replacing old insulation layer of exterior walls and stairway walls with a $30 \mathrm{~mm}$ thick layer of cement pearlite mortar;

- Insulating the opaque part of balcony doors; double glazing all windows.

Incremental Material Costs:

Walls $-0.03^{*}(2060+200) \mathrm{m}^{3} * ¥ 220 / \mathrm{m}^{3}=¥ 14916$.

Windows $-6^{*} 63.2^{*}\left(¥ 144 / \mathrm{m}^{2}-¥ 79 / \mathrm{m}^{2}\right)=¥ 24648$.

Neglecting the cost of door insulation, the total incremental cost of materials would be $¥ 39564$, or $¥ 12 / \mathrm{m}^{2}$.

$\mathrm{CSC}=\left(¥ 12 / \mathrm{m}^{2}\right) /\left(6.2 \mathrm{kgce} / \mathrm{m}^{2}\right.$ savings per heating season $)=¥ 1935 /$ annual tce.

$\mathrm{CCF}=¥ 227 / \mathrm{tce}$, assuming a 20 -year loan and $10 \%$ interest rate.

$\mathrm{SPT}=¥ 39564 /\left(¥ 150 / \mathrm{tce} * 6.2 \mathrm{kgce} / \mathrm{m}^{2}-\mathrm{yr} * 6 * 570 * 0.001\right) \approx 12$ years. 


\section{APPENDIX \\ B. CASE STUDY: A DEMONSTRATION OF ENERGY-EFFICIENT RESIDENTIAL BUILDING STANDARD}

This case study is a summary of Liu Yirong and Zhu Wenpeng's report: An Yuan Bei Li Residential District-An Eizergy-Efficient Building Project in Beijing.

The An Yuan Bei Li demonstration project consists of 17 buildings, including one six-story and seven 25-story residential buildings, one middle-school building, one primary-school builcling, one pre-school building, two shopping buildings, one office building, and a few miscellaneous small buildings. Total gross floor area is 132 thousand square meters. Residential floor area is 113 thousand square meters.

\section{Building Design Guidelines} rules:

The design of the An Yuan Bei Li buildings followed the following general

- Maximize passive solar heat gain in the winter. About $94 \%$ of the master bedrooms of all apartments are situated toward the south. All middle-school classrooms and $67 \%$ of primary-school classrooms look southward.

- Restrict the shape coefficients of buildings. In fact, the shape coefficients of all residential buildings ( 0.29 -twenty-five story; 0.33 -six story) are significantly lower than the upper limit (0.45) prescribed in the Beijing residential building standard.

- Restrict the window-to-wall area ratio. The Beijing residential building standard requires the window-to-wall area ratio be no greater than $20-35 \%$, depending on the direction of the windows.

- Utilize district heating. The project uses heat provided by an adjacent heat station powered by a $35 \mathrm{ts} / \mathrm{h}$ boiler. Two mains are used to connect the heat station and the project. Since the heat source is close by, construction costs of distribution network are low.

\section{Energy-Efficient Building Measures}

- Insulation of exterior walls: Polystyrene boards plus gypsum boards are applied to exterior walls of all residential buildings. The structure of the exterior walls of the 25-story residential buildings consists of a $250 \mathrm{~mm}$ concrete structure plus a $20 \mathrm{~mm}$ layer of air plus a $30 \mathrm{~mm}$ layer of polystyrene boards plus a $12 \mathrm{~mm}$ layer of gypsum boards from the outside to the interior. 
- Windows: Steel-frame single-glazed windows with tight seals are the most popular windows installed in the residential buildings. Some doubleglazed windows are also installed, but they cost twice as much as the singleglazed ones.

- Balcony doors: The steel part of the balcony door is insulated with $20 \mathrm{~mm}$ polystyrene boards.

- Roofs: Insulation layer of all building roofs is increased. Four types of combinations are used. The roof structure of the 25-story residential buildings consists of, from top down, a $10 \mathrm{~mm}$ waterproof layer, a $20 \mathrm{~mm}$ cement mortar layer, a layer of $50 \mathrm{~mm}$ concrete boards, a $50 \mathrm{~mm}$ air layer, a $150 \mathrm{~mm}$ aerated concrete layer, a $100 \mathrm{~mm}$ layer of cement slabs, and a layer of $130 \mathrm{~mm}$ hollow concrete slabs.

- Ground floor insulation: A layer of $50 \mathrm{~mm}$ polystyrene boards is applied to the ground floor of the 25-story buildings.

\section{The Central Heating System}

The station has a microcomputer to control boiler combustion. Operational efficiency of the $35 \mathrm{ts} / \mathrm{h}$ Loiler is above $80 \%$.

A synthetic plastic foam material is used to insulate the branch pipes of the distribution network. This new insulation material provides better strength and water resistance and enables direct underground burial that reduces construction costs significantly. The new insulation also reduces heat loss by $50 \%$ compared to conventional insulation.

A flow valve is installed at the heat inlet of each building. This addition allows better adjustment of the hydraulic balance of the distribution system.

\section{Monitoring Results}

Eight rooms of a twenty-five-story building are monitored and compared with rooms of a similar building in an adjacent district constructed without conservation measures. The measured seasonal heat load of the energy-efficient building is $22 \mathrm{~W} / \mathrm{m}^{2}$, compared to $36 \mathrm{~W} / \mathrm{m}^{2}$ of the reference building. This translates to about $10 \mathrm{kgce} / \mathrm{m}^{2}$ seasonal coal savings in Beijing.

Calculations also reveal that the six-story residential building in An Yuan Bei Li district saves about $8 \mathrm{kgce} / \mathrm{m}^{2}$ coal per season compared to similar buildings without efficiency measures.

\section{Economic Evaluation}

According to Liu and $\mathrm{Zhu}$, for the twenty-five-story buildings, incremental cost due to energy efficient measures is about $¥ 5 / \mathrm{m}^{2}$, about $1 \%$ of the total cost. 
The incremental cost for energy-efficient measures of the six-story building is about $¥ 20 / \mathrm{m}^{2}$, about $6 \%$ of the total cost. Prices are presumably in 1990 values.

For the twenty-five-story buildings,

$\mathrm{CSC}=\left(¥ 5 / \mathrm{m}^{2}\right) /\left(10 \mathrm{kgce} / \mathrm{m}^{2}\right.$ per season $)=¥ 500 /$ annual tce;

$\mathrm{CCF}=¥ 500 * 0.1175 /$ tce $=¥ 59 /$ tce, assuming a 20 -year loan and $10 \%$ interest rate;

$\mathrm{SPT}=\left(¥ 5 / \mathrm{m}^{2}\right) /\left(¥ 150 * 10 \mathrm{kgce} / \mathrm{m}^{2}-\mathrm{yr} * 0.001\right) \approx 3 \mathrm{yrs}$.

For the six-story building,

$\mathrm{CSC}=\left(¥ 20 / \mathrm{m}^{2}\right) /\left(8 \mathrm{kgce} / \mathrm{m}^{2}\right.$ per season $)=¥ 2500 /$ annual tce;

CCF $=¥ 2500^{*} 0.1175 /$ tce $=¥ 294 /$ tce, assuming a 20 -year loan and $10 \%$ interest rate;

$$
\mathrm{SPT}=\left(¥ 20 / \mathrm{m}^{2}\right) /\left(¥ 150 * 8 \mathrm{kgce} / \mathrm{m}^{2}-\mathrm{yr} * 0.001\right) \approx 17 \mathrm{yrs} .
$$

\section{Conclusions}

As the above data and calculations reveal, application of energy-efficient building standards to high-rise residential buildings is very cost-effective, resulting in a simple payback time of three years. Cost of conserved fuel is about $¥ 60 /$ tce, far less than the coal price of $¥ 150 /$ tce.

The case for the six-story building needs to be investigated more carefully. Although the $6 \%$ increase in construction costs for energy efficiency is close to the official limit of $5 \%$, it is very unfavorable compared to the case of the 25-story buildings. The simple payback time also seems to be too long. Since six-story or slightly higher buildings are very popular, it is important to identify costeffective energy-efficient measures in these buildings. 


\section{APPENDIX}

\section{DATA USED FOR FIGURES IN THE REPORT}

Figure 2-1. The Pattern of Sectoral Final Fuel Use ${ }^{\dagger}$, (Mtce) 1980-1990

\begin{tabular}{lcccccc} 
& Res. Biomass & Res. Modem & Commercial & Industrial & Agricultural & Transportation \\
\hline 1980 & 228.7 & 87.4 & 16.2 & 267.4 & 20.1 & 38.5 \\
1981 & 233.7 & 91.4 & 16.3 & 255.9 & 19.7 & 38.5 \\
1982 & 238.8 & 93.8 & 16.9 & 268.5 & 20.1 & 40.5 \\
1983 & 244.0 & 98.8 & 18.4 & 287.6 & 21.0 & 42.7 \\
1984 & 249.4 & 106.2 & 19.9 & 309.1 & 23.0 & 45.8 \\
1985 & 254.8 & 118.2 & 21.1 & 332.7 & 23.4 & 49.8 \\
1986 & 260.4 & 120.8 & 22.0 & 354.6 & 24.8 & 54.0 \\
1987 & 266.1 & 126.3 & 23.1 & 380.2 & 25.4 & 56.6 \\
1988 & 272.0 & 134.7 & 26.6 & 414.6 & 26.6 & 60.0 \\
1989 & 277.4 & 132.6 & 27.7 & 416.5 & 25.9 & 61.9 \\
1990 & 283.0 & 130.4 & 28.6 & 414.4 & 25.9 & 62.0. \\
\hline
\end{tabular}

+ Includes co-generation heat.

Source: Derived from data in SSB, 1990b; 1992b (methods described in Sinton, et al, 1992); Xu and Zhang, et al., 1990.

Figure 2-2. The Pattern of Sectoral Electricity Use (Billion kWh), 1980-1990

\begin{tabular}{lccccc} 
& Residential & Commercial & Industrial & Agricultural & Transportation \\
\hline 1980 & 10.5 & 8.6 & 185.2 & 27.0 & 2.7 \\
1981 & 11.8 & 9.3 & 188.4 & 28.2 & 2.9 \\
1982 & 12.1 & 10.2 & 202.1 & 28.6 & 3.0 \\
1983 & 13.7 & 11.3 & 218.4 & 28.6 & 3.6 \\
1984 & 15.9 & 12.9 & 234.0 & 28.8 & 4.1 \\
1985 & 22.3 & 16.0 & 246.2 & 31.7 & 6.3 \\
1986 & 24.8 & 16.8 & 273.0 & 32.2 & 6.7 \\
1987 & 28.7 & 19.8 & 299.3 & 36.0 & 7.7 \\
1988 & 34.3 & 22.8 & 327.9 & 37.9 & 9.0 \\
1989 & 39.5 & 24.9 & 345.2 & 41.1 & 9.9 \\
1990 & 48.1 & 27.9 & 361.6 & 42.7 & 10.6 \\
\hline
\end{tabular}

Source: SSB, 1990b; $1992 \mathrm{~b}$. 
Figure 2-3. Residential Energy Use by Energy Source (Mtce), 1980-1990

\begin{tabular}{lcccccc} 
& Biomass (a) & Coal (b) & Kerosene & Gaseous Fuel (c) & Heat (d) & Electricity \\
\hline 1980 & 228.7 & 82.6 & 1.5 & 1.7 & 1.6 & 4.3 \\
1981 & 233.7 & 86.3 & 1.7 & 1.8 & 1.6 & 4.8 \\
1982 & 238.8 & 88.9 & 1.5 & 1.8 & 1.6 & 4.9 \\
1983 & 244.0 & 93.3 & 1.8 & 2.0 & 1.7 & 5.5 \\
1984 & 249.4 & 99.8 & 2.2 & 2.4 & 1.8 & 6.4 \\
1985 & 254.8 & 111.6 & 1.8 & 2.9 & 1.9 & 9.0 \\
1986 & 260.4 & 113.0 & 2.0 & 3.6 & 2.2 & 10.0 \\
1987 & 266.1 & 117.7 & 1.9 & 4.0 & 2.7 & 11.6 \\
1988 & 272.0 & 125.1 & 1.8 & 5.2 & 2.6 & 13.9 \\
1989 & 277.4 & 121.7 & 1.9 & 6.2 & 2.8 & 16.0 \\
1990 & 283.0 & 119.2 & 1.5 & 6.6 & 3.1 & 19.4 \\
\hline
\end{tabular}

(a) Figures are linearly extrapolated from 1979 and 1987 data. Biomass includes mostly firewood and crop stalks. (b) Includes raw coal and briquettes. (c) Includes LPG, natural gas, and gases derived from coal. (d) Co-generated heat for district heating.

Source: SSB 1992b; Xu and Zhang, et al., 1990.

Figure 2-4. Energy Use by Energy Source in the Commercial Sector (Mtce), 1980-1990

\begin{tabular}{lllllc} 
& Coal & Oil & Gas & Cogen. Heat & Electricity \\
\hline 1980 & 11.1 & 4.1 & 0.3 & 0.7 & 3.5 \\
1981 & 11.7 & 3.6 & 0.3 & 0.7 & 3.8 \\
1982 & 12.6 & 3.5 & 0.2 & 0.7 & 4.1 \\
1983 & 13.8 & 3.7 & 0.2 & 0.7 & 4.6 \\
1984 & 15.7 & 3.3 & 0.2 & 0.8 & 5.2 \\
1985 & 16.6 & 3.9 & 0.3 & 0.3 & 6.5 \\
1986 & 17.6 & 3.7 & 0.4 & 0.3 & 6.8 \\
1987 & 18.4 & 3.8 & 0.5 & 0.4 & 8.0 \\
1988 & 20.4 & 5.2 & 0.5 & 0.5 & 9.2 \\
1989 & 20.8 & 6.0 & 0.5 & 0.4 & 10.1 \\
1990 & 21.8 & 5.6 & 0.5 & 0.5 & 11.3 \\
\hline
\end{tabular}

Source: SSB 1990b; 1992b. 
Figure 2-5. Residential and Commercial Fuel Use by Building Category (Mtce), 1980-1990

\begin{tabular}{lcccc} 
& Rural Res/Bio & Rural Res/Modern & Urban Residential & Commercial \\
\hline 1980 & 228.7 & 37.6 & 50.0 & 16.2 \\
1981 & 233.7 & 39.3 & 52.2 & 16.3 \\
1982 & 238.8 & 40.4 & 53.6 & 16.9 \\
1983 & 244.0 & 42.5 & 56.4 & 18.4 \\
1984 & 249.4 & 45.8 & 60.5 & 19.9 \\
1985 & 254.8 & 51.0 & 67.3 & 21.1 \\
1986 & 260.4 & 51.1 & 69.9 & 22.0 \\
1987 & 266.1 & 54.8 & 71.6 & 23.1 \\
1988 & 272.0 & 59.7 & 75.0 & 26.6 \\
1989 & 277.4 & 59.3 & 73.3 & 27.7 \\
1990 & 283.0 & 57.0 & 73.4 & 28.6 \\
\hline
\end{tabular}

Source: SSB, 1990b; $1992 b$.

Figure 2-6. Residential and Commercial Electricity Use by Building Category (Billion kWh), 1980-1990

\begin{tabular}{lccc} 
& Rural Residential & Urban Residential & Commercial \\
\hline 1980 & 4.4 & 6.1 & 8.6 \\
1981 & 4.9 & 6.9 & 9.3 \\
1982 & 5.1 & 7.0 & 10.2 \\
1983 & 5.8 & 8.0 & 11.3 \\
1984 & 6.7 & 9.2 & 12.9 \\
1985 & 10.0 & 12.3 & 16.0 \\
1986 & 10.4 & 14.4 & 16.8 \\
1987 & 12.4 & 16.2 & 19.8 \\
1988 & 14.9 & 19.4 & 22.8 \\
1989 & 17.0 & 22.5 & 24.9 \\
1990 & 20.9 & 27.2 & 27.9 \\
\hline
\end{tabular}

Source: SSB, 1990b; $1992 b$. 
Figure 2-7. Urban Residential Energy Mix (Mtce), 1980-1990

\begin{tabular}{lccccccc} 
& Raw Coal (a) & Briquettes (a) & Kerosene & LPG & Town Gas (b) & Cogen. Heat & Electricity \\
\hline 1980 & 33.2 & 13.2 & 0.1 & 0.7 & 1.0 & 1.6 & 2.5 \\
1981 & 34.3 & 14.3 & 0.1 & 0.8 & 1.0 & 1.6 & 2.8 \\
1982 & 34.4 & 15.5 & 0.1 & 0.8 & 1.0 & 1.6 & 2.8 \\
1983 & 35.7 & 16.8 & 0.1 & 1.0 & 1.0 & 1.7 & 3.2 \\
1984 & 38.0 & 18.2 & 0.1 & 1.0 & 1.4 & 1.8 & 3.7 \\
1985 & 42.7 & 19.7 & 0.1 & 1.6 & 1.3 & 1.9 & 5.0 \\
1986 & 43.0 & 20.9 & 0.2 & 2.0 & 1.6 & 2.2 & 5.9 \\
1987 & 42.6 & 22.2 & 0.1 & 2.1 & 1.9 & 2.7 & 6.6 \\
1988 & 43.4 & 23.6 & 0.2 & 2.3 & 2.9 & 2.6 & 7.9 \\
1989 & 39.1 & 25.1 & 0.1 & 2.6 & 3.6 & 2.8 & 9.1 \\
1990 & 36.9 & 26.6 & 0.2 & 2.7 & 3.9 & 3.1 & 11.0 \\
\hline
\end{tabular}

(a) Figures are linear extrapolation of 1981, 1985, and 1988 data. Raw coal use is calculated by subtracting briquettes consumption from total coal use. (b) Town gas includes natural gas and gases derived from coal.

Source: SSB, $1992 b$.

Figure 2-8. Per Capita Residential Energy Use, Rural vs. Urban (kgce/person), 1990

\begin{tabular}{ccccccc} 
& Biomass & Coal & Kerosene & Gas & Co-gen. Heat Electricity \\
\hline Rural & 336 & 67 & 2 & 0 & 0 & 10 \\
Urban & 0 & 207 & 1 & 22 & 10 & 36 \\
\hline
\end{tabular}

Source: Derived from data in SSB, 1992b, Xu and Zhang, et al., 1990.

Figure 2-9. Pattern of Eneray End-Use in Residential Buildings, China vs. USA, (\%) 1988

\begin{tabular}{lccccc} 
& Space Heating & Water Heating & Cooking & Lighting & Appliances \\
\hline Rural China & 29.6 & negligible & 68.1 & 1.9 & 0.4 \\
Urban China & 45.3 & negligible & 45.2 & 1.9 & 7.6 \\
USA & 40.0 & 16.5 & 4.8 & 6.4 & 32.2 \\
\hline
\end{tabular}

Source: China/detailed information in Tables 3-1 and 3-6; USA/Data base, International Energy Studies, Lawrence Berkeley Laboratory, 1991. 
Figure 2-12. Household Structure in China, 1982 and 1990 (million households)

\begin{tabular}{ccccccc} 
& One Perron & Two Persons & Three Persons & Four Persons & Five Persons & Six and Above \\
\hline 1990 & 17.355 & 30.605 & 65.718 & 71.51 & 49.114 & 42.608 \\
1982 & 17.55 & 22.181 & 35.313 & 43.01 & 40.39 & 62.712 \\
\hline
\end{tabular}

Source: SSB, 1989a; $1992 \mathrm{a}$.

Figure 2-13. The Trend of Urban Ownership of Appliances, 1981-1991 (units per hundred households)

\begin{tabular}{lccccc} 
& Fans & E/W TV & Color TV & Clothes Washer & Refrigerator \\
\hline 1981 & 43 & 57 & 0.6 & 6 & 0.2 \\
1982 & 53 & 72 & 1 & 16 & 0.7 \\
1983 & 64 & 81 & 3 & 29 & 2 \\
1984 & 66 & 82 & 5 & 40 & 3 \\
1985 & 74 & 67 & 17 & 48 & 7 \\
1986 & 90 & 65 & 27 & 60 & 13 \\
1987 & 104 & 65 & 35 & 67 & 20 \\
1988 & 118 & 59 & 44 & 73 & 28 \\
1989 & 129 & 56 & 51 & 76 & 36 \\
1990 & 135 & 52 & 59 & 78 & 42 \\
1991 & 143 & 44 & 68 & 80 & 49 \\
\hline
\end{tabular}

Source: SSB, 1992a.

Figure 2-14. The Trend of Rural Ownership of Appliances, 1985-1990; (units per hundred households)

\begin{tabular}{lccccc} 
& Fans & B/W TV & Color TV & Cothes Washer & Refrigerator \\
\hline 1985 & 10 & 11 & 1 & 2 & 0.1 \\
1986 & 14 & 17 & 2 & 3 & 0.2 \\
1987 & 20 & 22 & 2 & 5 & 0.3 \\
1988 & 28 & 29 & 3 & 7 & 0.6 \\
1989 & 34 & 34 & 4 & 8 & 0.9 \\
1990 & 41 & 40 & 5 & 9 & 1.2 \\
1991 & 53 & 47 & 6 & 11 & 1.6 \\
\hline
\end{tabular}

Source: SSB, 1991. 
Figure 3-1. Refrigerator Saturation in Selected Major Cities (units per hundred households), 1982, 1985, 1989

\begin{tabular}{lccc} 
& 1982 & 1985 & 1989 \\
\hline Chengdu & 0.7 & 8.7 & 60.3 \\
Guangzhou & 4.0 & 42.7 & 82.3 \\
Shanghai & 0.4 & 19.8 & 85.0 \\
Beijing & 2.7 & 41.9 & 89.4 \\
\hline
\end{tabular}

Source: SSB, $1989 \mathrm{~b}$. 


\section{APPENDIX}

D. CONVERSION FACTORS

\author{
Raw Coal \\ Coke \\ Coal Equivalent (Standard Coal) \\ Crude Oil \\ Fuel Oil \\ Kerosene \\ Gasoline \\ Diesel \\ LPG \\ Refinery Dry Gas \\ Natural Gas \\ Coke Oven Gas ${ }^{\dagger}$
}

Electricity $\#$
$20.91 \mathrm{GJ} / 1000 \mathrm{~kg}$

$28.44 \mathrm{GJ} / 1000 \mathrm{~kg}$

$29.31 \mathrm{GJ} / 1000 \mathrm{~kg}$

$41.82 \mathrm{GJ} / 1000 \mathrm{~kg}$

$41.82 \mathrm{GJ} / 1000 \mathrm{~kg}$

$43.07 \mathrm{GJ} / 1000 \mathrm{~kg}$

$43.07 \mathrm{GJ} / 1000 \mathrm{~kg}$

$42.65 \mathrm{GJ} / 1000 \mathrm{~kg}$

$50.18 \mathrm{GJ} / 1000 \mathrm{~kg}$

$46.00 \mathrm{GJ} / 1000 \mathrm{~kg}$

$38.93 \mathrm{GJ} / 1000 \mathrm{~m}^{3}$

$16.73 \mathrm{GJ} / 1000 \mathrm{~m}^{3}$

$11.84 \mathrm{GJ} / 1000 \mathrm{kWh}$

+ There is small amount of other type coal gas (gas derived from coal or oil) in China. For simplicity they are all treated as coke oven gas in the report in terms of heating value conversion.

t+ Electricity is converted into its primary energy equivalent according to then average thermal power plant efficiency. 


\section{REFERENCES}

American Council for an Energy-Efficient Economy (ACEEE). 1991. "Opportunities for Improving End-Use Electricity Efficiency in India," Washington, D.C.: ACEEE, Draft Report.

China Energy Research Society. 1991. Selected Articles on Urban Energy Use (in Chinese), Beijing.

Chen, Didi. 1991. Summary of Energy Consumption Data of Urban Buildings. Studies of Techno-Economic Policies of Building Energy Conservation (in Chinese), State Planning Commission and Ministry of Construction, Beijing.

Department of Energy (DOE). 1991. Annual Energy Review 1991, Energy Information Administration, Washington, D.C.

Department of Energy/Energy Information Agency (DOE/EIA). 1987. Housing Characteristics 1987, DOE/EIA-0314(87), Washington, D.C.

DOE/EIA, 1987. Characteristics of Commercial Buildings 1986. DOE/EIA0246(86), Washington, D.C.

Economic Report Daily. 1991. October 4, 1991. Beijing.

Gagil, A.J., Jannuzzi, G.M., 1990, Conservation Potential of Compact Fluorescent Lamps in India and Brazil, LBL-27210 Rev., Lawrence Berkeley Laboratory, Berkeley, CA.

He, Liang. 1988. "Critical Review on the Development of Rural Household Biogas Digesters, "Energy Journal No. 4 (in Chinese), Beijing, 1988.

Jiang, Zhengping. 1991. Urban Energy Use in China, Selected Papers on Urban Energy Use in China (in Chinese), China Energy Research Society, Beijing.

Koomey, Jonathan G. et al. 1991. "The Potential for Electricity Efficiency Improvements in the U.S, Residential Sector," Lawrence Berkeley Laboratory Report LBL-30477, Lawrence Berkeley Laboratory, Berkeley, CA.

Lang, Siwei. 1988. "Energy Use in Chinese Buildings," Proceedings of the ChineseAmerican Symposium on Energy Markets and the Future of Energy Demand, Lawrence Berkeley Laboratory Report LBL-26260, Lawrence Berkeley Laboratory, Berkeley, CA. 
Lang, Siwei. 1991. Preliminary Analysis of Space Heating Design Goals of "Energy-Efficient Design Standards for Residential Building." Studies of TechnoEconomic Policies of Building Energy Conservation, State Planning Commission and Ministry of Construction, Beijing.

Lang, Siwei. 1992. Personal Communication. Air-conditioning Research Institute, China Academy of Building Sciences, Beijing.

Lang, Siwei, Fan, Youchen, and Xu, Xuancai. 1991. Application of Passive Solar Technique to Multi-Story Residential Buildings in the Middle-to-Lower Reach Region of Yangtzi River, Joumal of Solar Energy (in Chinese), Vol. 12, No. 2, Beijing.

Lang, Siwei and Huang, Y.J. 1992. "Energy Conservation Siandard for Space Heating in Chinese Urban Residential Buildings," Energy - the International Journal, ,Pergamon Press, Great Britain, in press.

$\mathrm{Li}$, Qiuhui. 1987. Eco-Farming Is the Resolution of Rural Energy Problems, Energy Journal, No. 4 (in Chinese), Beijing.

Li, Qingyuan. 1992. China Market No. 7, Economic Information \& Agency, Hong Kong.

Liang, Baofen and $\mathrm{Gu}$, Shuhua. 1988. Diffusion of Efficient Stoves and Energy Conservation, Energy Future and New Energy Conservation Technology, (in Chinese), Academic Journal Press, Beijing.

Liu, Zhiping, and Qin, Shiping. 1988 , Evaluation of Energy Conservation Projects, Selected Articles on Energy Conservation in the Sixth Five-Year Plan (in Chinese), Editors: Wang, Bangcheng, and Xin, Dingguo, Energy Press, Beijing.

Liu, Yirong and Zhu, Wenpeng. 1991. An Yuan Bei Li Residential District-An Energy Efficient Building Project in Beijing. Studies of Techno-Economic Policies of Building Energy Conservation, State Planning Commission and Ministry of Construction, Beijing.

Liu, Feng, Davis, William B., and Levine, Mark D. 1992. An Overview of Energy Supply and Demand in China, Lawrence Berkeley Laboratory Report No. LBL32275, UC-350, Lawrence Berkeley Laboratory, Berkeley, CA.

Meyers, Stephan, et al. 1990. Energy Efficiency \& Household Electric Appliances in Developing and Newly Industrialized Countries, LBL- 29678, Lawrence Berkeley Laboratory, Berkeley, CA.

Ministry of Urban and Rural Construction (MoURC) 1987. Yearbook of China Urban Construction 1986/1987 (in Chinese), Beijing.

Ministry of Energy (MoE). 1990a. Energy in China, Beijing. 
MoE. 1990b. Electricity Power Industry in China, Ministry of Energy and Ministry of Water Resources, Beijing.

MoE, 1991. Problems of Energy Industry in the Seventh Five-Year Plan and Prospects in Ten Years, Energy of China, No. 3 (in Chinese), (Planning Department) Beijing.

Ministry of Goods and Materials (MoGM). 1988. Fuel Distribution in China (in Chinese), Harbin Industrial University Press, Harbin.

OECD, International Energy Agency. 1991. Energy Balances of OECD Countries 1980-1989, Publications Service, OECD, Paris.

People's Daily, 1991. Overseas Edition, July 4, 1991.

People's Daily. 1992b. Overseas Edition, June 4, 1992.

People's Daily, 1992c. Overseas Edition, August 5, 1992.

Qin, Huahu and Shen, Kai. 1991. Present Status and Future Outlook of China's Building Insulation Materials Production, Studies of Techno-Economic Policies of Building Energy Conservation, State Planning Commission and Ministry of Construction, Beijing.

Qin, Shipin and Xin, Dingguo. 1989. Analysis of Energy Conservation Projects (in Chinese), Energy Press, Beijing.

Qiu, Daxiong, et al. 1991. The Planning and Practice of Comprehensive Rural Energy Development (in Chinese), Tsinghua University Press, Beijing.

Sathaye, Jayant. 1993, Personal Communications, Lawrence Berkeley Laboratory, Berkeley, CA.

Schipper, Lee. 1993, Personal Communications, Lawrence Berkeley Laboratory, Berkeley, CA.

Sinton, Jonathan E. 1992, Indoor Air Pollution in China, Master's Project, Energy and Resources Group, University of California at Berkeley.

Sinton, Jonathan E. (eds.) et al. 1992., China Energy Databook, Lawrence Berkeley Laboratory Report LBL-32822, UC-350, Lawrence Berkeley Laboratory, Berkeley, CA.

SBP (State Bureau of Prices). 1990. China Yearbook of Prices (in Chinese), Beijing.

SSB (State Statistical Bureau). 1989a. China Population Statistics Yearbook 1989 , (in Chinese), Beijing. 
SSB. 1989b. National Survey of Income and Expenditure of Urban Households, 1982-1989 (in Chinese), Beijing.

SSB. 1990a. China Yearbook of Commodity Prices 1990 (in Chinese). China Statistics Press, Beijing.

SSB. 1990b. Energy Statistical Yearbook of China 1989 (in Chinese), Beijing.

SSB. 1991. Statistical Yearbook of China 1991 (SYC, 1991), Beijing.

SSB. 1992a. Statistical Yearbook of China 1992, Beijing.

SSB. 1992b. Energy Statistical Yearbook of China 1991 (in Chinese), Beijing.

Tu, Fengxiang and Li, Aixin. 1991. Comparison of Space Heating Requirements Between China and the Developed Countries, Studies of Techno-Economic Policies of Building Energy Conservation, State Planning Commission and Ministry of Construction, Beijing.

Tu, Fengxiang, Li, Aixing, and Shen, Jijun. 1991. Analysis of Heating Energy Consumption in Buildings (in Chinese), Studies of Techno-Economic Policies of Building Energy Conservation, State Planning Commission and Ministry of Construction, Beijing.

Tu, Fengxiang and Wang, Meijun. 1991. Energy Conservation in Buildings, Studies of Techno-Economic Policies of Building Energy Conservation, State Planning Commission and Ministry of Construction, Beijing.

Wang, Xunchang. 1989. Analysis of Energy Use in Tourist Hotels and Conservation Measures (in Chinese), report for internal circulation.

Wen, Li. 1991. Present Status of Space Heating by Boilers, Studies of TechnoEconomic Policies of Building Energy Conservation, State Planning Commission and Ministry of Construction, Beijing.

World Bank. 1991. China, Efficiency and Environmental Impact of Coal Use, Report No. 8915 CHA.

Xia, Meixiou. 1989. Electricity Pricing and Its Crisis, Energy of China, No. 1 Beijing.

Xu, Xichuen, Zhang, Zhengming, et al. 1990. National Rural Energy Planning (in Chinese), China Standard Press, Beijing.

Yang, Shanqing and Bai, Yuzheng. 1991. Major Factors that Influence Residential Heating Energy Use, Studies of Techno-Economic Policies of Building Energy Conservation, State Planning Commission and Ministry of Construction, Beijing. 
Zhang, Youliang, Bi, Jiang, and Xiang, Jei. 1990. The Research and Development of Household Appliances of Low Energy Consumption, Proceedings of the International Conference on Power \& Energy in China, Beijing.

Zhang, Shixiong, 1988, High Efficiency Preheat Type Electronic Ballast, Energy Journal (in Chinese), No.1, 1988, Energy Press, Beijing.

Zhou, Fengqi, Qu, Shiyuan, and Rong, Tao, 1989, Sectoral Energy Demand Analysis of China - the Application of MEDEE-S Model, Energy Press, Beijing. 

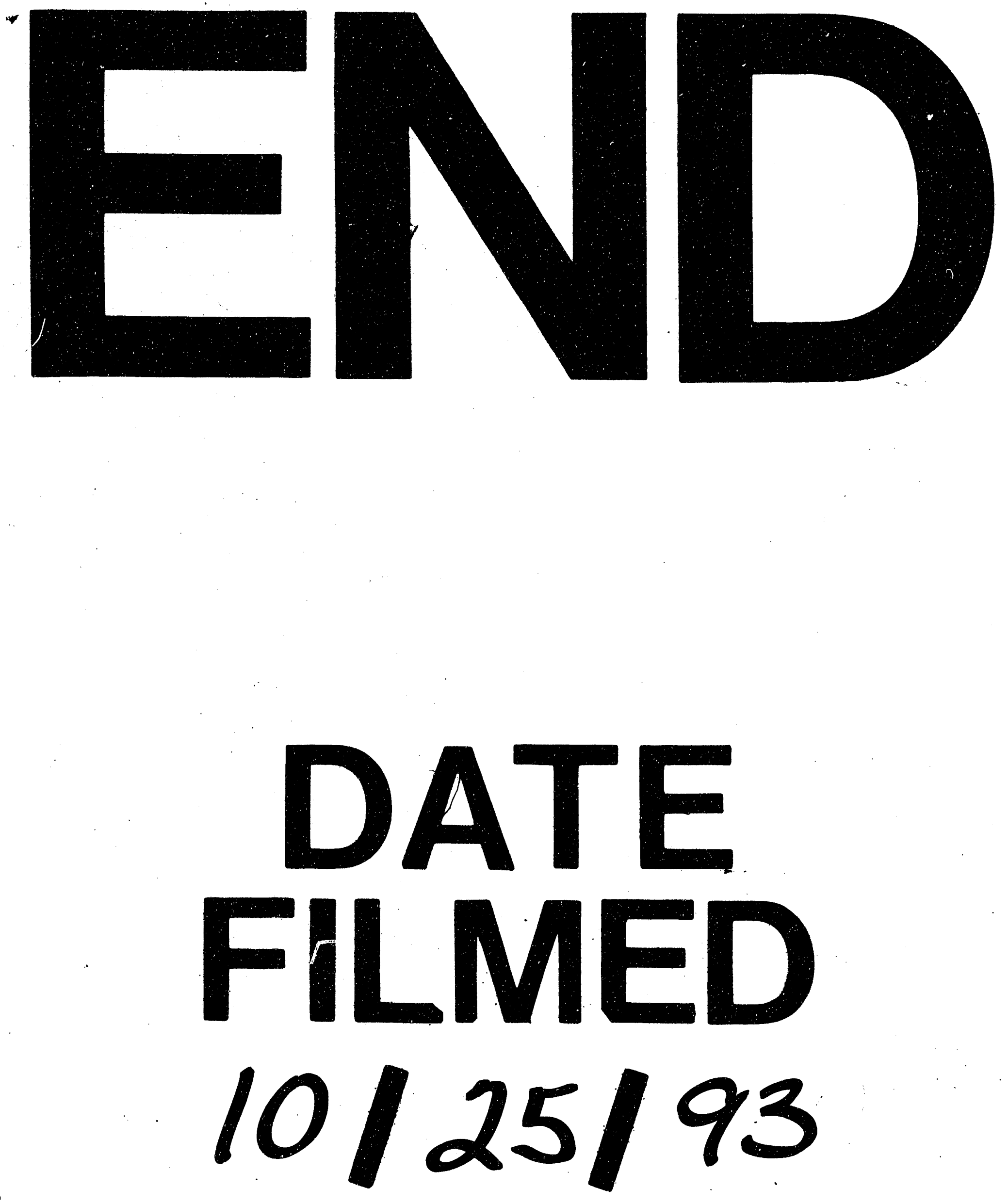

1 
